\title{
INSCRIPCIONES ROMANAS DE LA PROVINCIA DE ALICANTE
}

\author{
MANUEL A. RABANAL ALONSO \\ JUAN M. ABASCAL PALAZÓN \\ Universidad de Alicante
}

\begin{abstract}
El conjunto de inscripciones romanas conocidas hasta el presente en la provincia de Alicante comprende 107 textos, repartidos de forma desigual pero con una notable concentración en los principales núcleos romanos conocidos por las fuentes. Un gran número de testimonios son inéditos, y en otros se han corregido lecturas antiguas o se han completado zonas de difícil lectura. El conjunto permite rastrear la estructura social y las instituciones de los municipios y colonias romanas de la actual provincia de Alicante, dentro del marco de su posición geográfica y considerando su relativa cercanía a otros importantes focos de la costa de la Tarraconense.
\end{abstract}

The 107 Roman inscriptions known in the province of Alicante are unequally distributed, but there is a strong concentration in the principal roman sites quoted by the ancient writers. A lot of these inscriptions are unpublished, and we have modified ancient readings or completed parts of difficult reading. The inscriptions are very interesting for the study of the social structures and the institutions of the Roman municipia and coloniae in the province of Alicante, in relation to their site and their proximity to other importants sites at the Tarraconensian coast.

El conjunto epigráfico de la provincia de Alicante es hoy sensiblemente más numeroso que el incluido en su día en el Corpus Inscriptionum Latinarum y Supplementum. De una parte, los hallazgos casuales, y de otra, las excavaciones, han proporcionado nuevas piezas, conservadas en los $\mathrm{Mu}-$ seos de la provincia y en colecciones particulares, al tiempo que el paso de los años ha hecho desaparecer otras ya conocidas. En total, se incluyen en este trabajo 107 inscripciones, de las que tan sólo se conservan 59. Se han excluido testimonios y noticias dudosas, que figuran al final del mismo con numeración diferente, y objetos cerámicos de todo tipo, con tres excepciones: el ladrillo de Villajoyosa, que, por encima del soporte físico, representa un valioso dato sobre el posible origen de un sena- dor; un pondus del Tossal de Manises, perfectamente conservado, por ser algo más que un simple grafito; y un fragmento cerámico con un grafito pintado de grandes proporciones, que completa la onomástica conocida por otros epígrafes.

Por razones estrictamente metodológicas, han quedado excluidas las inscripciones griegas, pese a su importancia para calibrar el status y el funcionamiento cotidiano de las ciudades alicantinas en época romana, por no ser objetivos de este trabajo. Así mismo, algunos textos muy tardíos han sido marginados por exceder el espacio temporal previamente fijado por nosotros.

En las referencias bibliográficas de los epígrafes se ha incluido literatura anterior a CIL II, en contra de lo habitual, por ser obras en muchos ca- 


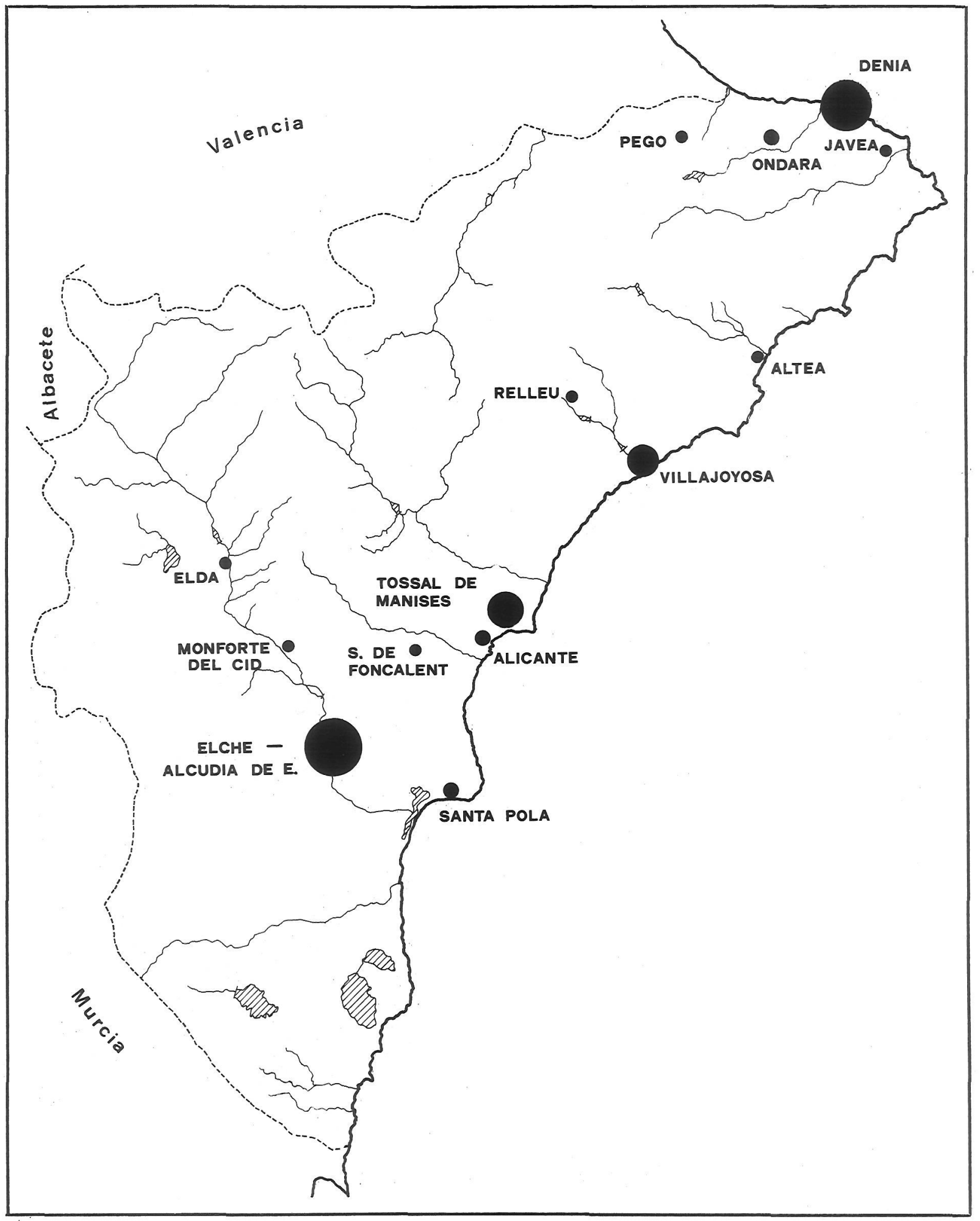

Fig. 1. Distribución de los hallazgos de epígrafes romanos en la provincia de Alicante. El tamaño de los círculos es proporcional al número de ejemplares. 
sos recientemente reeditadas, y presentar informaciones discutibles que confirman o ponen en duda algunos matices del CIL en inscripciones desaparecidas. En la restitución de la mayor parte de estas piezas desaparecidas se ha seguido, por razones obvias, la versión de Hübner.

En la transcripción, las letras fracturadas pero perfectamente legibles se recogen completas, y tan sólo se coloca un punto debajo de la letra cuando su lectura es dudosa o plantea diferencias de interpretación. Las medidas se expresan en el siguiente orden: anchura, altura, grosor. Las abreviaturas se dan desarrolladas y no se anotan interpunciones ni hederae, que tan sólo vienen incluidas en las descripciones de soportes. Para el desarrollo del epígrafe se utiliza el sistema de Leiden:

[ ]-restitución de zonas desaparecidas por fractura.

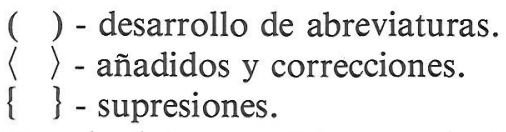

Para las letras perdidas no solucionadas se han utilizado guiones entre corchete, y los corchetes abiertos al principio o final del texto indican la posible existencia de líneas anteriores o posteriores. En pequeños fragmentos de imposible restitución, las letras se recogen en mayúsculas.

La redacción de este trabajo ha sido posible gracias a la colaboración prestada por diferentes Instituciones y particulares, que nos han facilitado el acceso a los materiales. Nuestro agradecimiento al Museo Arqueológico Provincial de Alicante, Museo Arqueológico Municipal de Elche, Museo de la Alcudia de Elche, Museo Arqueológico Municipal de Denia, Museo Etnográfico de Villajoyosa, Museo de Jávea, Ayuntamiento de Monforte del Cid y a los particulares que nos han permitido documentar piezas de su propiedad.

1.-Tossal de Manises (Alicante). Hallada en 1701. Conservada en el Museo de Bellas Artes de San Carlos, de Valencia. Sus dimensiones son $54 \times 38 \mathrm{cms}$.

\section{Bibliografía:}

CEAN BERMÚDEZ 1832, 44; VALCÁRCEL 1852 (1979), 14; CIL II 3563; LAFUENTE 1948, 77, Fig. 18; ILER 2071; DUTHOY 1976, 180; LLOBREGAT 1981, 23-38; ABAD 1984a, 91-92, n. ${ }^{\circ}$ 1; vid. ETIENNE 1958 (1974), 257; RABANAL 1985b, 380.
M(arco) Valerio Solania

no Severo Mure

nae f(ilio) Mag(istro), M(arcus) Popillius Onyxs

5 IIIIII(vir) Aug(ustalis) templum d(e) s(ua) $\mathrm{p}$ (ecunia) d(edit) i(dem)q(ue) p(robavit)

\section{Traducción:}

A Marcus Valerius Solanianus Severus, hijo de Murena, Magister; Marcus Popillius Onyxs, sevir Augustal, construyó a su costa el templo y, además, dio su aprobación.

Sobre el dedicante, vid. n. ${ }^{\circ} 2$. La presencia de la filiación de $M$. Valerius Solanianus induce a pensar más en una dedicación que en una indicación cronológica en forma de ablativo absoluto. Podría referirse el texto al templo de Juno citado en la inscripción n. ${ }^{\circ}$ 4. Tanto la función de magister como la presencia de seviri Augustales prueban la existencia de un culto imperial organizado y, por consiguiente, evidencian la existencia de una organización municipal en este enclave, en cuyo contexto se integran otro sevir (n. $\left.{ }^{\circ} 3\right)$ y los IIviri y el ordo mencionados en el texto $n .{ }^{\circ} 4$.

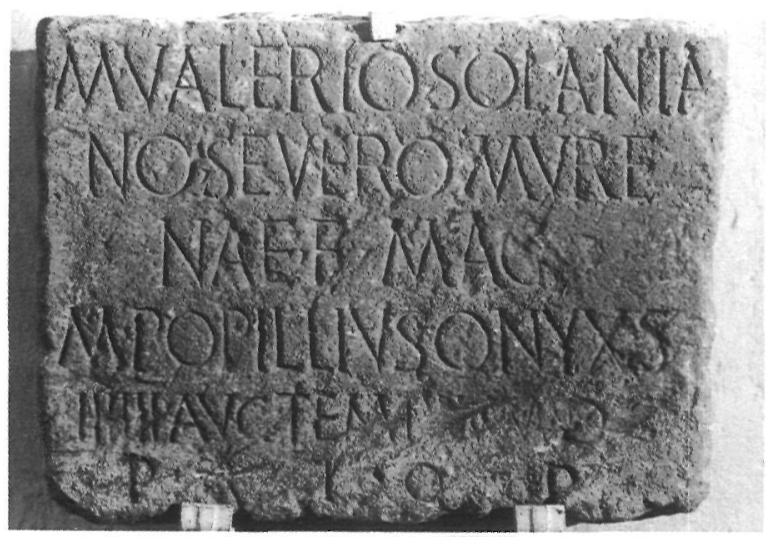

Fig. 2.-Inscripción n. ${ }^{\circ}$ 1. Foto Museo de Bellas Artes. Valencia.

2.-Tossal de Manises (Alicante). Hallada en las excavaciones de 1934 de don Francisco Figueras Pacheco. Se conserva en el Museo Arqueológico Provincial de Alicante. Bloque de piedra caliza en forma de «T» cuyas dimensiones máximas son $82 \times 48 \times 34 \mathrm{cms}$. Altura de las letras: 5,5 y $6 \mathrm{cms}$. (la Y se prolonga a $8 \mathrm{cms}$.). Presenta interpunciones triangulares. 


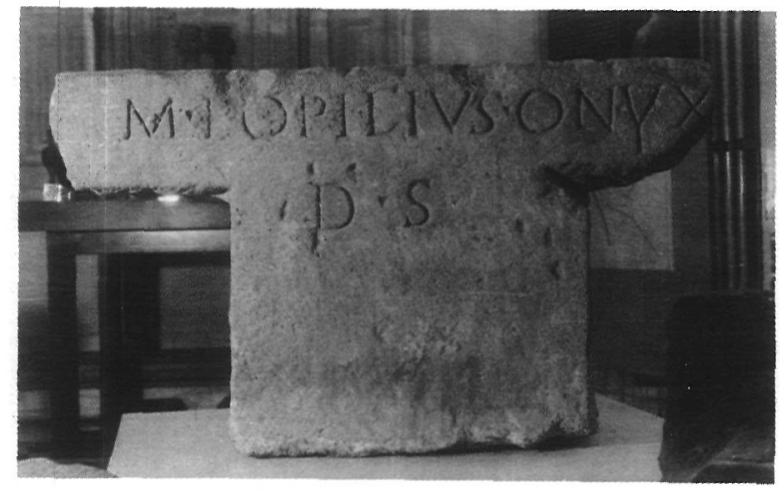

Fig. 3.--Inscripción n. ${ }^{\circ} 2$.

\section{Bibliografía:}

LAFUENTE 1948, $86=$ LAFUENTE 1959,65, n. $^{\circ} 138$; FIGUERAS PACHECO 1959, 62; MORA 1981, n. .26 ; ABAD 1984a, 92, n. ${ }^{\circ} 2$; Vid. ETIENNE 1958 (1974), 257; RABANAL 1985b, 380381

$$
\begin{aligned}
& \text { M(arcus) Popil(l)ius Onyx [s] } \\
& \text { d(e) s(uo) }
\end{aligned}
$$

\section{Traducción:}

(Lo hizo) Marcus Popil(l)ius Onyxs a su costa.

La inscripción fue encontrada a la entrada de un conjunto aparentemente termal, por lo que es probable que aluda a la financiación del mismo por parte de este individuo, sevir augustalis de la ciudad, al que conocemos también por la inscripción $n .^{\circ} 1$. El aspecto formal del monumento permite suponer que su función es la de servir de soporte de algún tipo de relieve o ara. Otro sevir del mismo enclave en $n .^{\circ} 3$.

3.-Tossal de Manises (Alicante). Placa de mármol blanco veteado en gris encontrada en este lugar en las excavaciones de 1978-79, y conservada en el Museo Arqueológico Provincial de Alicante. Presenta interpunciones circulares, salvo las dos hederae que completan las líneas $3 .^{2}$ y $5 .^{2}$. Dimensiones: $31 \times 28 \times 2 \mathrm{cms}$. Altura de las letras: 5 ; 4 ; 3,$5 ; 2,5 ; 2,5 \mathrm{cms}$.

\section{Bibliografía:}

LLOBREGAT 1981, 23-38; ABAD 1984a, 94, n. ${ }^{\circ}$ 6; RABANAL 1985a, 360.

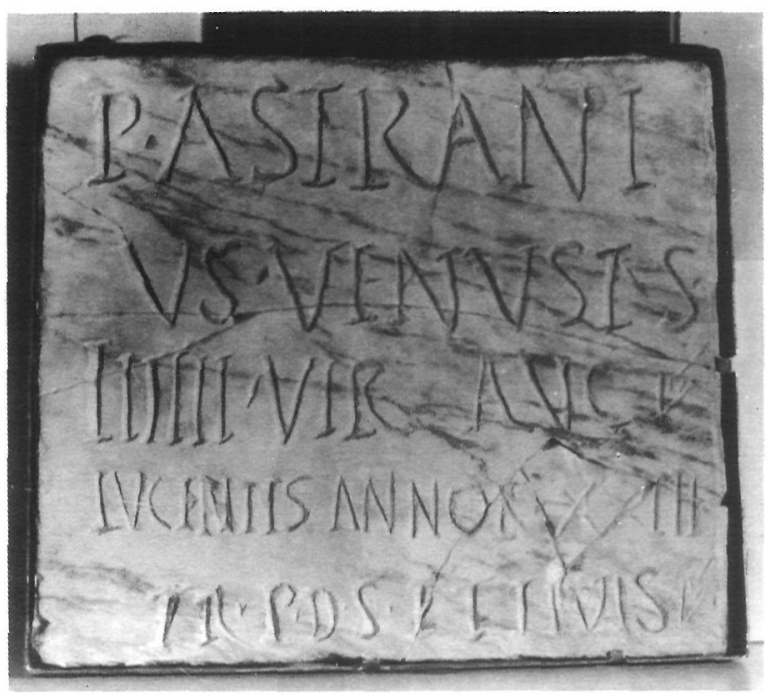

Fig. 4.-Inscripción n. ${ }^{\circ} 3$.

P(ublius) Astrani

us Venustus

IIIIIVir Aug(ustalis)

Lucentis, annor(um) XXIII

$5 \mathrm{t}$ (e) r(ogo) p(raeteriens) d(icas) s(it) t(ibi) $\mathrm{t}$ (erra) levis

\section{Traducción:}

(Aquí yace) Publius Astranius Venustus, sevir Augustal de Lucentes?, de 23 años; te ruego, caminante, que digas: «que la tierra te sea leve».

Venustus aparece en múltiples ocasiones en CIL II. El ejemplo más próximo es el de Sagunto (P. Baebius Venustus. CIL II 3864). Otros sevires de la zona alicantina en $n .^{\circ} 1$ y 2 . Sobre su función en el Tossal vid. n. ${ }^{\circ} 1$. La forma Lucentis plantea el problema del nombre de la ciudad; pensamos que éste debe estar expresado en genitivo, como es habitual (Vid. CIL II 4299 ó 4288 de Tarraco), por lo que habría que pensar en Lucens, Lucentis ó Lucentes para el nombre de la ciudad. Sobre las formas Lucentum (Plinio, Nat. hist. III, 20), Lucentia (P. Mela, Chor. II, 93) y Lucentes (Rav. IV $42[304,14]$ y V3[343,5] ), vid. ABAD 1984b, 348. Podría convenir al texto una cronología de la segunda mitad del siglo II.

4.-Tossal de Manises (Alicante). Bloque de piedra caliza encontrado en 1701 cerca de La Albu- 
fereta, cuyas dimensiones desconocemos, pues la pieza está perdida.

\section{Bibliografía:}

CIL II 3557; ILER 2072; TAFALLA 1972, 67: ABAD 1984a, 92, n. ${ }^{\circ} 3$; RABANAL 1985b, 381.

P(ublio) Fabricio Iusto

P(ublio) Fabricio Resp[e]ct(o)

IIvir(is) templ(um) Iunonis

ex decreto ordin(is)

5 d(e) s(ua) p(ecunia) r(es)p(ublica) restituit

\section{Traducción:}

Siendo duumviros P. Fabricius Iustus y $P$. Fabricius Respectus, la ciudad reconstruyó con fondos públicos el templo de Juno por mandato de los Decuriones.

Es éste el único testimonio de la institución duumviral para este enclave, y debe ponerse en relación con las funciones sacerdotales de las inscripciones $\mathrm{n} .^{\circ} 1,2$ y 3 . El templo de Juno (vid. $\mathrm{n} .^{\circ} \cdot 1$ ) debe ser el templo construido en el momento de recibir la promoción jurídica la comunidad. La restauración a la que se refiere el texto puede corresponder al siglo II. Iustus en la región, vid. n. ${ }^{\circ} 26$, Baebius Iustus, de Denia.

5.-Tossal de Manises (Alicante). Arula en piedra caliza encontrada en 1980 en La Albufereta, y conservada en el Museo Arqueológico Provincial de Alicante. Dimensiones máximas: $16 \times 14 \times 12$ cms. Campo inscrito: $9,5 \times 8,5 \mathrm{cms}$. Altura de las letras: $1,8 \mathrm{cms}$.

Inédita.

$$
\begin{aligned}
& \text { S[at]urni } \\
& \text { nus, Fur } \\
& \text { oni ser(vus), } \\
& \text { v(otum) ș(olvit) l(ibens) m(erito) }
\end{aligned}
$$

\section{V2: Ligaduras NV y VR.}

\section{Traducción:}

Saturninus, siervo de Furonius, cumplió de buen grado el voto.

La pieza se encuentra muy deteriorada y no conserva ningún indicio del nombre de la divinidad o culto al que estuviera dedicada, por lo que, dado su pequeño tamaño, debe corresponder a algún lugar de culto en el que habría sido depositada a modo de ofrenda. Su estado de conservación no es

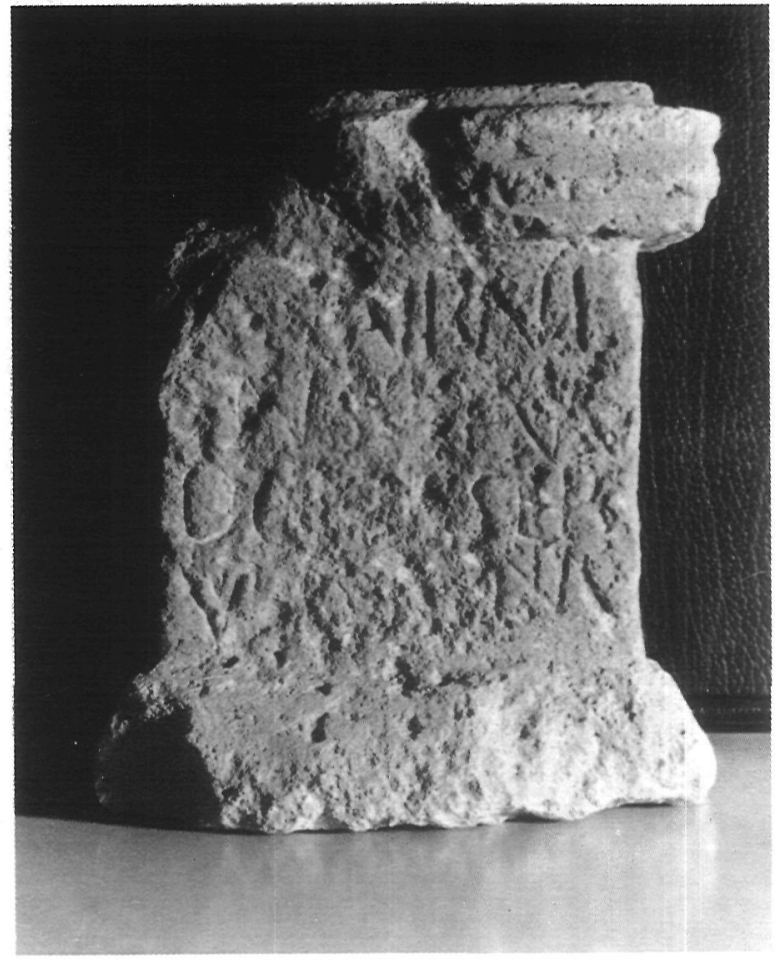

Fig. 5.-Inscripción n.$^{\circ} 5$.

bueno. El texto parece corresponder a los últimos años del siglo I d. C. El cognomen Saturninus aparece en otra pieza del mismo lugar $\left(n .^{\circ} 14\right)$ y está ampliamente difundido en Hispania. El cognomen Furonius es poco frecuente; vid. Furonia en Talavera de la Reina (Toledo) (CORTES et alii 1984, n. $\left.{ }^{\circ} 11\right)$.

6.-Tossal de Manises (Alicante). Hallada en las excavaciones del yacimiento y conservada en el Museo Arqueológico Provincial de Alicante. Ara funeraria en piedra caliza, con cabecera moldurada parcialmente perdida, sin foculus superior. Dimensiones máximas: $33 \times 88 \times 38 \mathrm{cms}$. Campo inscrito: $30 \times 42 \mathrm{cms}$. Altura de las letras: 4, 4, 4, 4, 4, $3 \mathrm{cms}$. Presenta interpunciones triangulares al final de la $1 .^{a}$ línea, y antes de la indicación de edad en la última.

\section{Bibliografía:}

LAFUENTE 1948, 88, Fig. $27=$ LAFUENTE 1959, n. ${ }^{\circ}$ 187, Fig. 17; ILER 4523; ABAD 1984a, 94, n. 5. 


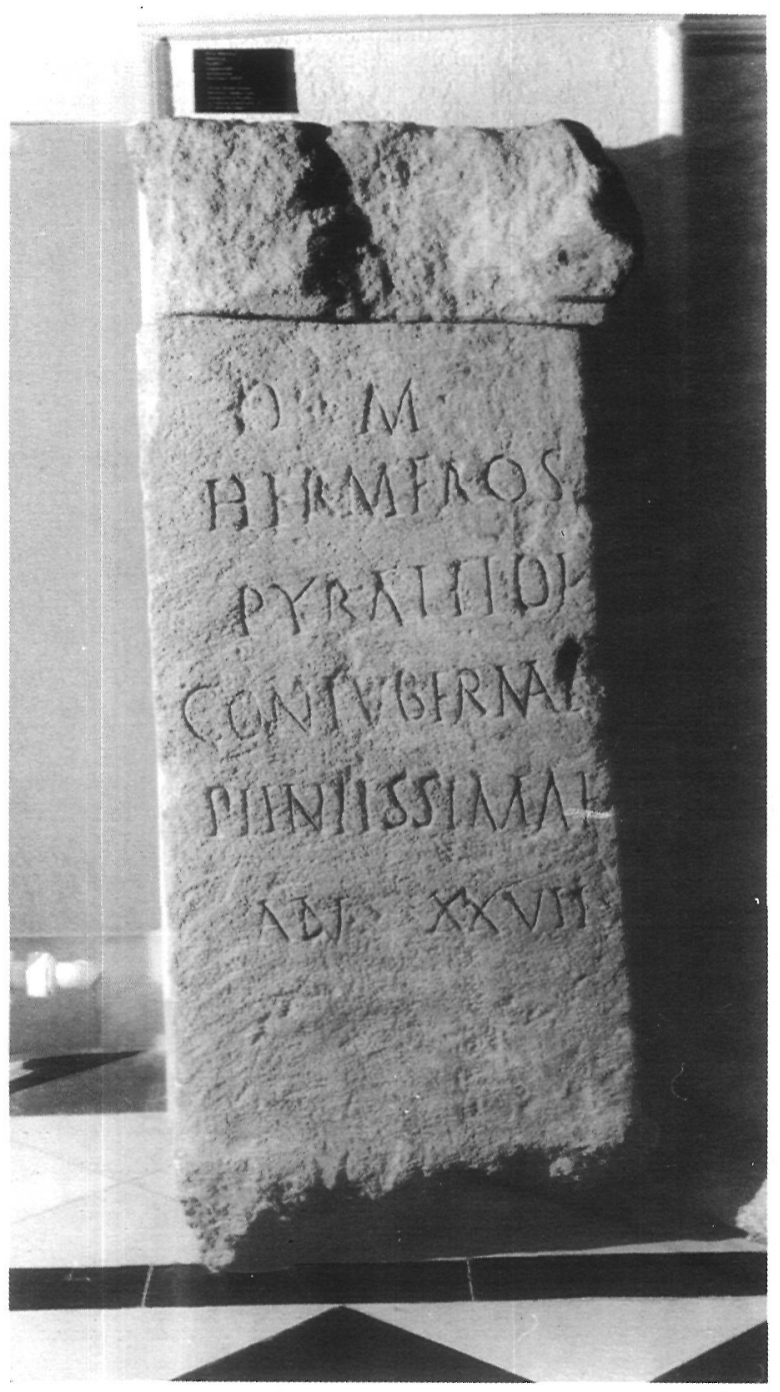

Fig. 6.-Inscripción n.$^{\circ} 6$.

$\mathrm{D}$ (is) M(anibus)

Hermeros

Pyraltidi

contubernali

5 pientissimae

an(norum) XXVII

V4: Ligadura NALI.

Traducción:

A los Dioses Manes. Hermeros (dedicó este monumento) a Pyraltide, su piadosísima compañera, de 27 años de edad.

La inscripción puede fecharse a finales del siglo II ó principios del III.
7.-Tossal de Manises (Alicante). Encontrada en 1934 (FIGUERAS 1971, 52ss.). Se conserva en el Museo Arqueológico Provincial de Alicante. Sillar de piedra caliza fracturado en todas sus caras excepto en la superior. Dimensiones: $34 \times 32 \times 31$. Altura de las letras: $9,6,6 \mathrm{cms}$. Presenta una interpunción circular al final de la tercera línea conservada.

\section{Bibliografía:}

LAFUENTE 1948, 87, Fig. $26=$ LAFUENTE 1959, n. ${ }^{\circ}$ 139; FIGUERAS $1971,52, \mathrm{n} \cdot{ }^{\circ} 164$.

[--]arino[--------]

[--]o Praeno[---]

[-co]niugis [----]

$[--$

\section{V2: Ligadura AE.}

\section{Traducción:}

A...(---)arinus...(--)us, esposo de Praeno(--)...

No parece faltar ninguna línea superior a juzgar por el espacio libre que se conserva. Puede fecharse entre fines del siglo I y comienzos del II.

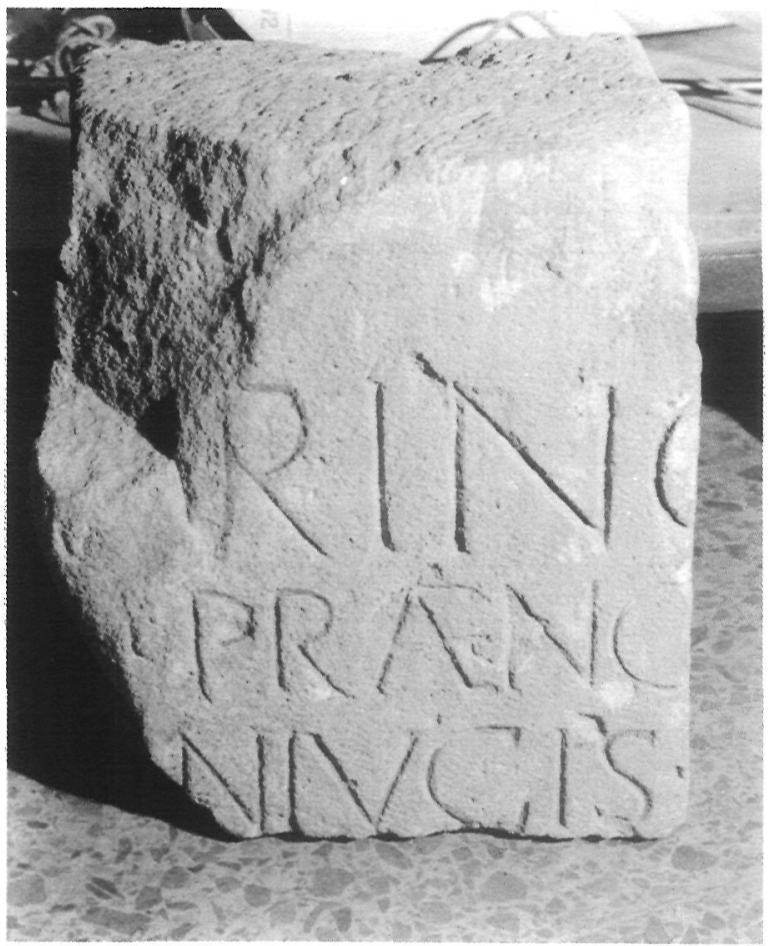

Fig. 7.-Inscripción n. ${ }^{\circ}$. 
8.-Tossal de Manises (Alicante). Inscripción encontrada hacia 1682 en la finca de «La Condomina», labrada en piedra caliza, pero de la que desconocemos otros datos por haber desaparecido. Bibliografía:

VALCÁRCEL $1780 ， 50-52=1852$ (1979), n. ${ }^{\circ} 21$; CEAN BERMÚDEZ 1832, 45; CIL II 3561; LAFUENTE 1948, 74, Fig. 17; ILER 2091; ABAD $1984 a, 94$, n. ${ }^{\circ} 4$.

Tadius M(arci) f(ilius)

Ruf(us), praef(ectus) tur(rim/res)

faciund(am) coer(avit).

V2: TVR(rim), Hübner.

Traducción:

Tadius Rufus, hijo de Marcus, prefecto (municipal), se encargo de la construcción de la/s torre/s.

No es posible detallar esta lectura, ni siquiera confirmarla, por haberse perdido el monumento. Si aceptamos la lectura transmitida desde el siglo XVIII y aquí recogida, preferimos el desarrollo tur(rim/res) a tur(mae), por ser la praefectura turmae una función desconocida dentro del cursus ecuestre. Más correcto nos parece suponer que este praefectus sea en realidad uno de los magistrados de la ciudad, que se ocupa temporalmente de las funciones de uno de los IIviri por ausencia de éste o que sustituye en el gobierno de la ciudad al propio Emperador, tal y como contempla la lex de $\mathrm{Sal}$ pensa (Salp. 23-24; D’ORS 1953, 144). Sobre Tadius, vid. CIL II 4165 y 4166 de Tarraco; sobre $R u$ fus, vid. n. ${ }^{\circ}$ 9. El texto puede fecharse en el siglo I a. C. (ALFÖLDY 1975, 102; ABAD 1984a, 99).

9.-Tossal de Manises (Alicante). Columna de mármol encontrada en la finca de «La Condomina» con anterioridad a 1604 (VALCÁRCEL 1780, 44ss.) y hoy perdida. Sus medidas son, según Valcárcel, «dos palmos y medio de ancha y otros cinco de alta».

Bibliografía:

VALCÁRCEL 1780, 44-45; CIL II

3564; LAFUENTE 1948, 101 ; BENDI-

CHO 1960, 24; ILER 2261a; ABAD

$1984 a, 94$, n. ${ }^{\circ} 8$.

C(aius) Lol(1)ius

Rufus

ann(orum) XXXIIII

\section{Traducción:}

(Aquí yace) C.Lollius Rufus, de 34 años de edad.

No es posible establecer la cronología, ni siquiera la autenticidad del epígrafe, pues sólo conservamos el dibujo y la noticia de Valcárcel. En Cartagena conocemos un P.Lollius Philemo (CIL II 3476). Sobre Rufus, vid. n. ${ }^{\circ} 8$.

10. - Tossal de Manises (Alicantc). Encontrada en 1606 en la finca de «La Condomina». Soporte y medidas desconocidos, pues la pieza está perdida.

Bibliografía:

VALCÁRCEL 1780, 46; CIL II 3565;

LAFUENTE 1948，87; ILER 3320;

ABAD 1984a, 94, n. ${ }^{\circ} 9$.

Diis Manibus (sic)

Primigenia

Sinponiaca

ann(orum) XXV

V2-3: PRIAMI.GENIA/SIMPRONIACA, Valcárcel.

\section{Traducción:}

A los Dioses Manes. (Aquí yace) Primigenia Sinponiaca?, de 25 años de edad.

Tanto la traducción del texto, como su interpretación, plantean la cuestión del doble cognomen de esta mujer, así como la ausencia de nomen. Primigenia es relativamente corriente en CIL II, con dos testimonios en Sagunto (ELSag 142 y CIL II 3923); no ocurre lo mismo con Sinponiaca, probable grafía de Symphoniaca. El texto podría corresponder al siglo II d. C.

11.-Tossal de Manises (Alicante). Inscripción encontrada en 1788 en la finca de "La Condomina», labrada sobre un bloque de caliza de extracción local, hoy desaparecido. Dimensiones: $136 \times 49$ cms., según Valcárcel.

Bibliografía:

CEAN BERMÚDEZ 1832, 45; VALCÁRCEL 1852 (1979), n. ${ }^{\circ} 23$; CIL II 3566; MANGAS 1971, 399; ILER 3508; ABAD 1984a, 94-95, n. 10.

Sicceia P(ubli) 1(iberta) Donata

Piero f(ilio) suo qui

obi(i)t annorum

XIIII, hoc m[onu

5 mentum] posu[it] 


\section{V3: OBIT.}

\section{Traducción:}

Sicceia Donata, liberta de Publius, puso este monumento para su hijo Pierus, que murió a los 14 años de edad.

La ausencia de paralelos para el gentilicio materno se compensa con la presencia del cognomen Pierus en diversos puntos (varios casos en Pax Iulia, ILER 1517); la forma Pieris aparece en Liria (CIL II 6016) y en Barcelona (CIL II 6154). El texto parece corresponder al siglo III d. C.

12.-Tossal de Manises (Alicante). Inscripción grabada sobre un soporte de alabastro (Valcárcel), encontrado en 1777 en La Albufereta. Dimensiones: $16,5 \times 7 \mathrm{cms}$. Altura de letras no precisable. Desaparecida.

\section{Bibliografía:}

VALCÁRCEL $1780 ， 56-57=1852$

(1979), n. ${ }^{\circ} 24$; CIL II 3562; PAPI $1889,245-247$.

$$
\begin{aligned}
& \text { [-----]u[------] } \\
& \text { [--]lice[ -------] } \\
& \text { [-]solverun[t-] } \\
& \text { [--]ast[ --------] } \\
& {[---}
\end{aligned}
$$
texto.

Es difícil proponer una interpretación para este

13.-Tossal de Manises (Alicante). Pondus encontrado en las excavaciones en el yacimiento y conservado en el Museo Arqueológico Provincial

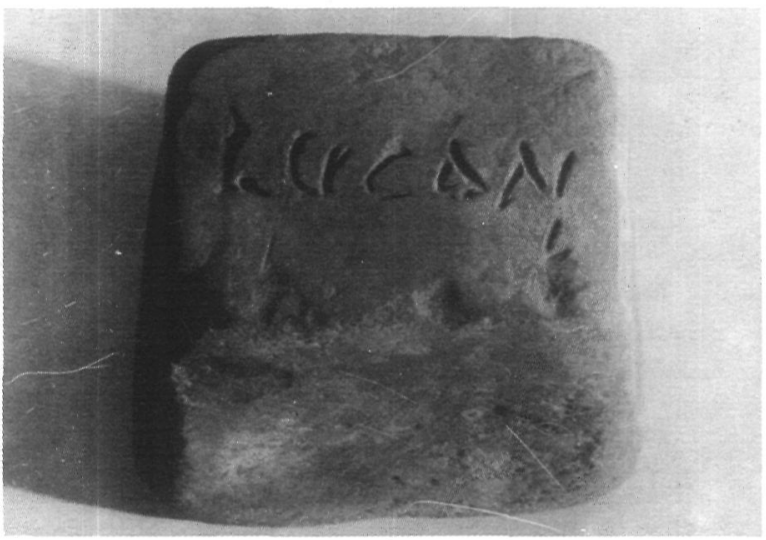

Fig. 8.-Inscripción $n .^{\circ} 13$. de Alicante. Presenta la cara superior inscrita con el nombre de su propietario en cursiva. Medidas de la superficie inscrita: $4,5 \times 3 \mathrm{cms}$. Medidas máximas: $6 \times 4 \times 6,5 \mathrm{cms}$. Altura de las letras: $5,5 \mathrm{cms}$. Inédita.

\section{Lucani}

\section{Traducción: \\ De Lucanus.}

14.-Tossal de Manises (Alicante). Grafito pintado en color rojo vinoso sobre el hombro de un olpe en pasta naranja, bajo una serie de trazos paralelos similares a los que aparecen en las piezas de La Alcudia de Elche o, incluso, en ejemplares hallados en el Tossal de Manises. Procede de las excavaciones en el yacimiento y se conserva en el $\mathrm{Mu}$ seo Arqueológico Provincial de Alicante; Ref. TM 5419. Medidas del fragmento: $6 \times 8,5 \mathrm{cms}$. Altura de las letras: 3,5 cms. en la primera línea. Inédita.

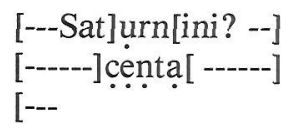

\section{Traducción:}

De Saturninus?...
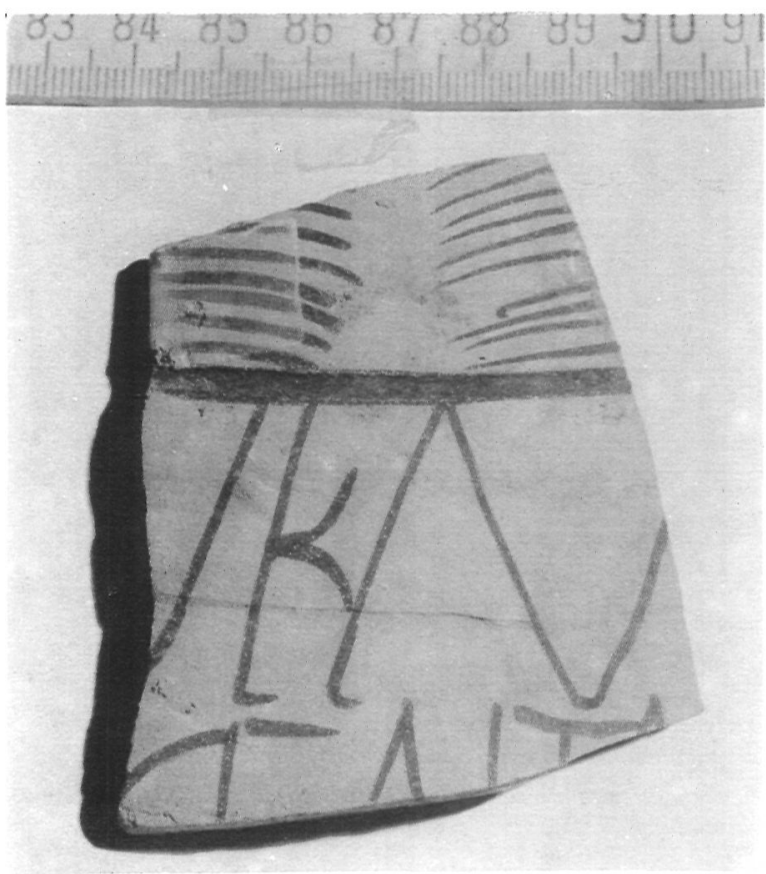

Fig. 9.-Inscripción n. ${ }^{\circ} 14$. 
Sobre Saturninus, vid. n. ${ }^{\circ}$ 5. El soporte cerámico de la pieza sitúa el texto a finales del siglo I y principios del II.

15.-Alicante. Inscripción encontrada en las cercanías de la confluencia de la Avenida de Oscar Esplá con la calle Catedrático Soler, hacia 1877. Es una placa de mármol hoy desaparecida, cuyas dimensiones son: $20 \times 16 \times 3 \mathrm{cms}$. Altura de las letras: 3,5-4 cms., según Hübner.
Bibliografía:

BRAH 8, 1888, 360; CHABAS 1888, $282=1889$, 241ss.; CIL II, Suppl. 5958; LAFUENTE 1948, 94, Fig. 28; TARRADELL y MARTÍN 1970, 1819; TAFALLA 1972, 70; LLOBREGAT 1981, 36-37; MAULEON 1983, n. ${ }^{\circ} 1751$; ABAD 1984a, 120-121; RABANAL 1985a， $365=$ RABANAL 1985b, 379.

[M(arcus) Aur(elius) Ant]oninus, L(ucius)[Aelius]

[Aurelius Commodu]s, Augg(usti) Ger(manici) Sar(matici)[--]

[-------- m]unicipi Lucen! [tis? ---------]

V3: Ligaduras VNI y PI.

Traducción:

Marcus Aurelius Antoninus y Lucius Aelius Aurelius Commodus, Augustos, Germánicos, Sarmáticos... (los decuriones del municipio de Lucentes?...

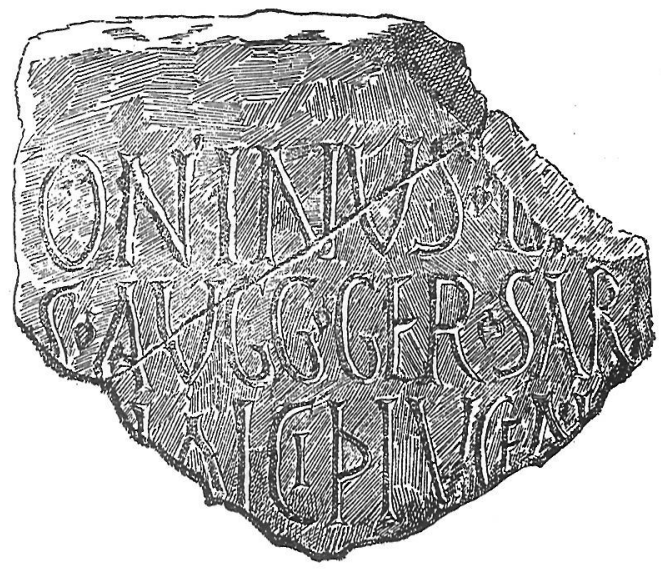

Fig. 10.-Inscripción n. ${ }^{\circ}$ 15. Dibujo según Rico.

Sobre el desarrollo Lucentis, vid. n. ${ }^{\circ} 3$. El texto puede fecharse entre los años 176 y $180 \mathrm{~d}$. C. Sobre los detalles del hallazgo, vid. Abad 1984a, 120.

16.-Alicante. Inscripción encontrada en «Los Antigones» (actualmente «barrio de Benalúa»). Sobre la identificación del enclave: Tarradell y Martín 1970, 16ss.; Abad 1984a, $114=1984 b, 195$.
La pieza estuvo antiguamente depositada en el «Huerto de Baver» y hoy está perdida. Sus dimensiones eran «cuatro palmos de ancho y seis de largo» según Hübner, que recoge fuentes anteriores. Bibliografia:

CIL II 3558; TARRADELL y MARTÍN 1970, 16; ILER 2064; MUÑIZ COELLO 1980, n. ${ }^{\circ}$ 183; ABAD 1984a, 111; ABAD 1984b, 193.

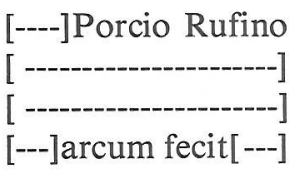

\section{Traducción:}

....a Porcius Rufinus...; ...hizo el arco...

Tradicionalmente se ha venido relacionando el texto con un acueducto (HÜBNER, TARRADELL ,...), pero recientemente $\mathrm{L}$. Abad ha planteado su vinculación a un arco funerario (ABAD 1984a, 112 y 1984b, 195), similar a los que evidenciarían otros epígrafes valencianos, pertenecientes todos en la región a las familias Porcia y Quintia, con los cognomina Rufus, Rufinus y Probus (ABAD 1984b, 197).

17.-Alicante. Inscripción recogida por Valcárcel de la que desconocemos las circunstancias del hallazgo. Antigüamente estuvo en la huerta de D. Nicolás Juan, en lo que hoy es el «barrio de Benalúa» en Alicante. Según Valcárcel, corresponde 
el fragmento a la parte izquierda de una inscripción. Desaparecida.

Bibliografía:

VALCÁRCEL 1780, 57; CIL II 3568.

---ENTA---

18.-Alicante. Inscripción de la que desconocemos otras referencias que su texto. Desaparecida.

Bibliografía:

HÜBNER, IHC 182; VIVES 1969, n. ${ }^{\circ}$ 266.

Aurelius Pu\{e\}r rec(essit)

ann(is) XII Fidel $\{\mathrm{i}\}_{S} \mathbb{R}$

Sarra Rui

reca(?) ma(ter?)

5 IISI

\section{V1: PVIR; V2: FIDELIIS}

\section{Traducción:}

Aurelius, niño, murió en paz a los doce años de edad. Sarra Ruireca??, su madre?,...

La forma recessit es poco frecuente ( $v$ id. RIT 944 y 958). La inscripción puede fecharse a fines del siglo IV.

19.-Sierra de Foncalent (Alicante). Grafito inciso sobre fragmento del hombro de un recipiente cerámico en pasta grisácea, conservado en el $\mathrm{Mu}$ seo Arqueológico Provincial de Alicante (Ref. FC1308). Presenta cuatro líneas de texto en caracteres cursivos.

\section{Bibliografía:}

LLOBREGAT 1970, 190-195, Lám. I; BUCHNER 1971, 195-201.

[Hono?]ratus

bir onnestus

commane(n)s

aput $\mathbb{R}$ v [i] $]$ am...

Según Buchner $(1971,201)$ la expresión commane(n)s aput... viam tendría un sentido de temporalidad refiriéndose a una estancia provisional o residencia de Honoratus en el lugar de hallazgo del fragmento, que sería parte de un objeto litúrgico para líquidos. Llobregat prefiere mantener commanes e interpretarlo como una expresión religiosa para significar la vinculación cristiana del difunto.

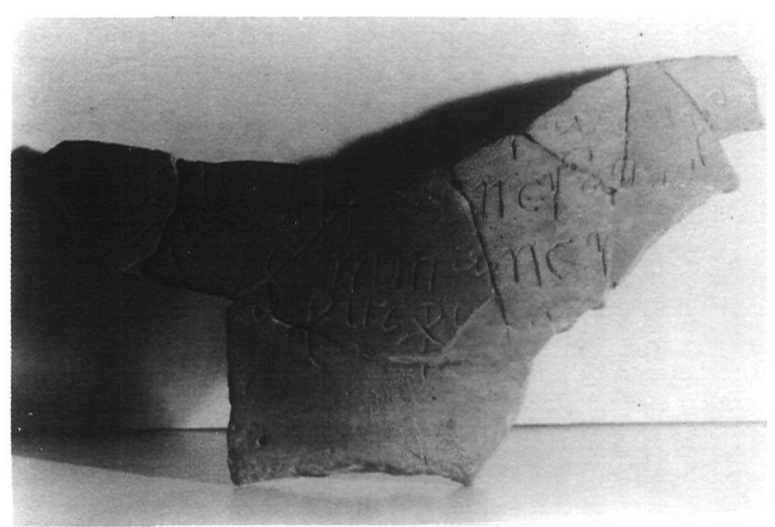

Fig. 11.-Inscripción n. ${ }^{\circ} 19$.

La cronología del texto debe situarse a finales del siglo IV y principios del V, en razón de su esquema, por más que su paleografía induzca a bajar esta fecha.

20.-Denia. Pedestal moldurado en piedra caliza encontrado en Denia con anterioridad a 1643. Se encuentra junto a la galería exterior del Ayuntamiento de Denia. Dimensiones máximas: $60 \times 126 \times 60 \mathrm{cms}$. Campo inscrito: $38 \times 45 \mathrm{cms}$. Altura de las letras: $4,5 \mathrm{cms}$.

\section{Bibliografía:}

PALAU 1643 (1975), 44-45; VALCÁRCEL 1852 (1979), n. ${ }^{\circ}$ 61; CIL II 3580; CHABAS 1874 (1972), 61-63, n. ${ }^{\circ}$ IV; LLORENTE 1886 (1985), 268; SANCHÍS 1920, n. ${ }^{\circ}$ 41; ETIENNE 1958 (1974), 257; MARTÍN 1970, n. 1; ILER 419; DUTHOY 1976, 179; RABANAL 1985a, 388.

Pro salute Aug(usti)

Veneri sacr(um)

Cn(eus) Octavius

Florus, IIIIIIvir

5 Aug(ustalis) municipio

$\mathrm{D}$ (ianensis) d(e)d(icavit)

1 (oco) d(ato) ex d(ecreto) D(ecurionum)

V1: Ligadura TE; V5: Ligadura NI.

Traducción:

Consagrado a Venus, por la salud de Augusto. Cneus Octavius Florus, sevir Augustal en el municipio Dianense, dedicó (este monumento) en el lugar fijado por decreto de los Decuriones. 


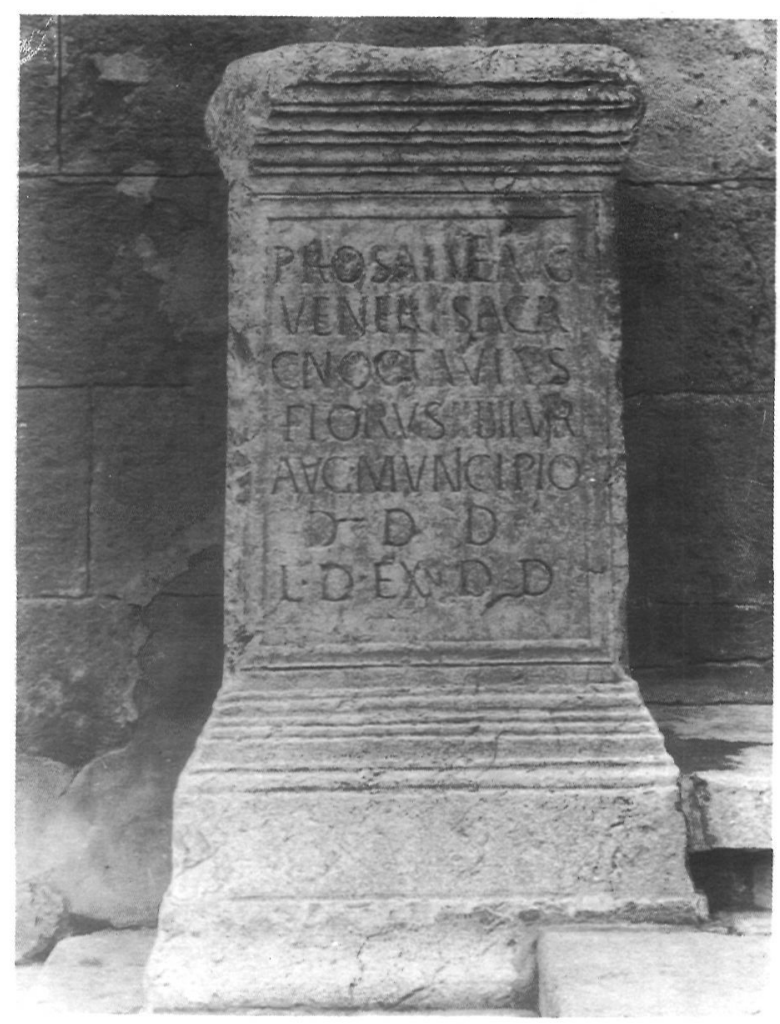

Fig. 13.-Inscripción n. ${ }^{\circ} 21$. Foto J. Gisbert.

El texto se encuentra perfectamente conservado y presenta interpunciones triangulares, salvo en las dos últimas líneas, en donde éstas son sustituidas por hederae distinguentes. Al final de la sexta línea aparece inciso un ramo oblicuo. Presenta foculus superior. Otros sevires en $n .^{\circ} 1,2$ y 3 . Sevires en Denia: $n .^{\circ} 31$. La inscripción se fecha en el siglo II.

21.-Denia. Inscripción sobre un bloque de piedra caliza encontrado en 1898 en la finca «Ponsech», conservada en el Museo Arqueológico Municipal de Denia. Dimensiones: $30 \times 44 \times 20 \mathrm{cms}$. Altura de las letras: $4 \mathrm{cms}$.

\section{Bibliografía:}

EE IX 356; FITA 1901, 97; SANCHÍS 1920, n. ${ }^{\circ}$ 69; MARTÍN 1970, n. ${ }^{\circ} 31$; MAULEON 1983, n. ${ }^{\circ} 1755$.

[S]ilvano p(osuit) Bassus

L(uci) V(aleri) Scrib(oniani) v(erna) pro salut(e)

5 (A)em(ilii) Adria ni

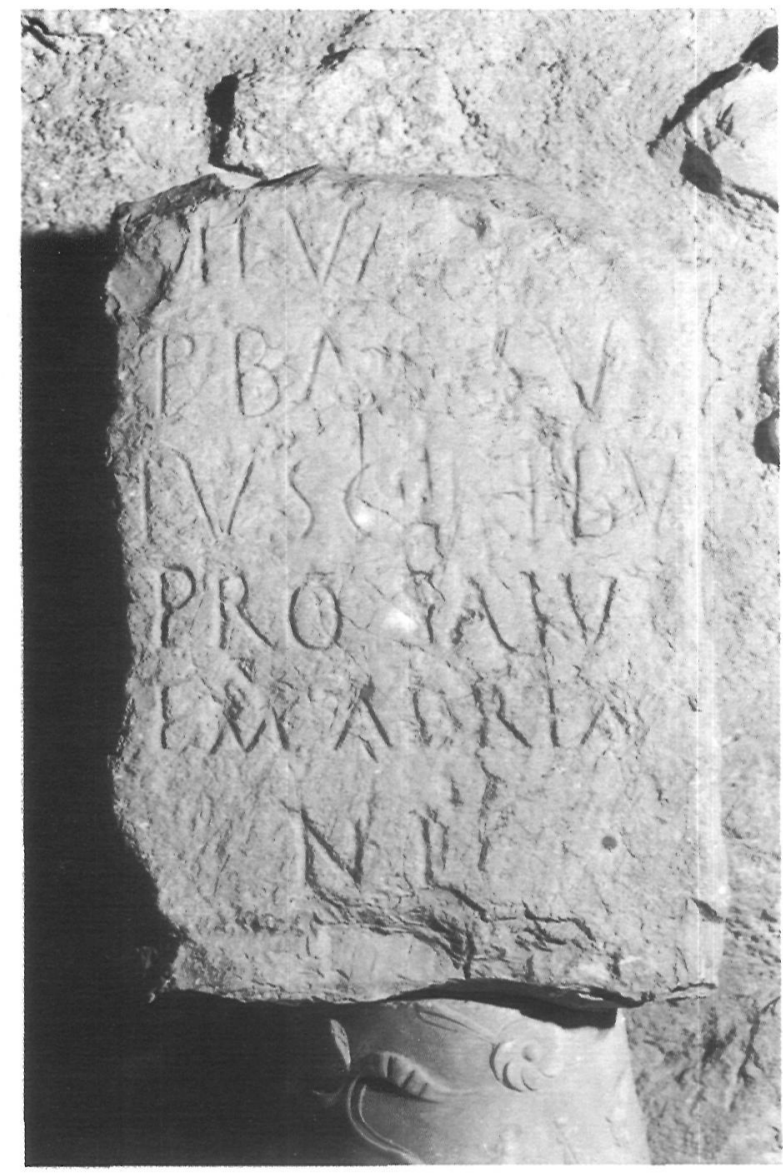

Fig. 12.-Inscripción n. ${ }^{\circ} 20$.

\section{Traducción:}

Bassus, esclavo de L.Valerius Scribonianus, puso (el monumento) para Silvano, por la salud de Aemilius Adrianus

El texto se encuentra algo deteriorado, y hay que destacar la forma arcaica de la «L». Las dudas sobre « $\mathrm{C} » \mathrm{u} « \mathrm{O}$ » en la tercera línea las resuelve $\mathrm{G}$. Alföldy a favor de la primera, siendo a él a quien debemos la lectura de este texto. El texto corresponde a la primera mitad del siglo II, al igual que algunos otros testimonios de dedicaciones similares documentados en Hispania (PASTOR, 1981, 103 ss.)

22.-Denia. Inscripción grabada en una roca en el acceso a la Cova de l'Aigua, en la ladera noreste del Montgó (Denia). Campo inscrito: $45 \times 72$ 
cms. Altura de las letras: 5,$5 ; 5 ; 4,5 ; 4,5 ; 4,5 ; 4,5$

cms.

\section{Bibliografía:}

PALAU 1643 (1975), 67-68; CIL II 3588 y Suppl. 5960; CHABAS 1874 (1972), 77-78, n. ${ }^{\circ} \mathrm{XX}$; SANCHÍS 1920, n. 55; BLÁZQUEZ 1962, $125-$
126; SAXER 1967, n. ${ }^{\circ}$ 125; MARTÍN 1970, n. ${ }^{\circ}$ 6; ILER 686 y 6002; LE ROUX 1972, n. ${ }^{\circ} 53$; ROLDÁN 1974, n. ${ }^{\circ} 713 ;$ ALFÖLDY 1978, 71; AE 1978, 440; LE ROUX 1982a, n. ${ }^{\circ} 207$; MAULEON 1983, n. ${ }^{\circ} 1754$.

\author{
C(aius) Iul(ius) Urbanus, vet(eranus) \\ princ(eps) vexil(lationis) leg(ionis) VII

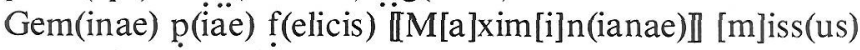 \\ cum suis a $\mathrm{D}[\mathrm{e}]$ cio $\mathrm{Va}[\mathrm{l}] \mathrm{er}[\mathrm{i}] \mathrm{a}$ \\ 5 no co(n)s(ulare) L(ucius) A[l]f[i]us Do \\ natus optio f(aciendum) c(uravit)
}

V2: Ligadura NI.

Traducción:

Caius Iulius Urbanus, veterano, princeps de la vexillación de la legio VII Gemina Pia Felix Maximiniana, enviado con los suyos por el consular Decius Valerianus. Lucius Alfius Donatus se ocupó de que fuera hecho (este epígrafe).

El texto se encuentra muy deteriorado habida cuenta de su exposición a la interperie. G. Alföldy mostró en 1978 la justificación de este destacamento en la costa de Denia como punto de vigilancia costero ante el temor de una intervención de los

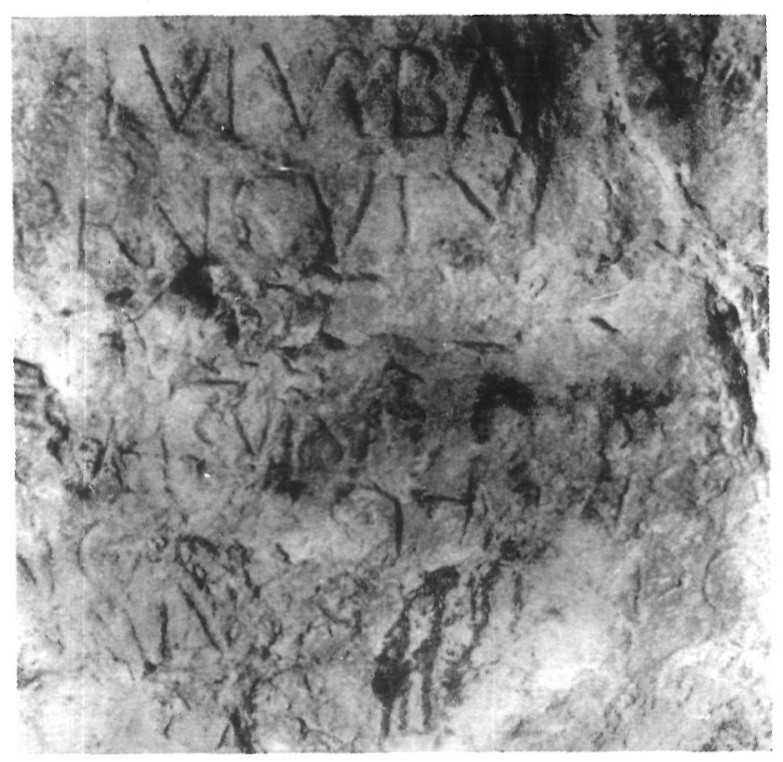

Fig. 14.-Inscripción n. ${ }^{\circ} 22$. Según G. Martín. adversarios de Maximino durante los acontecimientos del 238. Según el mismo autor, Decius Valerianus sería Q.L.Decius Valerianus, el legado de la citerior del 238, que ocuparía el trono el año 249 con el nombre de C.Messius Q.Decius Trajanus.

23.-Denia. Diversos fragmentos supuestamente procedentes del llamado "templo de Diana» de Denia. El primero de ellos (CIL II 3581) fue publicado por Paláu (1643/1975, 46-47), quien explica que se trataba de un conjunto de pequeños trozos unidos, en los que supuestamente se leía:

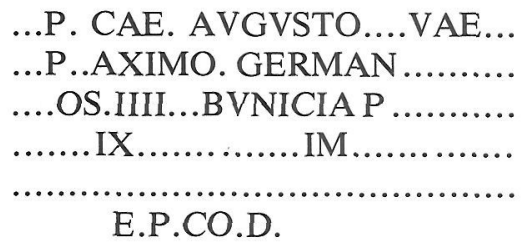

El fragmento fue reconstruido por Palau de la siguiente manera: Imp. Cae.Augusto Nervae Traiano P.Maximo Germanico Dacico, cos. IIII, tribunicia potestate IX, Imp. VI, p.p. dianienses E.P.CO.D.

Hübner ya mostró su extrañeza ante semejante lectura, y descartó su exactitud, entre otras razones, por la imposibilidad de hacer coincidir el consulado IIII con la potestad tribunicia IX en ninguno de los emperadores con los que encaja la denominación.

El segundo fragmento (CIL II 3595), también dado a conocer por Paláu ( $o p$. cit.), procede teóricamente del mismo enclave que el anterior, aunque tampoco en esta ocasión la vio Hübner, que se limita a recogerlo. Transcriben Paláu y Hübner: 
IANO

NEPO

AMI

Finalmente, un tercer fragmento fue dado a conocer por Fita en 1887, e incorporado por Hübner al Supplementum del CIL con el n. ${ }^{\circ}$ 5959. Según Fita, es de mármol blanco, y sus dimensiones son $16 \times 13$ cms., en él se leía ...ANIC.../...POT..., y, según Fita, faltaba un resto de otra línea, en la que debería figurar ...IMP...

Fita $(1887,331-332)$ desconfió de la edición de Paláu, proponiendo que este autor hubiera inventado el segundo fragmento (CIL II 3595) tomando éste (CIL II Suppl. 5959) como modelo. Ante esta suposición proponía la existencia real de sólo dos fragmentos (CIL II 3581 y Suppl. 5959), que pertenecerían al mismo epígrafe, cuyo texto sería:

\section{IMP.CAESARI.NERVAE.TRAIANO}

AVGVSTO.GERMANICO.DACICO.PONT. MAXIMO.TRIB́.POTESTATE VIIII

IMP IIII, COS V. P.P.

\section{RES PVBLICA DIANENSIVM}

Tanto la versión de Paláu como la de Fita llaman la atención por su diversidad. Aún aceptando que sólo Paláu vio el texto CIL II 3581, la fiabilidad que éste inspiraba a Fita era poca, cuando se permitió cambiar el orden de los términos en el nombre del Emperador, el orden de las aclamaciones y la línea final, en donde repentinamente aparece una res publica Dianensium que en nada se ciñe al texto de Paláu.

Estas y otras cuestiones obligan a plantear una serie de observaciones:

- La expresión Caesar Augustus no es habitual en la epigrafía, sino que suele ir interpolada por uno de los nombres del Emperador, por lo que la versión de Fita sobre CIL II 3581 parece una enmienda erudita al primitivo error de Paláu.

- La denominación de Germánico corresponde al nombre y no a las aclamaciones, por lo que no es correcto el orden propuesto por Paláu para la línea 2 de CIL II 3581, y debe entenderse que también aquí Fita corrige.

- La IX potestad tribunicia de Trajano corresponde a su $\mathrm{V}$ consulado (10 de diciembre 104/105), y no al IIII.

- La única inscripción de la que hay mayores garantías es el fragmento CIL II Suppl. 5959, que
Fita vio y que queda avalada por su cientifismo, que le impediría deformar el texto.

Por todo ello, pensamos que Paláu, como efectivamente sugiere Fita, "creó» CIL II 3595 sobre CIL II Suppl. 5959, lo que le permitía presentar dos textos diferentes con menciones imperiales, ya que la mención del título de Germánico ya estaba presente en el texto CIL II 3581, y por lo tanto era imposible suponerlos parte del mismo epígrafe. Por lo que respecta a este primer fragmento citado, CIL II 3581, las múltiples deformaciones y anomalías, su falta de datos sobre medidas o características evidentes del soporte, y sus nada casuales lagunas, nos llevan a pensar en una invención de Paláu y a descartar el fragmento por irreal. Otro tanto suponemos de CIL II 3595, que no pretende sino completar artificialmente al primero, al vincularlo a la figura de Trajano.

La razón de tal cúmulo de despropósitos no es otra que la de sobrevalorar la posible existencia en Denia de un templo dedicado a Diana, buscando así su relación con el nombre del municipio, Dianium, tarea ésta en la que estuvo empeñada una gran parte de la erudición hispana hasta fines del siglo XIX. Por inercia científica, los corpora y trabajos posteriores habrían transmitido la anomalía. En tales circunstancias, el fragmento CIL II Suppl. 5959 parece ser el único realmente existente, publicado por Fita $(1884,15=1887,331-332=$ MAULEON 1983, n. ${ }^{\circ} 1756$ ), y cuyo texto, salvando la posible existencia de una tercera línea conservada a la que alude Fita, sería:

$$
\text { [---Germ]anic[o-------------] }
$$

No nos es posible fijar la cronología del fragmento.

24.-Denia. Inscripción encontrada en Denia, grabada sobre un bloque de piedra caliza. Conservado en el Museo de Bellas Artes de San Carlos de Valencia. Dimensiones: $50 \times 69 \times 16 \mathrm{cms}$. Altura de las letras: 4 cms. en todas las líneas, excepto la última que mide $9 \mathrm{cms}$.

Bibliografia:

PALÁU 1643 (1975), 47-48; CIL II 3586 y Suppl. 5961; CHABAS 1874 (1972), $\quad 73-75=1889, \quad 258 \mathrm{ss} ; \quad$ FITA $1884,16=1886(1985), 332, n \cdot{ }^{\circ} 2$; LLORENTE 1886 (1985), 269; FITA 1888, 360; FLOREZ 1900, vol. VIII, 208, n. ${ }^{\circ} 11$; SANCHÍS 1920, n. ${ }^{\circ}$ 53; 
MARTÍN 1970, n. ${ }^{\circ}$ 5; ILER 1408; MAULEON 1983, n. ${ }^{\circ}$ 1757; RABANAL 1985a, 367.

[im]bribus per loca [diffi]cilia am[pl]issimo [su]mptu inductis mox [car]issima [a]nnona

5 [fru]mento [p]r [a]ebito [mun]icip[ib]us suis subv[e]nisset

[decr]eto Decurionum

Dianensium

\section{Traducción:}

A (-----), quien, canalizadas las aguas de lluvia con muchísimo gasto y por lugares difíciles, socorrió después a sus habitantes con el trigo proporcionado en un año de malas cosechas. Por decreto de los decuriones dianenses.

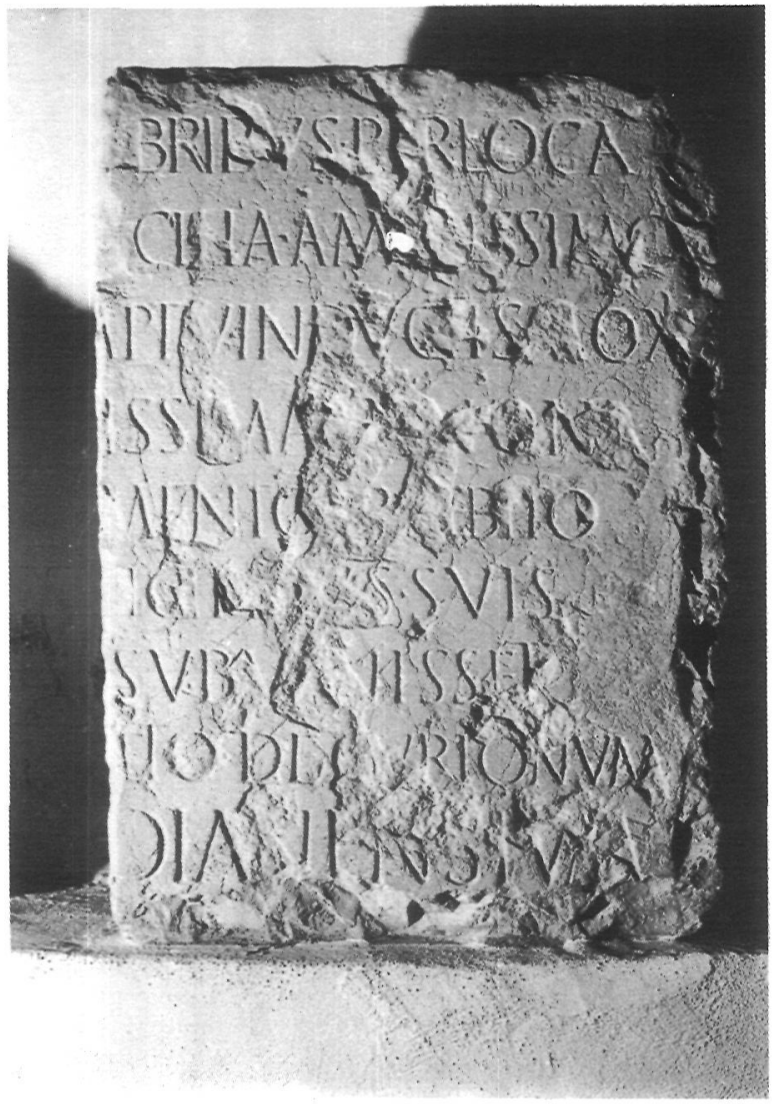

Fig. 15.-Inscripción n. ${ }^{\circ}$ 24. Foto J. Gisbert.
El texto presenta fractura en su parte izquierda, y probablemente carece de la línea o líneas superiores, en las que iría situado el nombre del benefactor, quien, sin duda, es alguno de los importantes personajes que figuran en otras inscripciones de Denia. El tipo de letra y el esquema del texto sitúan el monumento en el siglo II d. C.

25.-Denia. Lápida en piedra caliza con doble moldura lateral encontrada en las cercanías de la ermita de Santa Paula en Denia y empotrada en la pared del altar en la citada capilla. Dimensiones: $55 \times 88 \mathrm{cms}$. Campo inscrito: $39 \times 73 \mathrm{cms}$. Altura de las letras: $5 ; 5 ; 4,5 ; 4,5 ; 4,5 ; 4,5 ; 4,5 ; 4 ; 4 ; 4 ; 4 ; 4$ cms. Interpunciones triangulares.

Bibliografía:

PALÁU 1643 (1975), 74-75; CIL II 3584; CHABAS 1874 (1972), 64-66, n. ${ }^{\circ}$ VI; ETIENNE 1958 (1974), 140; MARTÍN 1970, n. ${ }^{\circ} 3$; ILER 1641; ALFÖLDY 1973, n. ${ }^{\circ}$ 67; RODRÍGUEZ NEILA $1978, \mathrm{n} \cdot{ }^{\circ} 10$.

L(ucio) Valerio L(uci) f(ilio)

Propinquo, omnibus ho noribus in $\mathrm{r}(\mathrm{e})$

5 p(ublica) sua functo, adlecto in $\mathrm{V}$ decurias, fla mini $\mathrm{p}$ (rovinciae) $\mathrm{H}$ (ispaniae) c(iterioris),

Gamus et

10 Trophime lib(erti) patrono optim[o] et indulgentissim[o]

\section{Traducción:}

A L.Valerius Propinquus, hijo de $\mathrm{Lu}$ cius, que desempeñó en su ciudad todas las magistraturas, admitido en las cinco decurias judiciales, flamen de la provincia Hispania citerior. Gamus y Trophime, sus libertos, (erigieron este monumento) para su patrono óptimo e indulgentísimo.

L.Valerius L.f.Gal.Propinquus es conocido por tres inscripciones de Denia $\left(n .^{\circ} 25,26\right.$ y 27$)$ y por otra de Tarragona (CIL II $4250=$ RIT 310). Como miembro de una de las familias de la élite municipal, ocupó todas las magistraturas ciudadanas, entre las que probablemente se incluye el fla- 


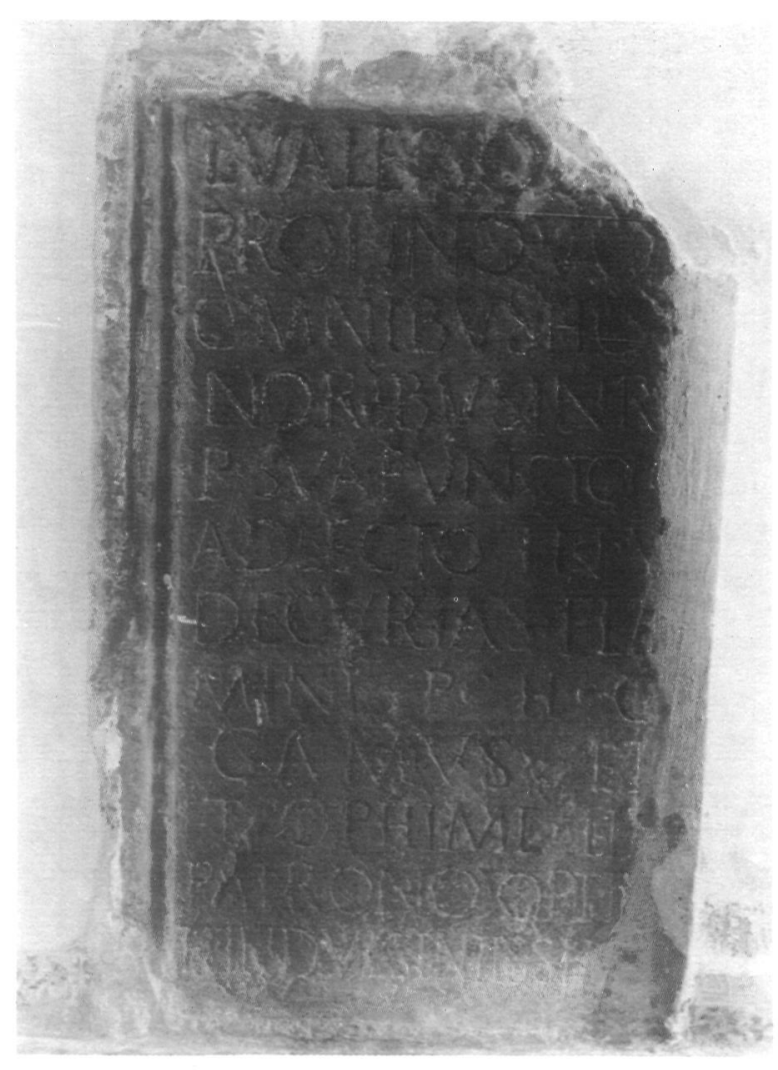

Fig. 16.-Inscripción n. ${ }^{\circ} 25$.

minado local, para pasar después a Tarraco, en donde desempeñó el flaminado provincial (n. ${ }^{\circ} 25 \mathrm{y}$ 26; CIL II 4250), tras lo cual sería incluido en las decurias judiciales, alterando el orden que supone Rodríguez Neila para estas dos últimas funciones $(1978,39)$. Su destacado papel en Dianium queda probado por el número de inscripciones dedicadas y por su relación con los dedicantes (dos libertos en este texto n. ${ }^{\circ} 25$; Baebius Iustus y Calpurnianus en el n. ${ }^{\circ} 26$ y Granius Anicetus en el n. $\left.{ }^{\circ} 27\right)$. Debe, además, ponerse de manifiesto su posible parentesco con M.Valerius M.f.Gal.Propinquus Grattius Cerealis, Edetano (CIL II 4251), que alcanzó el flaminado provincial hacia el año 100 (RIT 311) y con L.Valerius Gal.Propinquus Granius Grattius Cerealis Geminius Restitutus (CIL II 6084; LE ROUX 1982b, 457 con toda la bibliografía), un senador probablemente originario de alguna ciudad de la costa levantina en la primera mitad del siglo II. Sobre éstas y algunas otras vinculaciones, Vid. RIT 149, p. 82. El esquema del texto sitúa el epígrafe según Alföldy (RIT 310) con posterioridad al año 120 , al tiempo que sus funciones sacerdotales en Tarragona no se desarrollan más allá del año 180. Etienne es partidario de situar al personaje bajo el reinado de Antonino Pío (ETIENNE 1958, 132 y 140).

26.-Denia. Inscripción antigüamente empotrada en una fachada junto a la Iglesia de San Telmo en esta localidad y hoy desaparecida.

Bibliografía:

CIL II 3585; CHABAS 1874 (1972), 63-64, n. ${ }^{\circ}$ V; SANCHÍS 1920, n. $^{\circ} 45$; ETIENNE 1958 (1974), 140; MARTÍN 1970, n. 19; ILER 1642; ALFÖLDY 1973, n. ${ }^{\circ} 67$.

L(ucio) Valeri[o]

L(uci) f(ilio) Gal(eria tribu)

$\operatorname{Pr}[0]$ pinqu[o]

flamini

5 (rovinciae) $\mathrm{H}$ (ispaniae) $\mathrm{c}$ (iterioris)

Baebi(us) Iust[u]s

et Calpurnia

nus amic[o]

optimo

\section{Traducción:}

A Lucius Valerius Propinquus, hijo de Lucius, de la tribu Galeria, flamen de la provincia Hispania citerior. Baebius Iustus y Calpurnianus (dedicaron el monumento) a su buen amigo.

Sobre el personaje y la cronología del epígrafe, vid. $\mathrm{n} .^{\circ} 25$ y 27.

27.-Denia. Bloque de piedra caliza fracturado a ambos lados, con restos de moldura en la parte superior e inferior. Encontrado en Denia hacia 1911 y conservado en el Museo Arqueológico Municipal de la ciudad. Dimensiones: $32 \times 114 \times 62$ cms. Campo inscrito: $60 \times 27 \mathrm{cms}$. Altura de las letras: 7,$5 ; 7,5 ; 6,5 ; 5,5 ; 3,5 ; 5 ;$ ?

Bibliografía:

SANCHÍS 1920, n. 44; MARTÍN 1970, n. $^{\circ} 4$.

[L(ucio)] Valer[io]

[L(uci)] fil(io) G[al(eria tribu)]

[Pr]opin[quo]

Grani[üs]

5 [A]nicetu[s]

[a]mico opt[imo]

d(e) s(uo) 
V3: Ligadura IN

Traducción:

A L.Valerius Propinquus, hijo de $L u$ cius, de la tribu Galeria. Granius Anicetus (erigió este monumento) a su costa para su amigo óptimo.

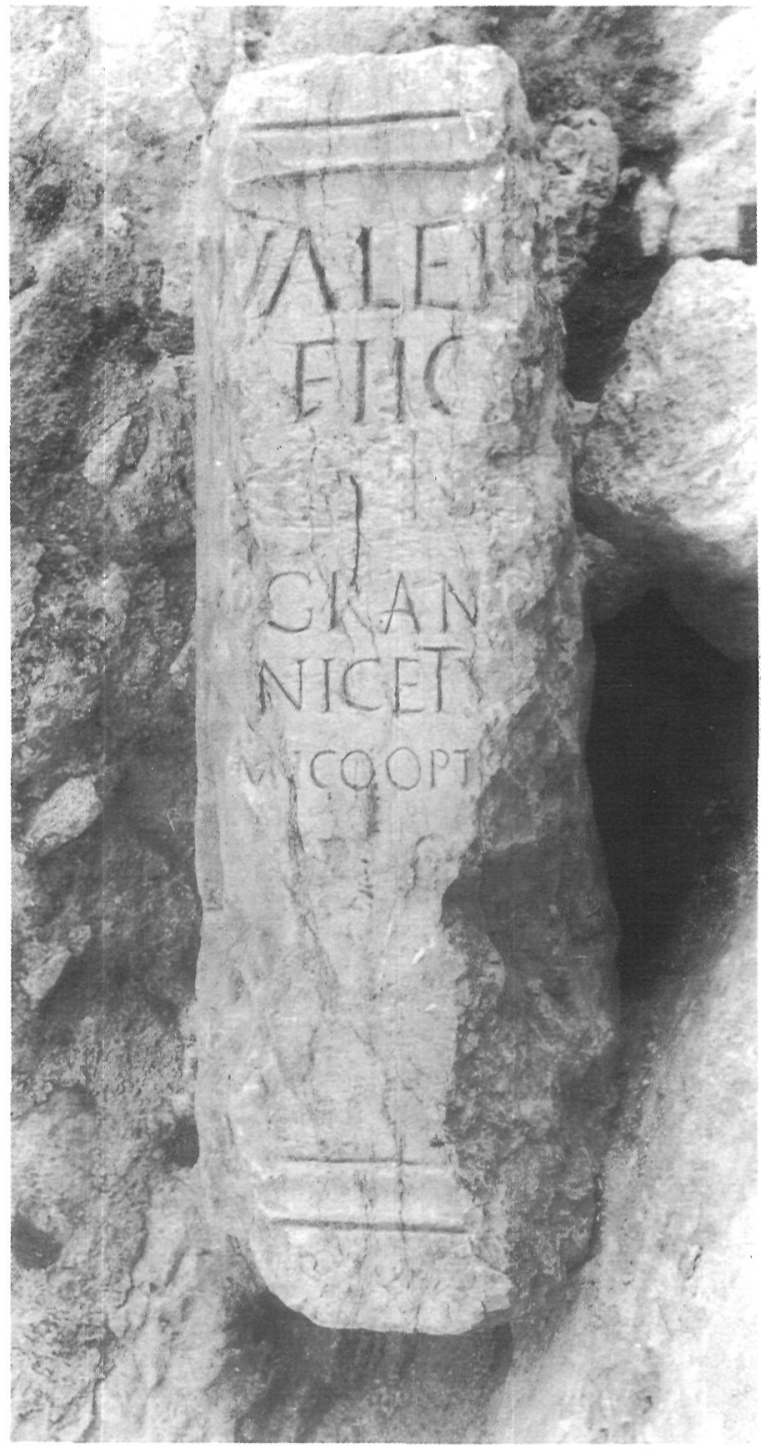

Fig. 17.-Inscripción n. 27.

Sobre el personaje, vid. n. ${ }^{\circ} 25$ y 26 . Esta es, probablemente, la más antigua de las dedicaciones erigidas a este individuo, pues no se menciona ninguna de las funciones que conocemos por otros epígrafes. El margen de tiempo en que se sitúa es el ya expresado para la $n .^{\circ} 25$. Sobre el dedicante, vid. Granius Clemens en el n. ${ }^{\circ} 28$. Anicetus en Sagunto (CIL II 3903a).

28.-Denia. Lápida de piedra caliza parcialmente erosionada en su parte izquierda, encontrada en 1872 en las excavaciones en la ciudad, en lo que tradicionalmente se ha identificado con un templo de Diana (CHABAS 1874, 76). Conservada en el Museo Arqueológico Municipal. Dimensiones: $69 \times 129 \times 18$. Altura de las letras: $7 ; 7 ; 6 ; 6 ; 5$; 4,$5 ; 4,7$ (prolongadas $\mathrm{T}$ en la segunda línea, $\mathrm{BI}$ en la tercera, I en la cuarta y $\mathrm{T}$ en al quinta).

\section{Bibliografía:}

CHABÁS 1874 (1972), 76, n. ${ }^{\circ}$ XVII;

FITA 1884, 18; CIL II Suppl. 5962;

FITA 1887 (1985), 18; SANCHÍS 1920, n. ${ }^{\circ} 46$; MARTÍN 1970, n. ${ }^{\circ} 10$; MAULEON 1983, n. ${ }^{\circ} 1758$.

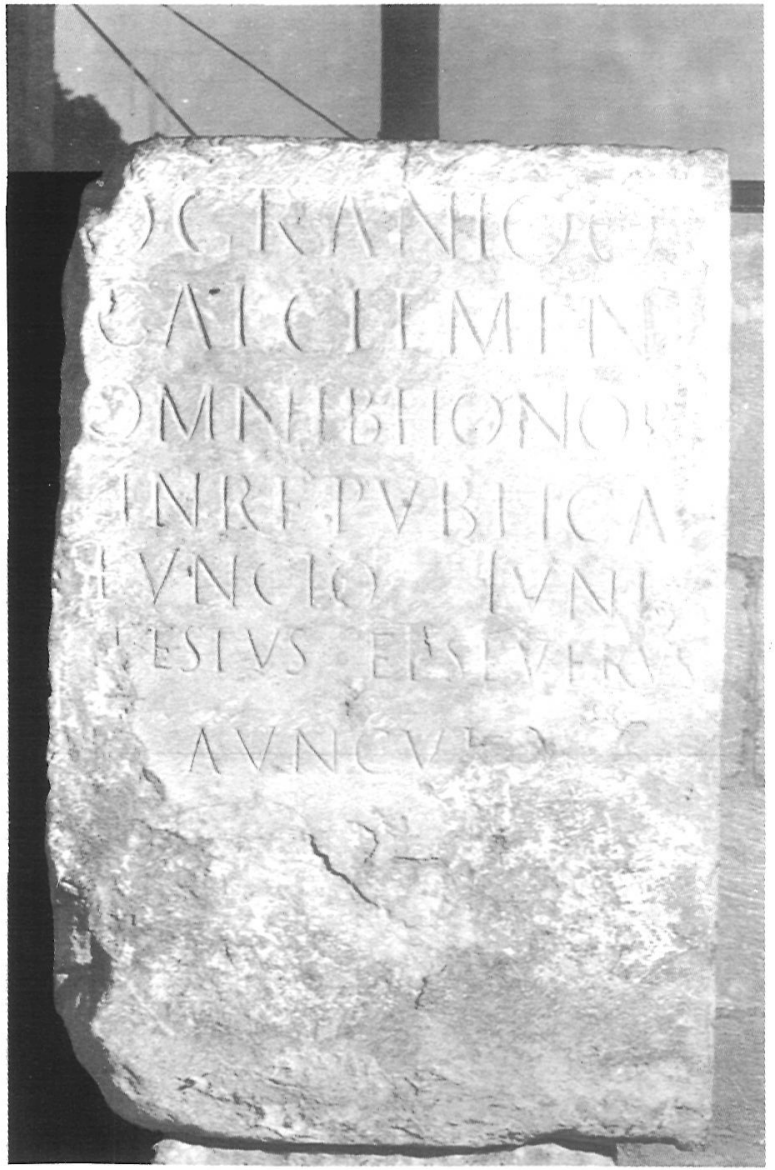

Fig. 18.-Inscripción n. ${ }^{\circ}$ 28. Foto J. Gisbert. 
Q(uinto) Granio Q(uinti) f(ilio)

Gal(eria tribu) Clementi

omnib(us) honorib(us)

in re publica <sua>

5 functo, Iuni(us)

Festus et Severus

av(u)nculo

V2: Ligadura NT; V3: Ligadura IB.

Traducción:

A Q.Granius Clemens, hijo de Quintus, de la tribu Galeria, que ocupó todas las magistraturas en su ciudad. Iunius Festus y Severus (erigieron este monumento) a su tío.

Sobre Granius en Levante, vid. RIT 149, p. 82; Granianus en Tarraco (CIL II 4225 = RIT 228; CIL II 4226=RIT 229; RIT 321) y en Baetulo (CIL II 4609). El esquema del texto y su relación con otros epígrafes del mismo lugar, sitúan el monumento a mediados del siglo II. El segundo dedicante, Severus, es, sin duda, T.Iunius Severus, el personaje homenajeado en el epígrafe n. ${ }^{\circ} 29$. Vid. Iunia Festina en Liria (CIL II 6014) y Medina de Torres (Badajoz) (ILER 4239).

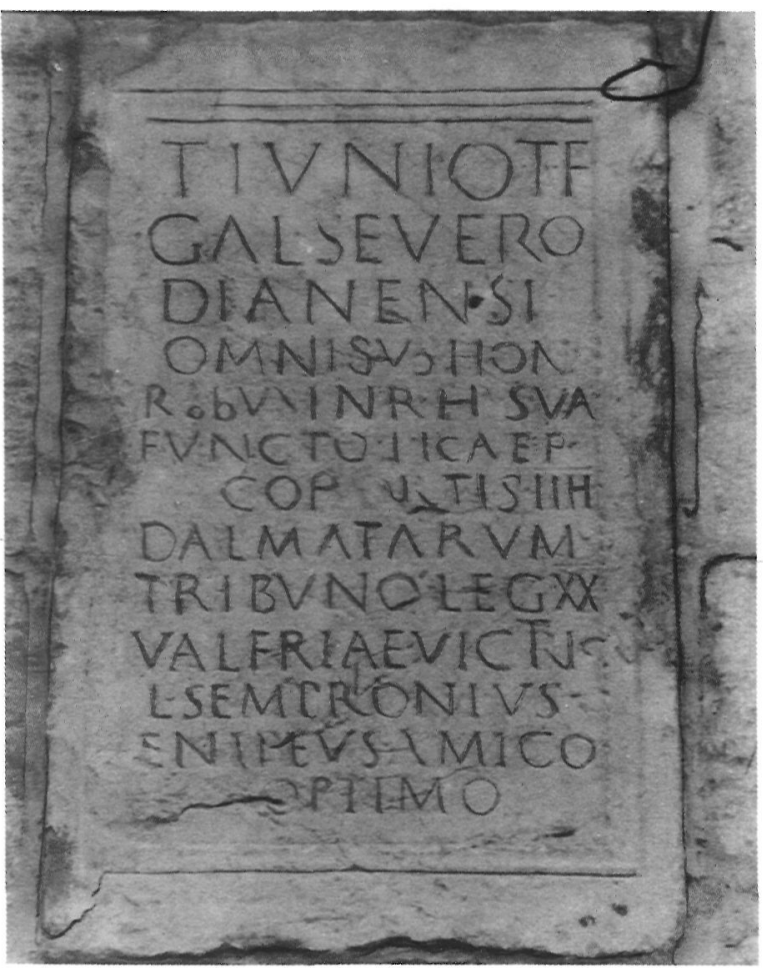

Fig. 19.-Inscripción n..$^{\circ} 29$.
29.-Denia. Bloque de piedra caliza encontrado en la ciudad en el siglo XVII y empotrado en la fachada del Ayuntamiento de Denia.

Bibliografía:

PALÁU 1643 (1975), 45-46; VAL-

CÁRCEL 1852 (1979), n. ${ }^{\circ}$ 60; CIL II 3583; CHABAS 1874 (1972), 60-61, n. ${ }^{\circ}$ III; FITA 1884, 18: LLORENTE 1886 (1985), 262; FITA 1887, 337; SANCHÍS 1920, n. ${ }^{\circ}$ 38; MARTÍN 1970, n. ${ }^{\circ} 2$; ILER 1406; MAULEON 1983, n. ${ }^{\circ} 1759$; RABANAL 1985a, 368.

T(ito) Iunio $\mathrm{T}$ (iti) f(ilio)

Gal(eria tribu) Severo

Dianensi, omnibus hono

5 ribus in re p(ublica) sua

functo, praef(ecto)

cohortis IIII

Dalmatarum tribuno leg(ionis) XX

10 Valeriae Victric(is),

L(ucius) Sempronius

Enipeus, amico

optimo

Traducción:

A T.Iunius Severus, Dianense, hijo de Titus, de la tribu Galeria, que desempeñó todas las magistraturas en su ciudad, prefecto de la cohors IIII Dalmatarum, tribuno de la legio $X X$ Valeria Victrix. Lucius Sempronius Enipeus (dedicó este monumento) a su buen amigo.

El cursus parece estar ordenado en sentido ascendente, con lo que este personaje habría pasado desde las funciones municipales a los primeros escalones del orden ecuestre, sin ocupar el flaminado provincial entre ambos. La legio $X X V$.v. permaneció estacionada en Chester desde Claudio (RITTERLING, RE XII, 2, 1925/1972, 1769ss; DAREMBERG-SAGLIO III, 2, 1969, 1088), sin que podamos fijar el momento en que el personaje ocupó el tribunado. El epígrafe dianense, por su aspecto formal, parece corresponder a los años centrales del siglo II, por lo que es segura la estancia en Chester de Iunius Severus. Sobre su relación familiar, vid. n. ${ }^{\circ} 28$. Sobre Sempronius en DeniaOndara, vid. n. ${ }^{\circ} 33,34,35$ y 49 . Recientemente, el parecido onomástico de este dianense con el sena- 
dor T.Iunius Severus ha sido puesto de manifiesto por Le Roux (1982b, 460), quien llega a suponer una relación familiar entre ambos, lo cual es bastante plausible considerando que este último ocupó un consulado suffecto hacia $154 \mathrm{~d}$. C., coincidiendo extraordinariamente esta cronología con la del personaje de Denia. El cursus de CIL II 3583 podría haber precedido a una función senatorial, con lo que podría incluso pensarse en identificar a los dos personajes.

30.-Denia. Epígrafe encontrado en Denia hacia 1573 , sin que se pueda precisar las circunstancias o sus características, por haberse perdido.

\section{Bibliografía:}

PALÁU 1643 (1975), 48-49; CIL II 3582; CHABÁS 1874 (1972), 69-70, n. ${ }^{\circ}$ X; SANCHÍS $1920, n{ }^{\circ} 42$; MARTÍN 1970, n. ${ }^{\circ}$ 18; ILER 1405.

[Q(uinto) Cor]nelio

$\mathrm{Q}$ (uinti) filio

Gal(eria tribu) Placido, omnibus

5 honoribus

in rep(ublica) sua

functo

Aemilia L(uci) fil(ia)

Severina

10 marito.

\section{Traducción:}

A Q.Cornelius Placidus, hijo de Quintus, de la tribu Galeria, que desempeñó todas las magistraturas en su ciudad. Aemilia Severina, hija de Lucius, (dedicó este monumento) a su marido.

Es probable la vinculación de este personaje con el Q.Cornelius Placidus que aparece en un ánfora de Ilici (CIL II 6254=IBARRA 1879/1981, 111). Otro Cornelius Placidus aparece en Mérida (CIL II 5267). Una Cornelia Placida, probablemente esposa de P.Popillius Hebdomus, aparece en Sagunto (CIL II 6062). Sobre Severina, vid. n. ${ }^{\circ}$ 28,29 y 53 . El esquema de la inscripción permite fecharla a mediados del siglo II.

31.-Denia. Pedestal de piedra caliza fracturado parcialmente en las esquinas, conservado en el Ayuntamiento de Ondara, pero procedente seguramente de Denia. Dimensiones: $63 \times 98 \times 43 \mathrm{cms}$. Campo inscrito: $42 \times 68 \mathrm{cms}$. Altura de las letras:
$4,5 \mathrm{cms}$., salvo la $\mathrm{O}$ de honore functo al final de la tercera línea. Presenta interpunciones triangulares.

\section{Bibliografía:}

CEAN BERMÚDEZ 1832, 102; VAL-

CÁRCEL 1852 (1979), n. ${ }^{\circ} 222$; CIL II

3597; FITA 1884, 21; LLORENTE

1886 (1985), 270; FITA 1887, 339;

ETIENNE 1958 (1974), 257; MARTÍN

1970, n. ${ }^{\circ}$ 14; ILER 1680; DUTHOY

1976, 179; RABANAL 1985a, 368.

[Se]x(to) Terentio

Lemnaeo hon

ore functo

seviratus

5 Sex(tus) Terentius

Lemnaeus fi

lius et $\mathrm{Ae}$

mil(ia) Scintil

la, marito

10 dignissim[o]

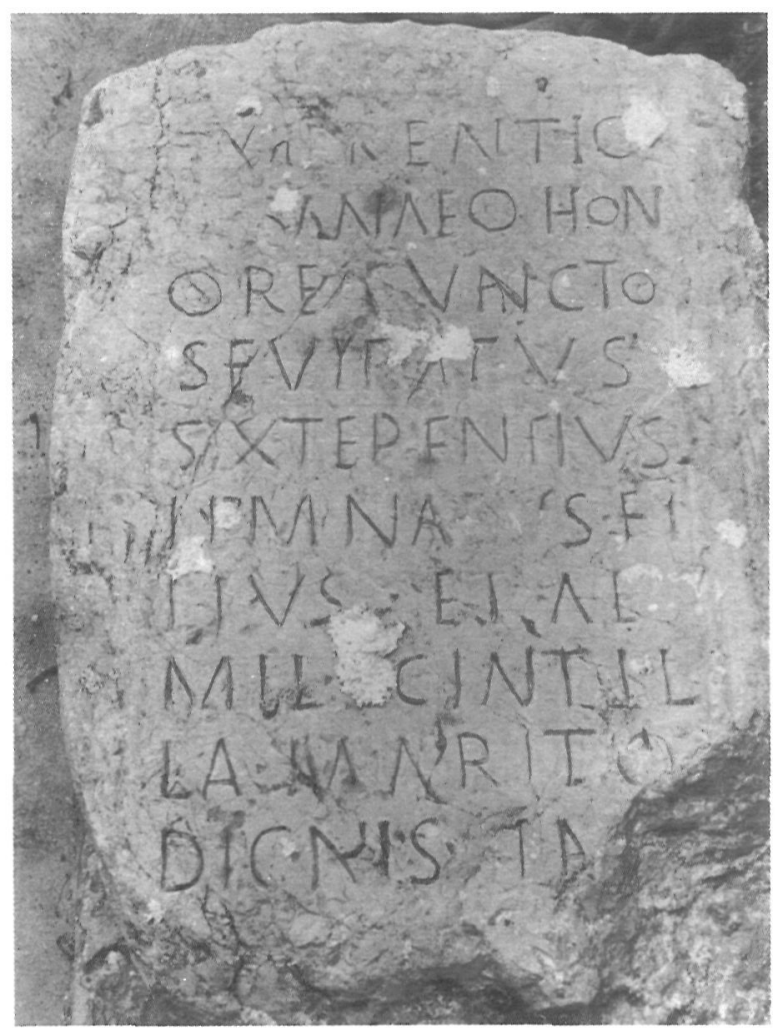

Fig. 20.-Inscripción n. ${ }^{\circ} 31$. 


\section{Traducción:}

A Sex.Terentius Lemnaeus, que desempeñó el honor del sevirato. (Hicieron este monumento) Sex.Terentius Lemnaeus, su hijo, y Aemilia Scintilla para su dignísimo marido.

Sex.Terentius Lemnaeus, marido de Aemilia Scintilla y padre de Terentia Doryphoride y de Sex.Terentius Lemnaeus, es conocido a través de esta inscripción y de la n. ${ }^{\circ} 32$. Ambas inscripciones proceden de Denia, a juzgar por la identidad de los personajes y del soporte, y, junto al monumento del n. ${ }^{\circ} 33$, salieron del mismo taller, como evidencia el rombo que figura en un costado de las piezas citadas. Cronológicamente, esta inscripción es anterior a la n. ${ }^{\circ} 32$, pues si Sex.Terentius Lemnaeus, el padre, hubiera sobrevivido a su hija, figuraría entre los dedicantes del epígrafe citado. El aspecto formal de la pieza y las fórmulas afectivas la sitúan a finales del siglo II. Otro sevir de Denia en $n .^{\circ} 20$.

32. - Denia. Pedestal de piedra caliza con moldura lateral muy bien conservada. Encontrado el 10 de febrero de 1876 en las proximidades de la inscripción n. ${ }^{\circ} 17$, cerca de Denia, y conservada en el Museo Arqueológico Municipal. Dimensiones: $63 \times 99 \times 47 \mathrm{cms}$. Campo inscrito: $56 \times 62 \mathrm{cms}$. Altura de las letras: $4,8 \mathrm{cms}$. Presenta interpunciones triangulares.

\section{Bibliografía:}

FITA 1884, 21; LLORENTE 1886 (1985), 270; FITA 1887 (1985), n. ${ }^{\circ} 7$; CIL II Suppl. 5970; SANCHÍS 1920, n. ${ }^{\circ}$ 49; MARTÍN 1970, n. ${ }^{\circ} 13$; ILER 4742; MAULEON 1983, n. ${ }^{\circ} 1764$.

Terent(iae) Do

ryphoridi, Sex(ti)

filiae, Aemilia

Scintilla fil(iae)

5 pientissimae

et Sex(tus) Teren

tius Lemnae

us sorori

V1: Ligadura NT.

Traducción:

A Terentia Doryphoride, hija de Sextus. (Erigieron este monumento) Aemilia Scintilla para su piadosísima hija y Sex. Terentius Lemnaeus para su hermana.

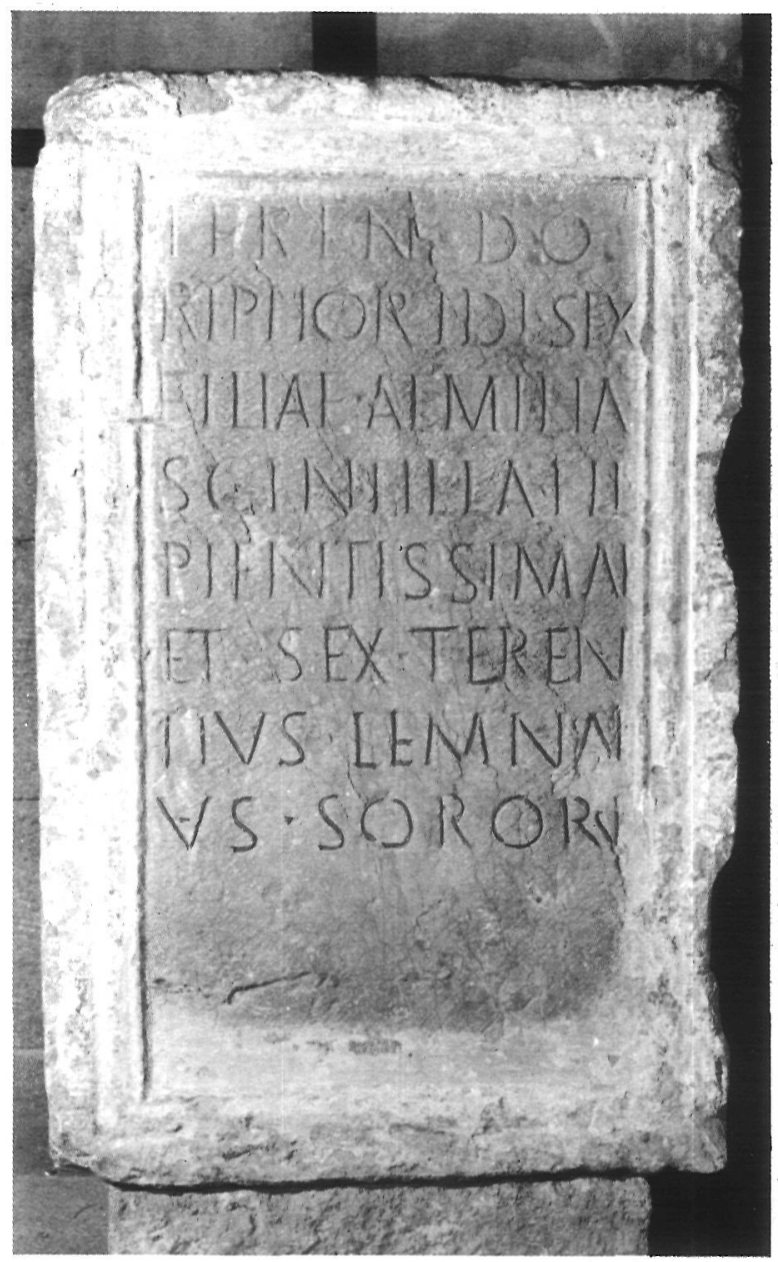

Fig. 21.-Inscripción n. ${ }^{\circ}$ 32. Foto J. Gisbert.

Sobre las relaciones familiares, estilo y cronología, vid. n. ${ }^{\circ} 31$.

33.-Denia. Bloque de piedra caliza con moldura lateral, fracturado en el ángulo inferior izquierdo, encontrado en Denia, sin que se pueda precisar en qué circunstancias. Conservado en el Museo Arqueológico Municipal. Dimensiones: $55 \times 95 \times 48 \mathrm{cms}$. Campo inscrito: $38 \times 55 \mathrm{cms}$. Altura de las letras: $6 ; 5,5 ; 5 ; 5 ; 5 ; 5 ; 4,5 \mathrm{cms}$.

\section{Bibliografía:}

PALÁU 1643 (1975), 48; VALCÁRCEL 1952 (1979), n. ${ }^{\circ}$ 59; CIL II 3590; CHABAS 1874 (1972), 68-69, n. ${ }^{\circ}$ IX; LLORENTE 1886 (1985), 268; SANCHÍS 1920, n. ${ }^{\circ} 43$; MARTÍN 1970, n. ${ }^{\circ} 8$; ILER 4427. 


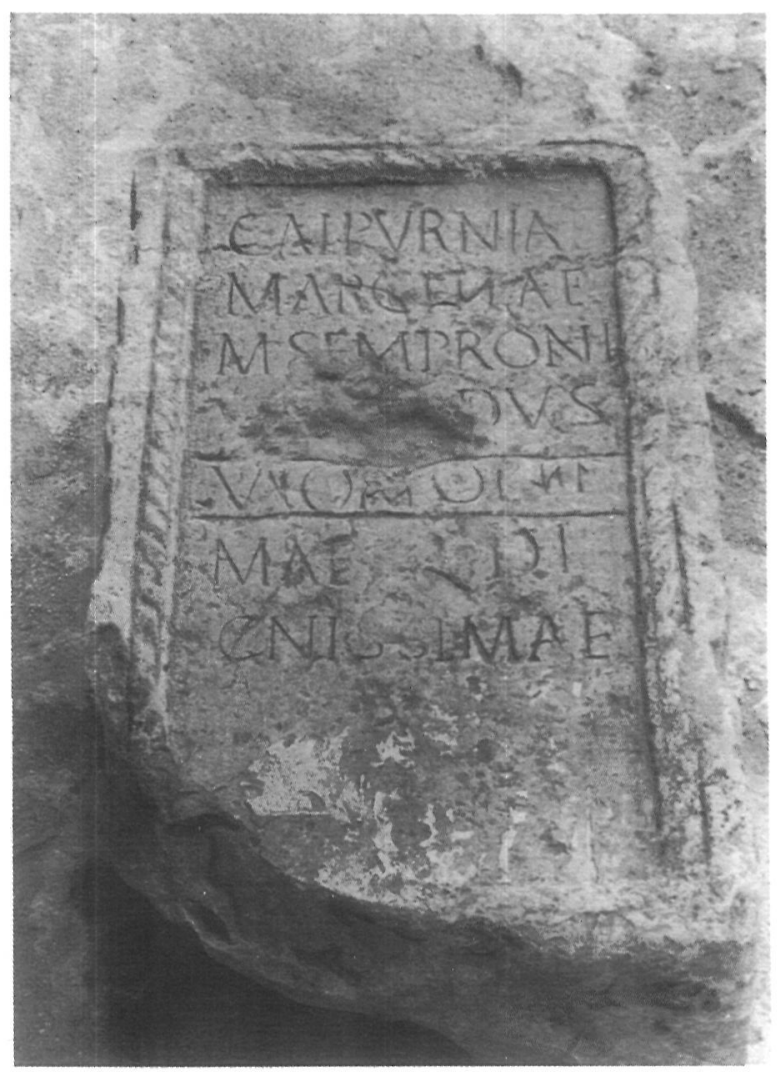

Fig. 22.-Inscripción n. ${ }^{\circ} 33$.

Calpurniae

Marcellae,

M(arcus) Semproni

u[s------]dus

5 uxori opti

mae [et] di

gnissimae

\section{Traducción:}

\section{A Calpurnia Marcella; M.Sempronius}

(----)dus (hizo este monumento) para

su esposa óptima y dignísima.

El tipo de monumento es idéntico a los n. ${ }^{\circ} 31$ y 32. Igualmente se ajusta a la cronología de finales del siglo II. Sobre Sempronius, vid. n. ${ }^{\circ} 29,34,35$ y 49. Un Calpurnianus en el n. 26.

34.-Denia. Bloque de piedra caliza con restos de una moldura en el ángulo superior derecho y fracturado a la altura de la cuarta línea. Encontrado en 1872 , cerca del supuesto templo de Diana, en Denia, y conservado en el Museo Arqueológico

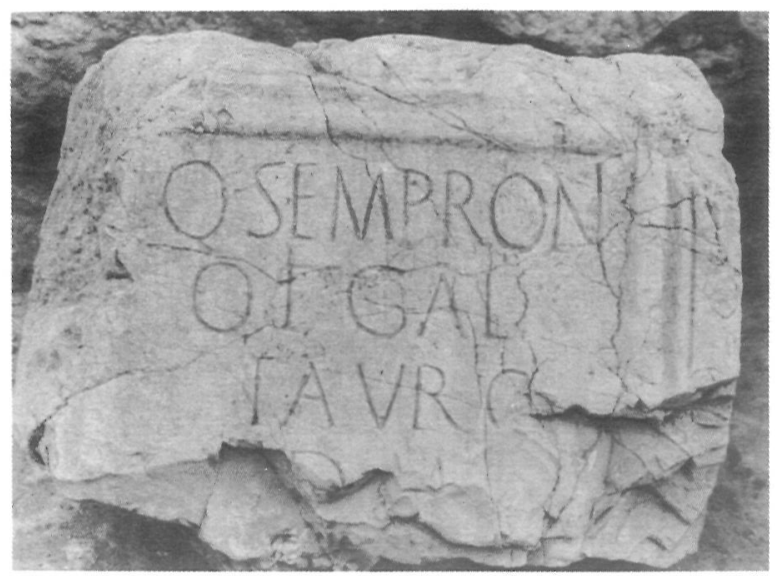

Fig. 23.-Inscripción n. ${ }^{\circ} 34$.

Municipal. Dimensiones: $60 \times 50 \times 53 \mathrm{cms}$. Campo inscrito: $37 \times 27 \mathrm{cms}$. Altura de las letras: 6,$5 ; 5,5$; $5,5 \mathrm{cms}$.

\section{Bibliografía:}

CIL II 3592; CHABAS 1874 (1972), 76, n. $^{\circ}$ XVIII; SANCHÍS 1920, n. ${ }^{\circ}$ 39; MARTÍN 1970, n. 21.

Q(uinto) Semproni(o)

Q(uinti) f(ilio) Gal(eria tribu)

Tauro

$\mathrm{D}$ (ecurioni) M(unicipii)

$[--$

\section{V1: Ligadura NI.}

\section{Traducción:}

A Q.Sempronius Taurus, hijo de Quintus, de la tribu Galeria, decurión del municipio

Otros Sempronii de Dianium en n. ${ }^{\circ} 29,33,35$ y 49. Sobre Taurus, vid. n. ${ }^{\circ} 64$ de Elche. El tipo de letra y la molduración del epígrafe corresponden al siglo II. Agradecemos a G. Alföldy la proposición de lectura para la última línea del epígrafe.

35.-Denia. Bloque cúbico de piedra caliza muy bien conservado, encontrado en la ciudad en 1872 cerca del supuesto templo de Diana. Conservado en el Museo Arqueológico Municipal. Dimensiones: $52 \times 62 \times 53$ cms. Altura de las letras: $6,6,6,6,5 \mathrm{cms}$. (en las líneas primera y cuarta algunas letras son de menor tamaño). Presenta hederae en todas las separaciones de palabras. 


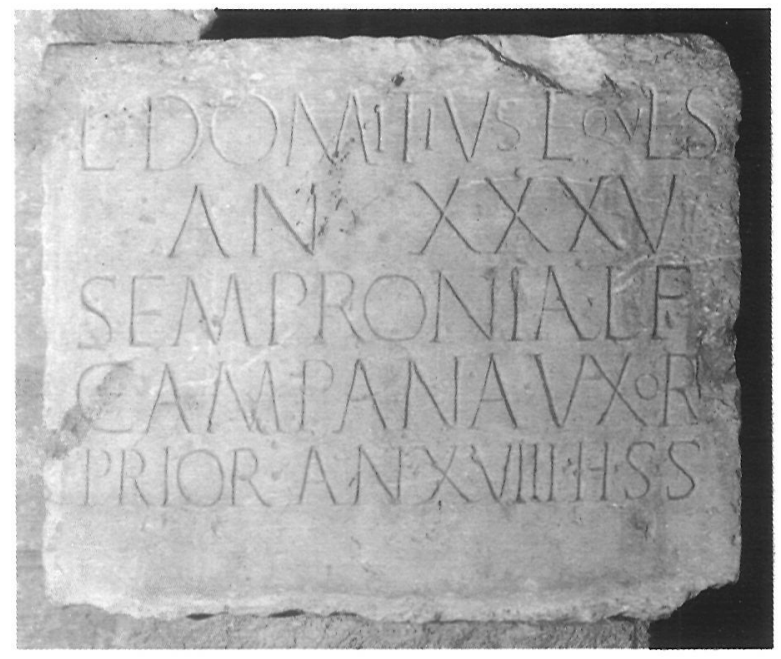

Fig. 24.-Inscripción n. ${ }^{\circ}$ 35. Foto J. Gisbert.

\section{Bibliografía:}

CHABAS 1874 (1972), 75-76, n. ${ }^{\circ}$ XVI; FITA $1884,17=1887(1985)$, n $^{\circ}$ 2; CIL II Suppl. 5964; SANCHÍS 1920, n. ${ }^{\circ}$ 62; MARTÍN 1970, n. ${ }^{\circ}$ 9; ILER 5592; MAULEON 1983, n. ${ }^{\circ}$ 1761.

L(ucius) Domitius Eques an(norum) XXXV

Sempronia L(uci) f(ilia)

Campana, uxor

5 prior, an(norum) XVIII,h(ic) s(iti) s(unt).

\section{Traducción:}

Aquí yacen L.Domitius Eques, de 35 años de edad, y su primera esposa, Sempronia Campana, hija de Lucius, de 18 años.

Una Sempronia M.f. Campana aparece en Obulco (CIL II 2149). Sobre Sempronius en DeniaOndara, vid. n. ${ }^{\circ} 29,33,34$ y 49. Eques parece el cognomen del individuo, y no su condición militar. El texto puede fecharse en la segunda mitad del siglo I.

36.-Denia. Ara de mármol blanco con cornisa superior y cartela para el texto. Antigüamente estuvo empotrada en la muralla del castillo de Denia y hoy se conserva en el Museo Arqueológico Municipal. Dimensiones: $43 \times 93 \times 28 \mathrm{cms}$. Campo ins-

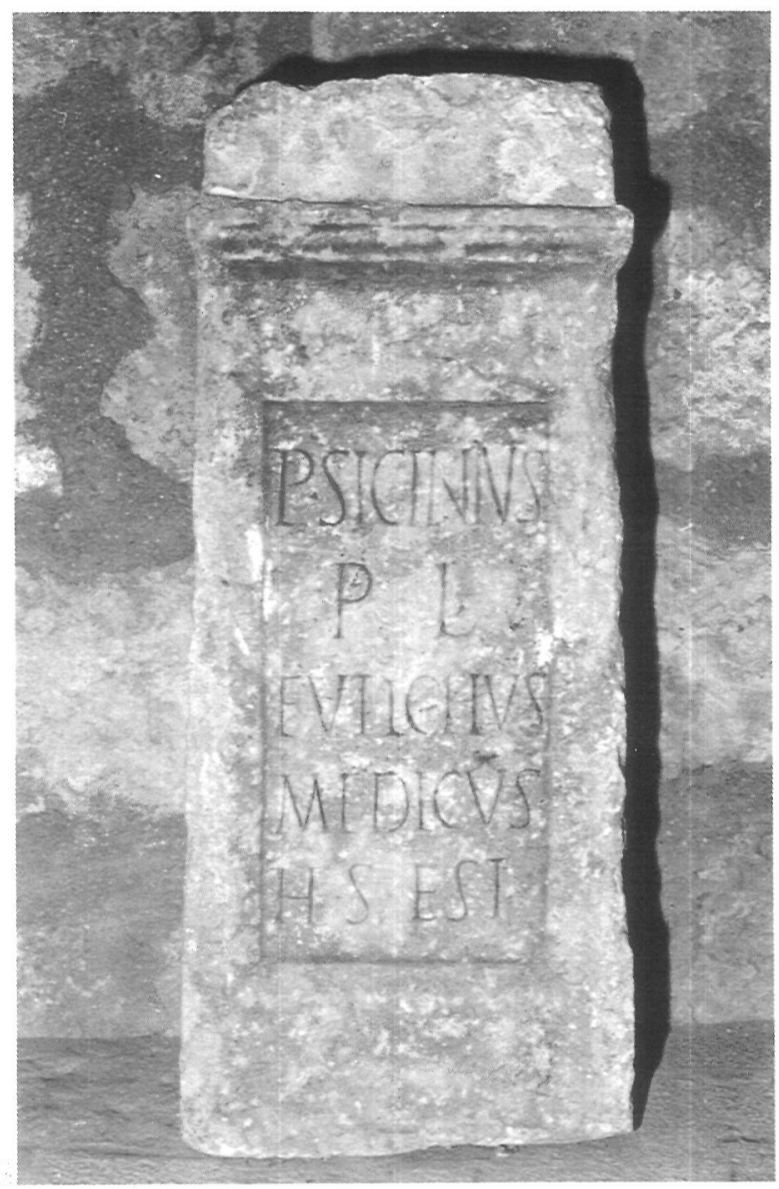

Fig. 25.-Inscripción n. ${ }^{\circ}$ 36. Foto J. Gisbert.

crito: $48 \times 34$ cms. Altura de las letras: 4,5; 4,5; 5 ; 5; $5 \mathrm{cms}$. Presenta interpunciones triangulares.

Bibliografía:

VALCÁRCEL 1852 (1979), n. ${ }^{\circ}$ 58; CIL 3593; CHABAS 1874 (1972), 6667, n. ${ }^{\circ}$ VII; LLORENTE 1886 (1985), 262; SANCHÍS 1920, n. ${ }^{\circ} 37$; MARTÍN 1970, n. ${ }^{\circ}$ 8; ILER 5731; CRESPO y SAGREDO 1976, n. ${ }^{\circ} 16$; RABANAL 1985a, 385.

$\mathrm{P}$ (ublius) Sicinius

P(ubli) 1(ibertus)

Eutychus

medicus

5 h(ic) s(itus) est

\section{Traducción:}

Aquí yace P. Sicinius Eutychus, liberto de Publius, médico. 
El estilo del monumento es completamente distinto al del resto de los encontrados en Denia. Puede fecharse en la segunda mitad del siglo I. Las formas Sicinius/a y Siscinius/a aparecen mayoritariamente en ejemplares béticos (Jerez y Baelo).

37.-Denia. Placa de mármol blanco fracturada en su parte derecha, encontrada en 1872 en la propiedad Morand de Denia. En 1970 estaba todavía allí. Dimensiones: $39 \times 28 \mathrm{cms}$. Altura de las letras: $6 ; 4,5 ; 5,5 ; 5 ; 2 ; 2$. Presenta interpunciones triangulares.

\section{Bibliografía:}

FITA $1884,17=1887$ (1985), 332; CIL

II Suppl. 5965; SANCHÍS 1920, n. ${ }^{\circ}$

59; MARTÍN 1970, n. ${ }^{\circ} 11$; ILER

5774; MAULEON 1983, n. ${ }^{\circ} 1762$.
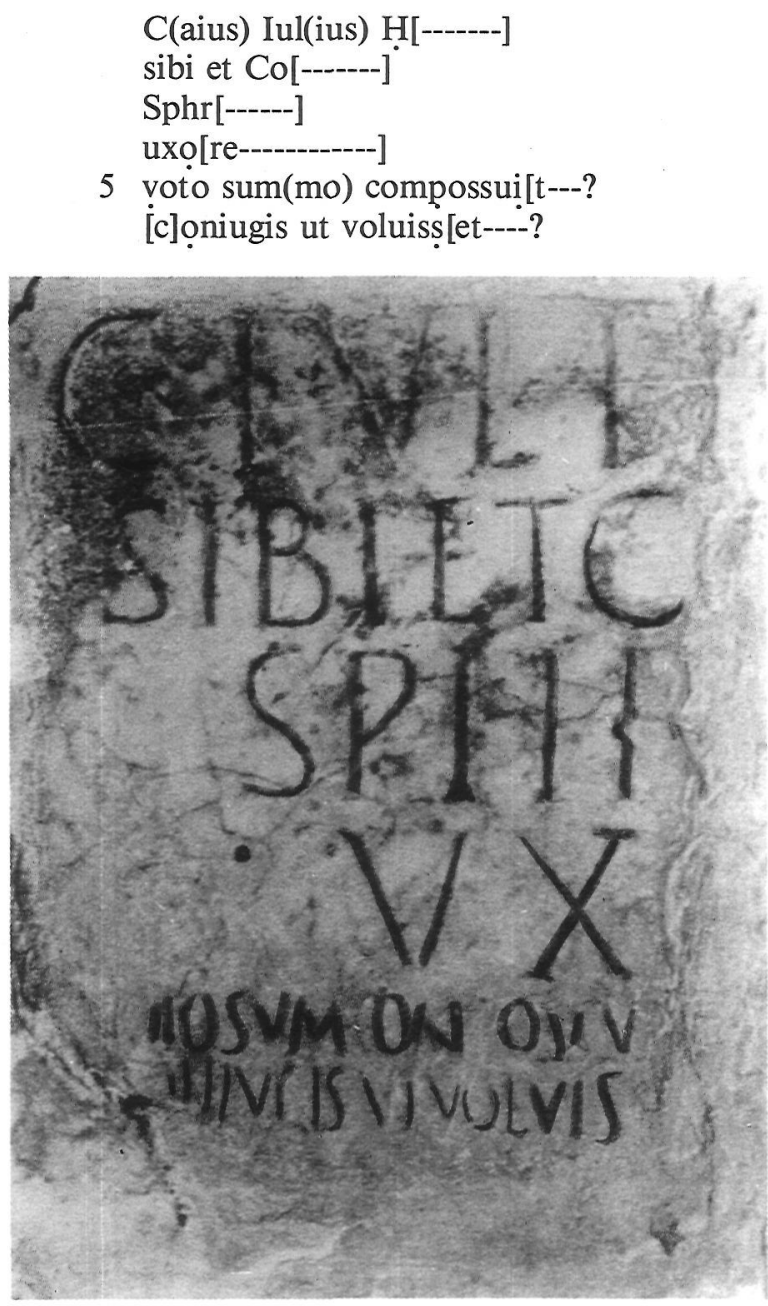

Fig. 26.-Inscripción n. ${ }^{\circ}$ 37. Según G. Martín.
V1: C.IVL(ius) H(ermadio), Fita; V2-3: Corneliae Sphragidianae, Fita; V5-6: Suplementos dudosos.

\section{Traducción:}

Caius Iulius H....... (hizo este monumento) para sí y para su mujer, Co(rnelia?) Sphr(.....); cumplió el último deseo de su esposa... tal y como quería...

Las dos últimas líneas parecen haber sido añadidas posteriormente, y sobre su interpretación las diferentes versiones no son coincidentes. Es difícil restituir también la onomástica, aunque es probable que tanto el cognomen de C.Iulius como el de su esposa sean de origen griego, y que ellos mismos puedan ser libertos.

38.-Denia. Dos fragmentos de una placa de mármol, encontrados en Denia, en el supuesto templo de Diana según Paláu, y vista posteriormente por Valcárcel en el convento de San Francisco. En 1886 Chabás dice haber encontrado la pieza izquierda $(1886,268)$, al comentar el trabajo de Bayer, y con sus anotaciones hemos modificado la transcripción que dio Hübner. Dimensiones: $23 \times 21 \times 3 \mathrm{cms}$. según las anotaciones de Valcárcel. Desaparecida.

Bibliografía:

PALÁU 1643 (1975), 49-50; VALCÁRCEL 1852 (1979), 33, n. ${ }^{\circ} 57$; CIL II 3589; CHABÁS 1874 (1972), 70-71, n. ${ }^{\circ} \mathrm{XI}$; LLORENTE 1886 (1985), 268; SANCHÍS 1920, n. ${ }^{\circ}$ 54; MARTÍN 1970, n. ${ }^{\circ}$ 15; ILER 4740; MANGAS 1971, 407.

Aufidia [P(ubli) lib(erta)]

[S]aturi[a et]

Aufidia [P(ubli) 1(iberta) Hediste]

soror[es pientissim(ae)]

\section{V3: Ligadura TE.}

\section{Traducción:}

(Aquí yacen) Aufidia Saturia y Aufidia Hediste, libertas de Publius, hermanas piadosísimas.

Tanto Valcárcel como Paláu proporcionan sólo lecturas parciales de la pieza, pues cada uno de ellos vio uno de los dos fragmentos. Hübner acepta las dos versiones y restituye el texto, asegurando que Morand vio la pieza. La estructura del texto 
parece apuntar una cronología de fines del siglo II y comienzos del III.

39.-Denia. Placa de mármol encontrada el 1 de marzo de 1887 en los cimientos de la casa de D. Carmelo Pallarés en la calle Colón de Denia (Chabás), vista por Hübner y actualmente perdida. Dimensiones: $20 \times 21$ cms. Altura de las letras (Hübner): $6 \mathrm{cms}$.

\section{Bibliografía:}

CHABÁS 1887 (1985), 372; BRAH 10, 1887,241 y $11,1887,286$; CIL II Suppl. 5963; SANCHÍS 1920, n. ${ }^{\circ} 60$; MARTÍN 1970, n. ${ }^{\circ}$ 22; ILER 5412; MAULEON 1983, n. ${ }^{\circ} 1760$.

Capraria Valentis <uxor > Sesquiplicani et Roga tae filia, vixsit an(n)is LI hic s(ita) est,s(it) t(ibi) [t(erra) l(evis)] Fita.

V2: TESQUIPLICANI, Fita; V3: AN(n)IS II,

\section{Traducción:}

Aquí yace Capraria, esposa de Valens, hija de Sesquiplicanus y de Rogata, que vivió 51 años. Que la tierra te sea leve.

Hübner discrepa de la versión de Fita y cree que no debe tratarse de un sepulcro infantil, pues la edad debe ser LI, estableciendo la restitución que transcribimos. El texto puede corresponder al siglo III.

40.-Denia. Placa de mármol encontrada en Denia, en la casa de Morand (Fita), actualmente perdida. Dimensiones: $23 \times 13 \mathrm{cms}$.

\section{Bibliografía:}

FITA 1884, 19 y 1887 (1985), n. ${ }^{\circ} 4$; CIL II Suppl. 5968; SANCHÍS 1920, n. ${ }^{\circ}$ 52; MARTÍN 1970; n. ${ }^{\circ}$ 26; ILER 4655; MAULEON 1983, n. ${ }^{\circ} 1766$.

ann(orum) LX, h(ic) s(itus) e(st)

[M]unatia Restitut[a]

[c]ont[ub]ernali

posuit.

\section{Traducción:}

.... de 60 años, yace aquí. Munatia

Restituta puso (este monumento) a su compañero.
Munatius/a aparece en testimonios de Oliva (Valencia), cerca de Denia (CIL II 3610 y 3611).

41.-Denia. Inscripción sobre mármol encontrado en Denia, vista en 1816 por Ribelles en el huerto de los Padres Recoletos de esa ciudad, según Sanchís. Actualmente desaparecida.

Bibliografia:

SANCHÍS 1920, n. $^{\circ} 70$; MARTÍN 1970, n. $^{\circ} 32$.

-----ANTONI-----

42.-Denia. Inscripción sobre soporte desconocido, encontrada en Denia, cerca del supuesto templo de Diana, según Chabás, que a finales del siglo XIX se encontraba empotrada en la fachada de una casa, detrás del castillo, según anota Hübner. Desaparecida.

\section{Bibliografía:}

CIL II 3591; CHABÁS 1874 (1972), 73; FITA 1884, 19; MARTÍN 1970, n. 20 ; ILER 3893.

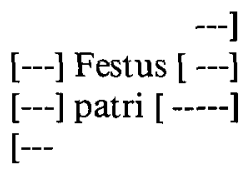

Traducción:

... Festus ... para su padre .....

Sobre Festus en Denia, vid. n. ${ }^{\circ} 28$.

43.-Denia. Inscripción encontrada en esta ciudad, de la que desconocemos otras referencias que no sean sus medidas $(12 \times 18 \mathrm{cms}$.). Desaparecida.

Bibliografía:

BRAH 12, 1888, 100; CIL II Suppl. 5966; SANCHÍS 1920, n. ${ }^{\circ}$ 64; MARTÍN 1970, n. ${ }^{\circ}$ 24; MAULEON 1983, n. ${ }^{\circ} 1765$.

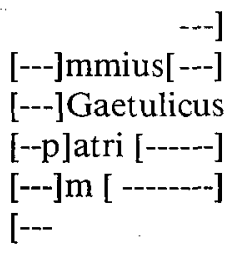




\section{Traducción:}

...(...)mmius Gaetulicus... para su padre?...

Aunque Gaetulicus es un cognomen poco frecuente, no debe ponerse necesariamente en relación con el senador C.Iulius C.f. Gal.Tiro Gaetulicus (CIL II 3661), de origen hispano, muerto hacia el 106 (LE ROUX 1982b, 459, con el resto de la bibliografía), cuya localidad natal está aún por establecer, si bien la tribu se corresponde con la de Denia, y la terminación fragmentada en el nomen de CIL II 5966 (...mmius) puede ser un error debido a Fita y a Chabás, pues Hübner no llegó a ver la pieza. Gaetulicus aparece también en Tortosa (CIL II 4066).

44.-Denia. Inscripción sobre soporte de arenisca empotrada antigüamente en lo alto de la Alcazaba de Denia, cerca de la garita del ángulo septentrional, en la muralla llamada del Vergeret, según Fita, y actualmente perdida. Dimensiones: $13 \times 22 \mathrm{cms}$.

\section{Bibliografía:}

FITA 1884, 19; LLORENTE 1886 (1985), 270; CIL II Suppl. 5967; SANCHÍS 1920, n. ${ }^{\circ}$ 51; MARTÍN 1970 , n. ${ }^{\circ} 25$; MAULEON 1983, n. ${ }^{\circ} 1767$.

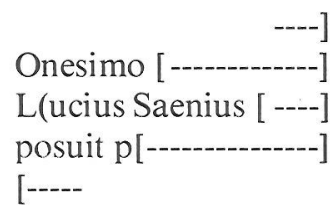

V1: Ligadura NE; V2: Ligadura NI. Traducción:

\section{A.......Onesimus; Lucius Saenius puso.....}

Como supone Alföldy (RIT 303, p. 166-67), L.Saenius Iustus, flamen en Tarraco en la primera mitad del siglo II (CIL II 4243) sería originario de Denia, y podría ponerse en relación con este personaje L.Saenius (...), de la misma familia. Una relación similar supone Fita $(1884,19)$. La inscripción de Tarragona es un pedestal para una estatua ecuestre, aunque ignoramos el nivel social de este personaje dianense, y la fecha que propone $\mathrm{Al}$ földy para aquél, entre los años 120-140 (1973, n. ${ }^{\circ}$
$60=$ RIT 303, p. 167), no puede extenderse a éste por ausencia de datos. La vinculación entre Onesimus y L.Saenius puede ser familiar, como evidenciaría un desarrollo posuit p(atri)...; el cognomen Onesimus está ampliamente difundido con muchos testimonios en la costa levantina, algunos de ellos relativamente próximos a Denia, en Sagunto (CIL II 3897) y Almenara (CIL II 3974).

45.-Denia. Inscripción, según Fita, encontrada en la finca de Morand, sin que conozcamos otros datos. Desaparecida.

Bibliografía:

FITA 1884, $22=1887,347$; CIL II

5971b; MAULEON 1983, n. ${ }^{\circ} 1769$.

--- NV ----

---- AV ----

46.-Denia. Inscripción encontrada, según Fita, en la finca de Morand. Desaparecida. Dimensiones: $18 \times 15 \mathrm{cms}$. Altura de las letras: $10 \mathrm{cms}$.

Bibliografía:

FITA 1884, $22=1887,347$; CIL II 5971a; MAULEON 1983, n. 1768.

$$
\begin{aligned}
& ---L . D \text { D --- } \\
& ----S \text {---- }
\end{aligned}
$$

Según Hübner, la letra era de época de Augusto.

47.-Denia. Bajorrelieve funerario en piedra caliza, encontrado en la C/Caballeros de Denia, formando parte de la obra de fábrica de una casa. Se conserva en el Museo de Bellas Artes de San Carlos, en Valencia. Dimensiones: $43 \times 28 \mathrm{cms}$. Campo inscrito: $18 \times 26 \mathrm{cms}$. Altura de las letras: 2,$5 ; 2,5 ; 2,5 ; 2$ cms. Presenta interpunciones triangulares.

\section{Bibliografía:}

FITA 1884, $20=1887$ (1985), n. ${ }^{\circ} 6$; CIL II Suppl. 5969; SANCHÍS 1920, n. ${ }^{\circ}$ 47; MARTÍN 1970, n. ${ }^{\circ}$ 12; ILER 4074; MANGAS 1971, 402; MAULEON 1983, n. ${ }^{\circ} 1763$. 
$\mathrm{P}$ (ublius) Statilius African[us ann(orum)]

XIIII, m(ensium) II,d(ierum) XIII, P(ublius) S[tatilius]

Pammon, pater et [---.------]

mater, fili(o) dulcis[simo-----------]

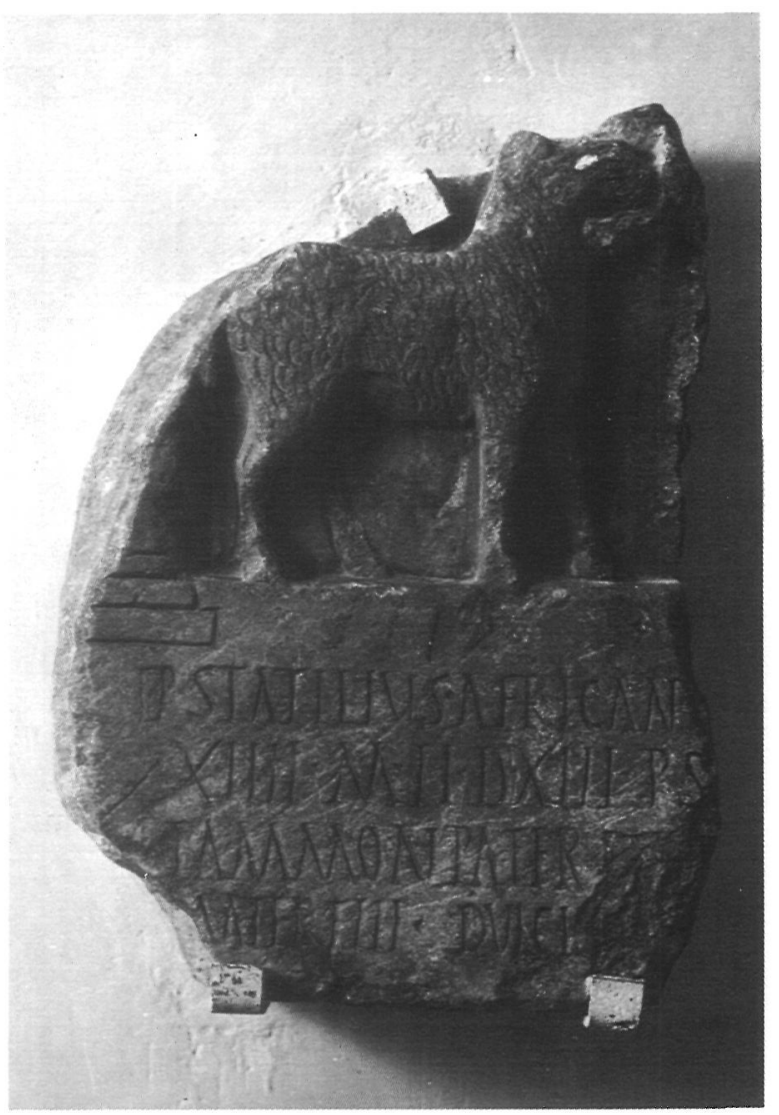

Fig. 27.-Inscripción n. ${ }^{\circ}$ 47. Foto Museo de Bellas Artes. Valencia.

\section{Traducción:}

(Aquí yace) P.Statilius Africanus, de 14 años, 2 meses y 13 días de edad. P.Statilius Pammon, su padre, y (----), su madre, (pusieron este monumento) para su hijo dulcísimo...

La parte conservada de la decoración escultórica y la estructura del texto sugieren una cronología de la primera mitad del siglo III. Sobre Statilius en Ilici, vid. n. 64 .

48.-Denia. Inscripción sobre un mosaico sepulcral blanquinegro encontrado en esta ciudad el 16 de diciembre de 1878 en una propiedad de Morand. Conservado en el Museo de Bellas Artes de
San Carlos, en Valencia. Dimensiones del campo inscrito: $50 \times 84 \mathrm{cms}$.

\section{Bibliografía:}

HÜBNER 1871, 410; FITA 1884, 23; CHABÁS 1886 (1985), 2-4, 9-11 y 17 -

18; PALOL 1967, 334-336; VIVES 1969, 77, n. ${ }^{\circ} 261$; MARTÍN 1970, 3034; LLOBREGAT 1977, 19-21.

Severina

vixit an

nos XXXX

decessit in

5 pace terti u(s) Idus Feb(ruari)

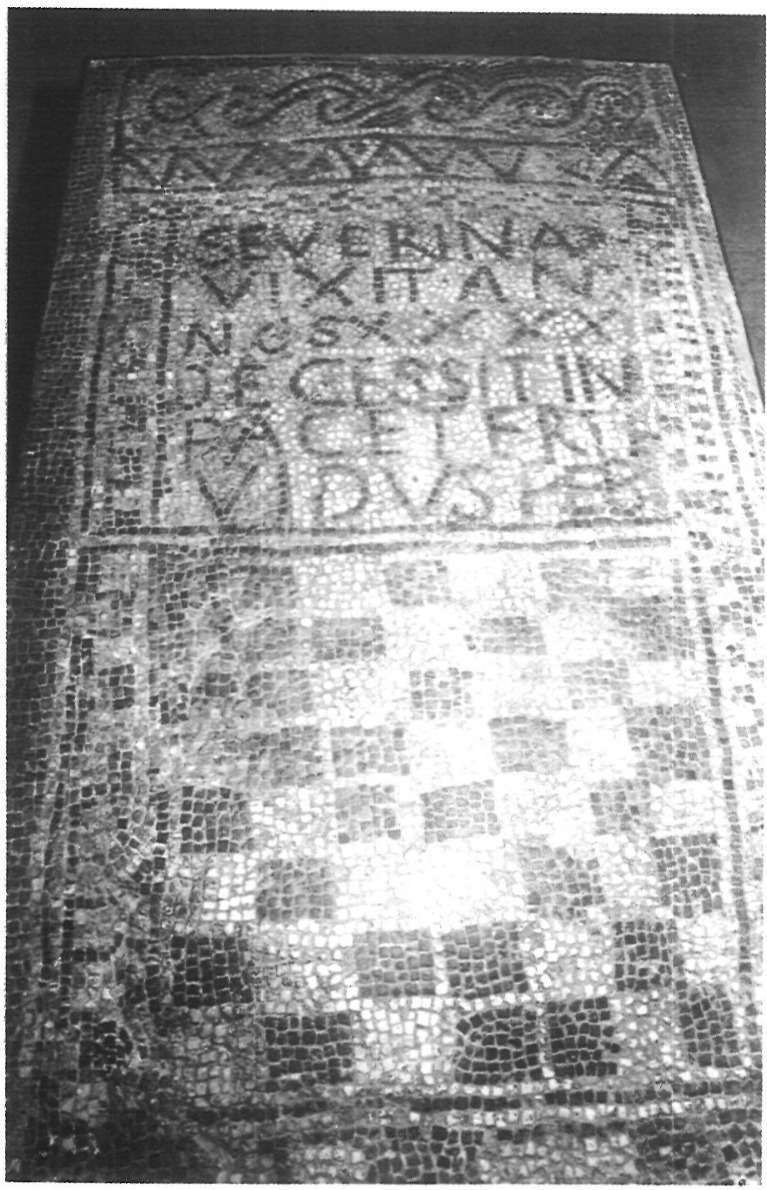

Fig. 28.-Inscripción n. ${ }^{\circ}$ 48. Foto J. Gisbert. 


\section{Traducción:}

Severina, que vivió 40 años, murió en paz el día once de febrero.

El mosaico puede fecharse en el siglo V d. C.

49.-Ondara. Inscripción sobre una columna encontrada, según Paláu, en el castillo de esta localidad. Desaparecida.

Bibliografía:
PALÁU 1643 (1975), 128-130;
3598; ILER 1407.

Q(uinto) Sempronio
Q(uinti) f(ilio) Gal(eria tribu)
Valeriano
Semproni\{i\}
5 Valerianus
et Marina
fil(io) dulcissimo
ex decreto
ordinis
10 honore contenti
impensam
statuam
remiserunt

\section{Traducción:}

A Q.Sempronius Valerianus, hijo de Quintus, de la tribu Galeria; Sempronius Valerianus y (Sempronia) Marina, por decreto de los decuriones y agradecidos por el honor, erigieron una costosa estatua a su hijo dulcísimo.

Más que en un error, puede pensarse que en la expresión Sempronii se oculta el gentilicio de ambos cónyuges, es decir, Q.Sempronius Valerianus y Sempronia Marina. Otros Sempronii de la zona Denia-Ondara en $n .^{\circ} 29,33,34$ y 35 . Las fórmulas afectivas situarían el texto a fines del siglo II y principios del III d. C.

50.-Ondara. Placa de mármol blanco encontrada en esta ciudad sin que se puedan precisar las circunstancias. Valcárcel dice haberla visto debajo de los pórticos de la plaza de Denia. Dimensiones: $35 \times 51,5$ cms. Desaparecida.

\section{Bibliografía:}

VALCÁRCEL 1852 (1979), 79-80; CIL II 3596; ILER 6430; MANGAS 1971, 408; LABORDE 1975, 122, tab. $143,33$.
$D($ is) $M$ (anibus) sacrum

T(ito) Iuni(o) Gal(eria tribu) Achillei

decurialis scribae librarii

quaestorii trium decuriarum

5 marito pio et incomparabili

Pacideia Hedone uxor commune

monumentum fecit ut $a b$ eo cum quo per annos quinque et triginta socia iucundam vitam

10 aequabili concordia vixisset nec sepulcro separaretur.

\section{Traducción:}

Consagrado a los dioses Manes. A T.Iunius Achilles, de la tribu Galeria, escriba en el despacho del quaestor de tres decurias. Pacideia Hedone, su mujer, hizo este monumento común para no ser separada por la muerte de aquél con quien había vivido durante 35 años una placentera vida común en continua concordia.

Hay diferencias de lectura en las líneas 4, 9, 10 entre las apreciaciones de Valcárcel y Hübner. Las líneas 2 y 3 presentan un desarrollo excesivamente complejo. Achilles y sus formas latinas presentan un reparto irregular en la Península Ibérica, y los dos testimonios de Hedone que conocemos (CIL II 5445 y 1834) son béticos. Iunius sí aparece en más ocasiones en Denia (n. ${ }^{\circ} 28$ y 29 ), y la tribu Galeria parece poder remitir también a esta ciudad. El texto puede enmarcarse en la primera mitad del siglo III d. C. En Ilici, se documenta un cognomen Iunianus (n. $\left.{ }^{\circ} 73\right)$.

51.-Ondara. Lápida en mármol oscuro, fracturada, y conservada antiguamente, según Valcárcel «en el recodo del convento de Mínimos». Dimensiones: $98 \times 51 \mathrm{cms}$. Desaparecida.

\section{Bibliografía:}

PALÁU 1643 (1975), 130; VALCÁRCEL 1852 (1979), 79, n. $^{\circ} 223$; CIL II 3599; ILER 4522; MANGAS 1971, 484, n. ${ }^{\circ}$ 16; LABORDE 1975, 122, tab. $143,40$.

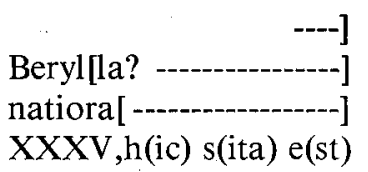

Pausilipus contuber(nali) 
V2: Ligadura TI.

\section{Traducción:}

Aquí yace ....Berylla?..., de 35 años de edad. Pausilipus (puso este monumento) a su compañera.

52.-Ondara. Inscripción sobre mármol blanco, encontrada en la calle Serra de esta localidad. Desaparecida. Dimensiones: $98 \times 54 \mathrm{cms}$.

\section{Bibliografía:}

VALCÁRCEL 1852 (1979), 79, n. ${ }^{\circ}$

221; CIL II 3600.

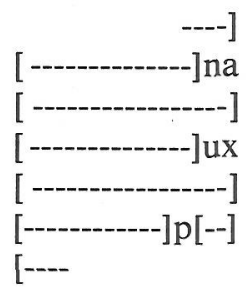

53.-Villajoyosa. Mesa del macellum de Villajoyosa, encontrada en las cercanías de la «Torre de

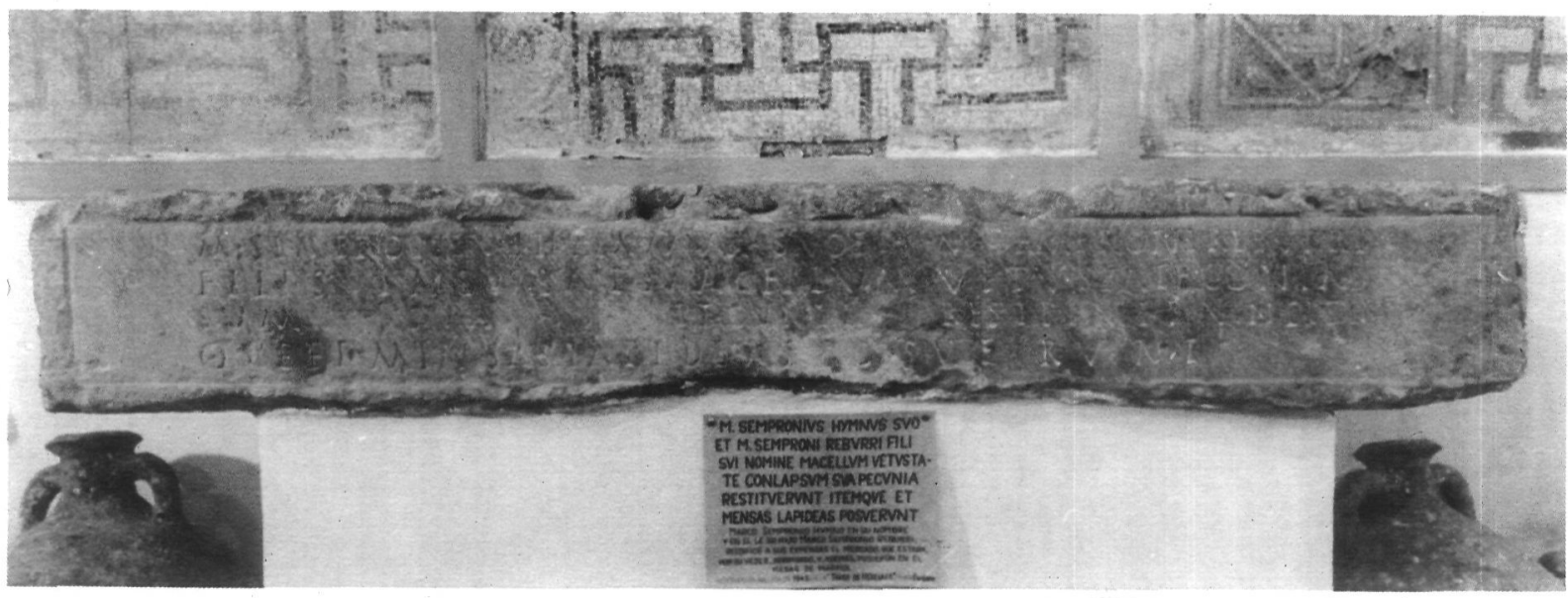

Fig. 29.-Inscripción n. ${ }^{\circ} 53$.

M(arcus) Sempronius Hymnus suo et M(arci) Semproni Reburri fili sui nomine, macellum vetustate $c o<1>1 \mathrm{la}\langle\mathrm{p}\rangle$ sum, sua pecunia restituerunt item que et mensas lapideas posuerunt

Hércules» con anterioridad al siglo XVII. Está realizada en piedra caliza muy dura, y en su parte frontal presenta la inscripción perfectamente conservada, rodeada de una leve moldura. Dimensiones: $202 \times 30 \times 74 \mathrm{cms}$. Campo inscrito: $156 \times 18$ cms. Altura de las letras: $3 \mathrm{cms}$. Presenta interpunciones triangulares.

Bibliografía:

VALCÁRCEL 1852 (1979), n. ${ }^{\circ}$ 331; CIL II 3570; CHABÁS 1889, 261; ILS 5586; ILER 6073; PUIG i CADAFALCH 1934, 238; RUYT 1983, 219.
V2: MARCELLVM, con la $\mathrm{R}$ añadida probablemente en época renacentista por encima de línea.

V2-3: CONLABSUM. V3-4: ITEMQVE ET

\section{Traducción:}

M.Sempronius Hymnus, en su nombre y en el de M.Sempronius Reburrus, su hijo, repararon a su costa el mercado, deteriorado por el paso del tiempo, y colocaron las mesas de piedra. 
El macellum al que hace referencia el texto es, con toda probabilidad, el de Villajoyosa, cuyo emplazamiento no ha sido localizado, pero que se contabiliza entre los escasos restos de este tipo de construcciones conocidos en España, junto a los de Baelo, Bracara y Emporion (RUYT 1983, 267). El estilo de la mesa de Villajoyosa es similar en su molduración al de otro ejemplar de Djemila (Ibid., Fig. 102), y el texto frontal aparece en una mesa de Leptis Magna (Ibid. Fig. 101). El macellum de Villajoyosa habría sido presumiblemente construido en el siglo I, coincidiendo con la elevación al rango de municipio que parece obtener la localidad en época flavia ( $\mathrm{Vid}$. n. ${ }^{\circ}$ 54. WIEGELS 1985, 145) y la reconstrucción a que alude el texto, y por lo tanto él mismo, pueden ser de finales del siglo II (RUYT 1983, 219). Los Sempronii son una familia bien conocida en Denia (n. ${ }^{\circ} 29,33,34,35$ y 49). El cognomen Reburrus es propio de áreas célticas de la Península Ibérica (RUBIO 1959). Sobre los personajes y el entorno epigráfico y arqueológico de esta inscripción, vid. el trabajo de L. Abad y M. Bendala en esta misma revista.

54.-Villajoyosa. Pedestal en mármol grisáceo encontrado en 1688 en las cercanías de Villajoyosa, en casa de Pedro Linares (Valcárcel), conservado actualmente en el Museo Etnográfico de Villajoyosa. La pieza se encuentra fracturada en dos mitades, habiéndose perdido la cuarta línea de texto en la rotura, y está cortada en su parte derecha, sin que se pueda apreciar aquí la moldura que rodea la inscripción en los laterales conservados. Las dimensiones corresponden a la superficie total. Dimensiones: $52 \times 114 \times 38$ cms. Campo inscrito: $35 \times 70 \mathrm{cms}$. Altura de las letras: 5,$5 ; 5,5 ; 5,5 ;(-)$, 5,$5 ; 5,5 ; 6,5 ; 6 \mathrm{cms}$.

Bibliografía:

VALCÁRCEL 1852 (1979), n. 334; CIL II 3571; ILER 5212; TAFALLA 1972, 67; ETIENNE 1958 (1974), 211; WIEGELS 1985, 145.

Q(uinto) Manlio

Q(uinti) f(ilio) Quir(ina tribu)

Celsino

[IIvir III, fla]

5 mini III

Manlia

Chrysis

uxor
V4: Según Hübner, sin que conozcamos su fuente de información.

\section{Traducción:}

A Q.Manlius Celsinus, hijo de Quintus, de la tribu Quirina, IIvir en tres ocasiones, flamen en tres ocasiones. Manlia Chrysis, su mujer (dedicó este monumento).

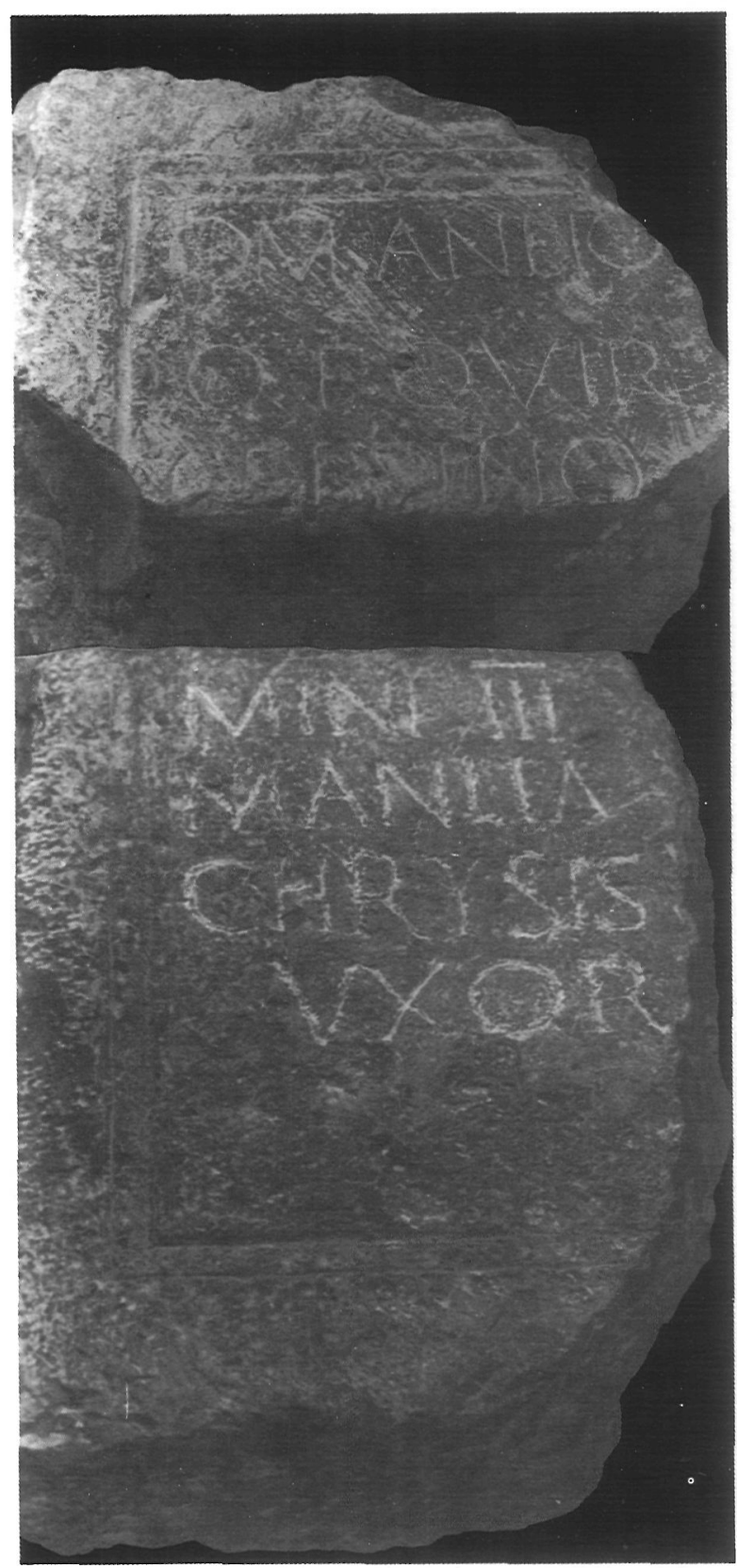

Fig. 30.-Inscripción n. ${ }^{\circ} 54$. 
Este texto recoge el único testimonio de la tribu Quirina en la zona estudiada. Su vinculación a Villajoyosa plantea la posible progresión jurídica del municipio en época flavia (WIEGELS 1985, 145) frente a la mayor antigüedad del resto de los enclaves cercanos. El homenajeado es, indudablemente, miembro de la aristocracia local. El tipo de letra y las características del epígrafe, inducen a fecharlo en la primera mitad del siglo II d. C. Los Manlii aparecen en diversas inscripciones de Sagunto (CIL II 3858, 3862 y EE IX 369), Tarraco (CIL II 4118, 4389 y RIT 618) y Valentia (CIL II 3764). Celsus aparece en diversos ejemplos de la costa levantina. Un Celsianus existe en Tarraco (RIT 158).

55.- - Villajoyosa. Inscripción encontrada en circunstancias no precisables y conservada en el exterior de uno de los muros en la casa de la finca de L'Almiserá, entre Villajoyosa y Finestrat, a 1,50 metros del suelo. Es un bloque de piedra caliza fracturado en su parte superior y derecha, con una magnífica conservación en el fragmento aún existente. Dimensiones: $49 \times 61 \mathrm{cms}$. Campo inscrito: $26 \times 39 \mathrm{cms}$. Altura de las letras: 7, 6, $6 \mathrm{cms}$. Presenta interpunciones triangulares.

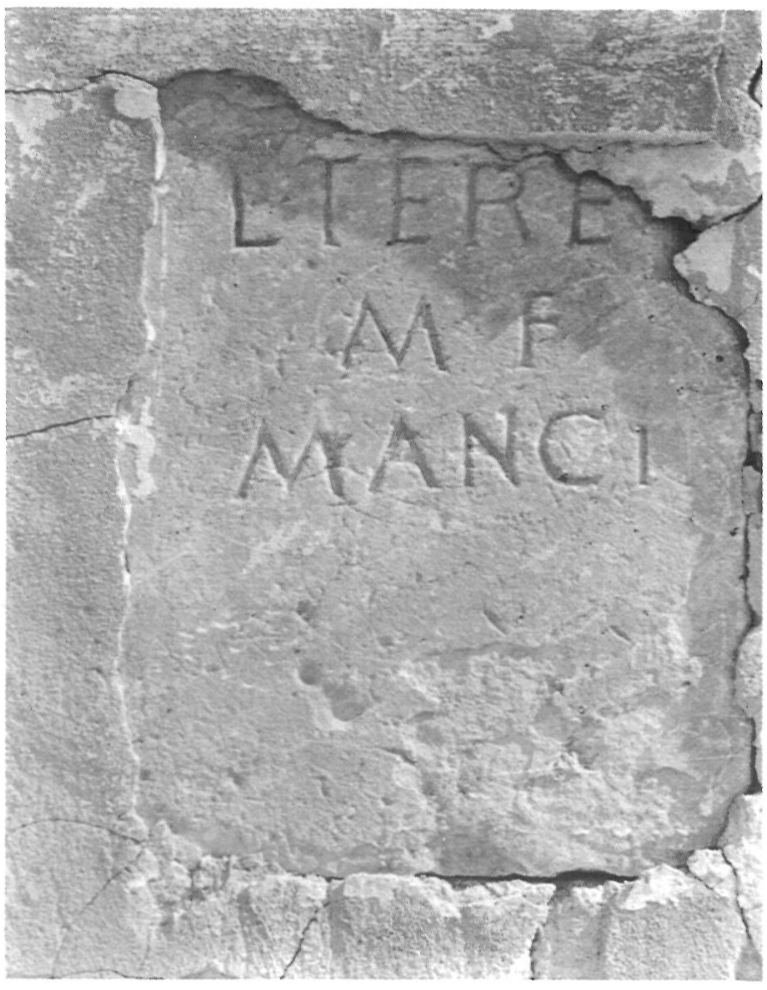

Fig. 31.-Inscripción n. ${ }^{\circ} 55$.
Bibliografía:

VALCÁRCEL 1852 (1979), n. ${ }^{\circ}$ 336;

CIL II 3576; ILER 2236.

L(ucio) Tere[ntio?]

M(arci) f(ilio)

Mancin[o?]

[---

\section{V1: L. TERE; V3: MANCIN}

\section{Traducción:}

... Lucius Terentius Mancinus, hijo de Marcus...

El estado fragmentario del texto impide incluso precisar el caso en que se desarrolla. Sobre Terentius, vid. n. ${ }^{\circ} 31,32,55$ y 94.

56.-Villajoyosa. Ara funeraria en mármol oscuro, de origen no precisable, que se conserva en la

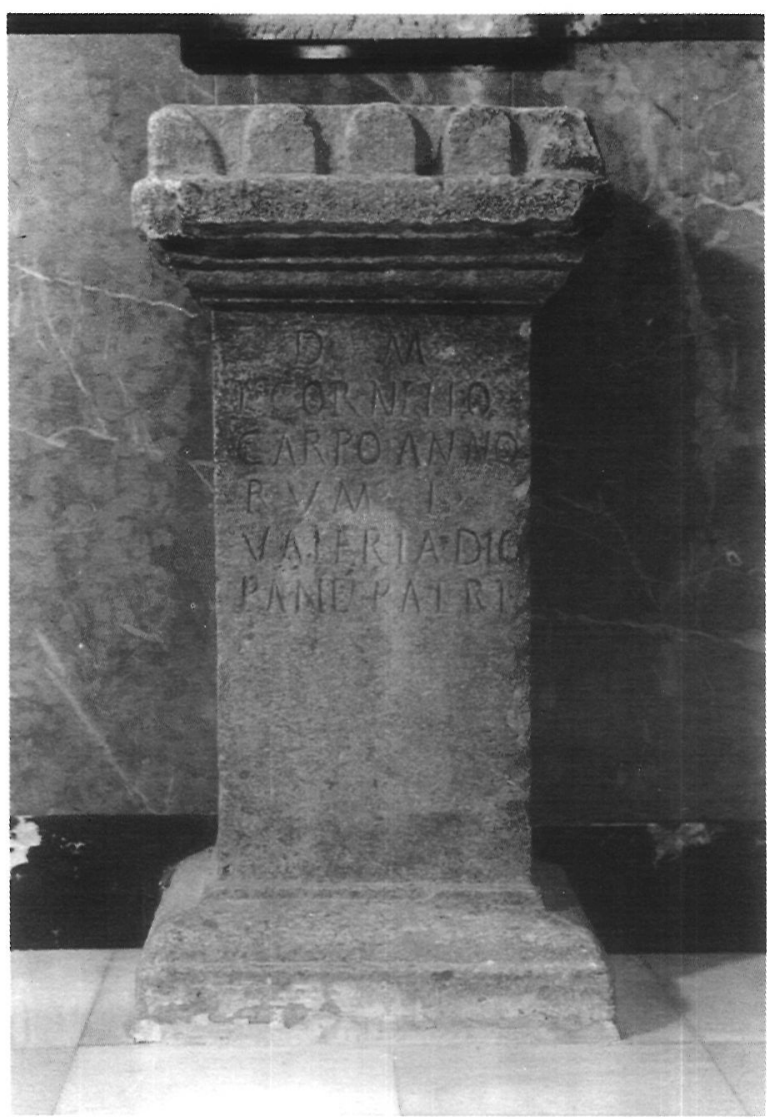

Fig. 32.-Inscripción n. ${ }^{\circ} 56$. 
Iglesia de Villajoyosa, sirviendo de pila bautismal. Presenta pie y cornisa moldurados, con un remate superior de ovas alrededor del foculus. Dimensiones máximas: $63 \times 120 \times 41 \mathrm{cms}$. Campo inscrito: $37 \times 37 \mathrm{cms}$. Altura de las letras: $4,5 \mathrm{cms}$. Presenta interpunciones triangulares en las líneas 2,5 y 6 , con una hedera en la línea 4.

Bibliografía:

CEAN BERMÚDEZ 1832, 126; VAL-

CÁRCEL 1852 (1979), n. ${ }^{\circ} 332$; CIL II 3573; ILER 3917.

$\mathrm{D}$ (is) $\mathrm{M}$ (anibus)

L(ucio) Cornelio

Carpo, anno

rum $\mathrm{L}$

5 Valeria Dio

pane patri

\section{Traducción:}

A los Dioses Manes. A L.Cornelius Carpus, de 50 años. Valeria Diopane (dedicó este monumento) a su padre.

El texto no ofrece problemas de lectura debido a su excelente estado de conservación, y puede ser fechado a mediados del siglo II d. C. Sobre Cornelius, vid. n. ${ }^{\circ} 30$ y 96 . Sobre Valerius/a, vid. n. ${ }^{\circ} 1$, 25, 26, 27.

57._Villajoyosa. Lápida en piedra caliza de origen no precisable, empotrada en la pared exterior de la capilla de Santa Marta en la Iglesia de Villajoyosa. Dimensiones: $44 \times 57 \mathrm{cms}$. Campo inscrito: $39 \times 44 \mathrm{cms}$. Altura de las letras: $3,5 \mathrm{cms}$. El texto se encuentra muy deteriorado por efectos de la climatología.

Bibliografía:

VALCÁRCEL 1852 (1979), n. ${ }^{\circ} 335$;

CIL II 3572; ILER 6440; LABORDE $1975,117$.

$\mathrm{D}$ (is) $\mathrm{M}$ (anibus)

Alfius Zosim[us]

an(norum) $\dot{L} V, h(i c)$ s(itus) est,

homo optime s(it) t(ibi) t(erra) 1(evis)

5 Ulp(ia) Diiofa[ne]

an(norum) $\dot{\mathrm{X}} \dot{\mathrm{L}} \mathrm{V}, \mathrm{h}$ (ic) s(ita) e(st)

mulier optima

s(it) t(ibi) t(erra) l(evis)

V5: VLP. myRINE, Hübner.

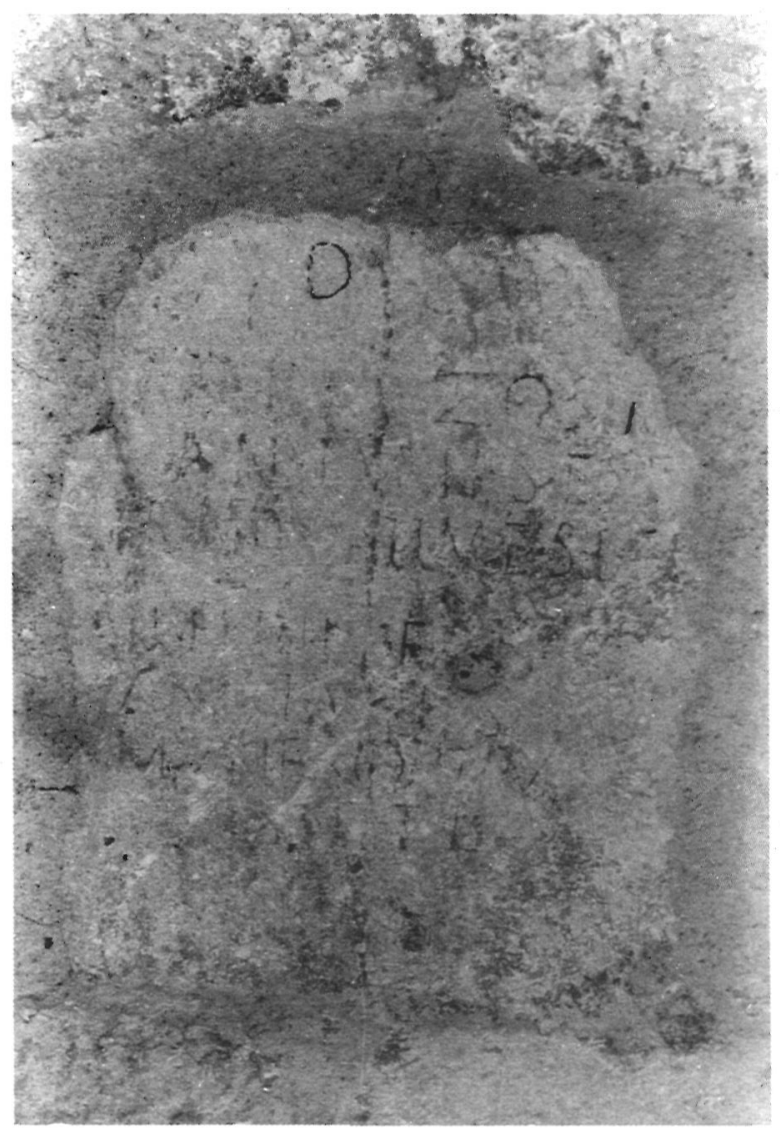

D M

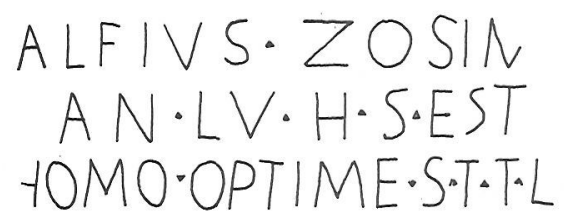

VLP.DIIOFL

$A N \cdot X L V \cdot H S$

MVLIEROPTIM

$S \cdot T \cdot T \cdot L$

Fig. 33.-Inscripción n. ${ }^{\circ}$ 57. Calco sobre fotografia.

\section{Traducción:}

A los Dioses Manes. Aquí yace Alfius Zosimus, hombre óptimo, de 55 años de edad; que la tierra te sea leve; Aquí yace Ulpia Diiofane mujer óptima, de 45 años de edad; que la tierra te sea leve. 
El deterioro del texto es más acusado en la quinta línea, en la que figura el nombre de la mujer, a pesar de lo cual, G. Alföldy ha podido leerla tal y como nosotros presentamos gracias a su amabilidad. Los difuntos ocultan, probablemente, su condición de libertos, ambos de ascendencia griega. El texto parece fecharse en el siglo II. Sobre el cognomen de la mujer, vid. Diopane en n. 56.

58.-Villajoyosa. Ara funeraria en piedra caliza encontrada en circunstancias no precisables y. conservada en el domicilio de $\mathbb{D}$. Joaquín Ors en Villajoyosa. Presenta base y cornisa moldurada parcialmente deteriorada, y el texto se encuentra muy perdido. Dimensiones máximas: $50 \times 90 \times 64$ cms. Campo inscrito: $25 \times 32 \mathrm{cms}$. Altura de las le-

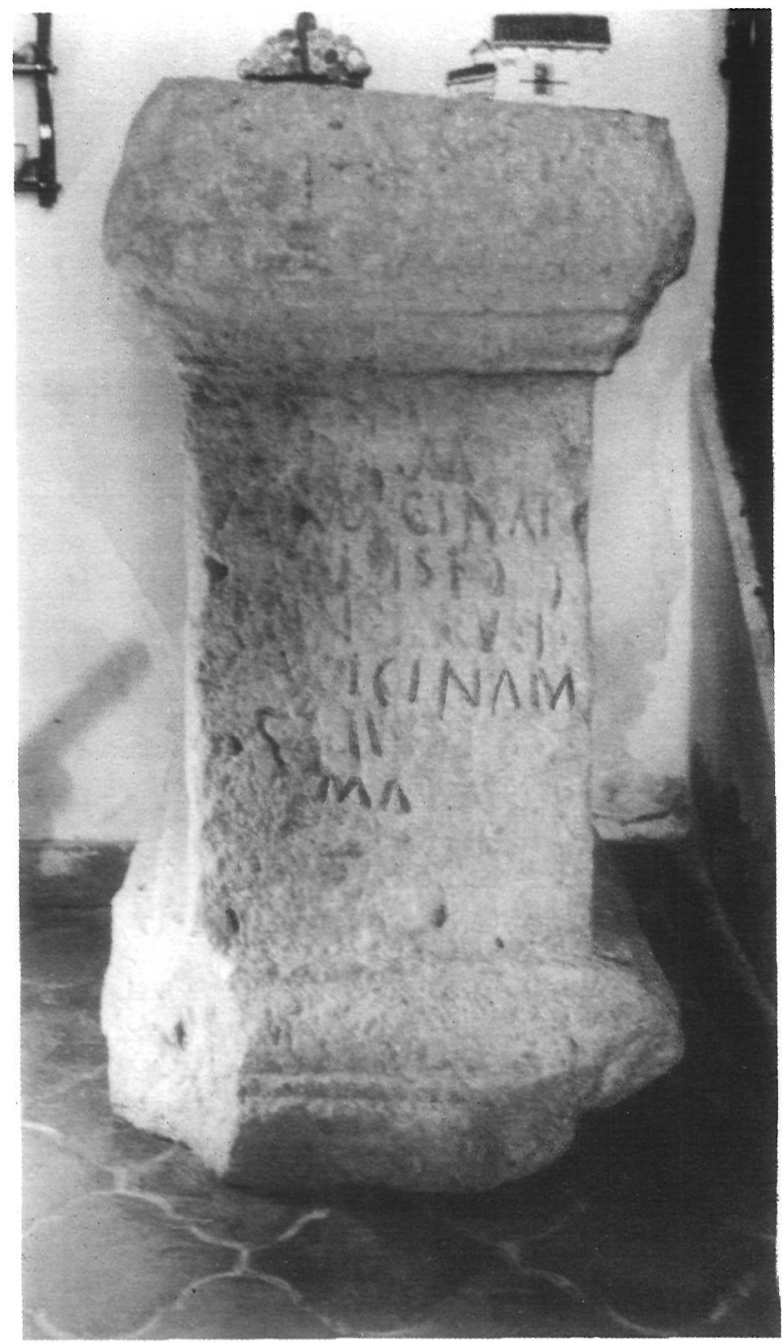

Fig. 34.-Inscripción n.$^{\circ} 58$. tras: $4,5 \mathrm{cms}$. en la primera línea y $3,5 \mathrm{cms}$. en el resto.

\section{Bibliografía:}

CEAN BERMÚDEZ 1832, 126; VAL-

CÁRCEL 1852 (1979), n. ${ }^{\circ} 333$; CIL II

3577; LAFUENTE 1959, n. ${ }^{\circ} 188$; ILER 4237.

$\mathrm{D}$ (is) M(anibus)

M(arco) Volcinae[o]

Callisto ann(orum) XVIII,

5 Vọicinaea

Cälliste

mater

\section{V4: Ligadura AN \\ Traducción:}

A los Dioses Manes. A Marcus Volcinaeus Callistus, de 18 años (le dedicó esta inscripción) Volcinaea Calliste, su madre.

La transmisión del texto mediante una copia en yeso conservada en el Museo Arqueológico Provincial de Alicante ha desfigurado la lectura, que, con dificultad, puede ser hoy establecida como recogemos. El monumento puede fecharse en la segunda mitad del siglo II.

59.- Villajoyosa. Ladrillo encontrado en el paraje de Torre de la Cruz en Villajoyosa, y conservado en el Museo Arqueológico Provincial de Alicante. Dimensiones: $19 \times 14 \times 2,5 \mathrm{cms}$. Campo inscrito: cartela de $8 \times 2,5 \mathrm{cms}$. Altura de las letras: $0,6 \mathrm{cms}$.

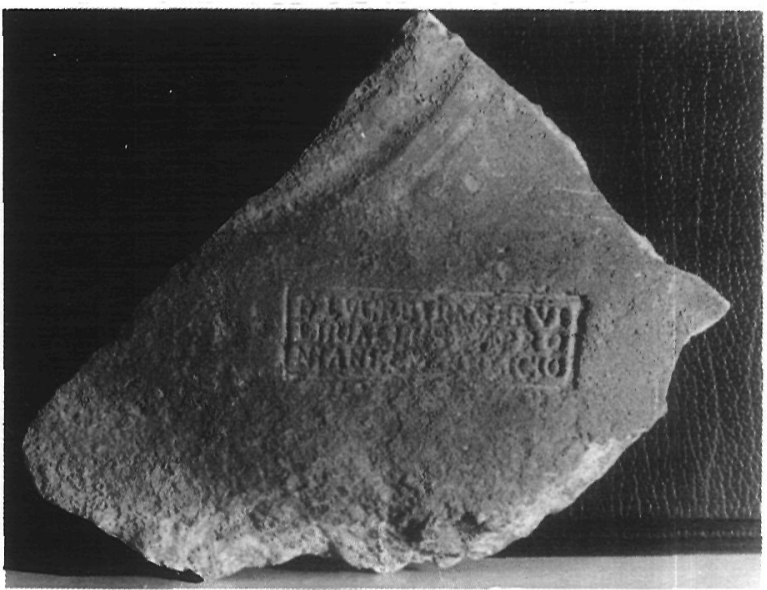

Fig. 35.-Inscripción n. ${ }^{\circ} 59$. 


\section{Bibliografía:}

LAFUENTE 1959, n. ${ }^{\circ}$ 164; ALFÖLDY 1977, 217; AE 1977, 449.

L(ucii) Lucreti\{i\} Servi

lii Galli Sempro

niani c(larissimi) v(iri) $\mathrm{F}<\mathrm{e}>$ licio (fecit)

\section{V1: LUCRETIO; V3: FLICIO.}

\section{Traducción:}

De Lucius Lucretius Servilius Gallus

Sempronianus, hombre notabilísimo.

(Lo hizo) Felicio.

La restitución que presentamos es la publicada por Alföldy, quien fecha la inscripción en el siglo III $(1977,221)$. El senador sería de origen hispano, quizá incluso de Villajoyosa (Alföldy 1977, 217ss.; LE ROUX 1982b, 458), si bien no se conoce con claridad su familia ni su cursus.

60.- - Villajoyosa. Inscripción encontrada de forma casual en el patio de la finca de Els Bañets, y conservada empotrada en la fachada exterior de la misma, a 1,50 metros del suelo. Es un fragmento de inscripción funeraria en piedra caliza grisácea, muy fracturada, cuyas dimensiones totales son $37 \times 23 \mathrm{cms}$. Altura de las letras: $6 \mathrm{cms}$. Inédita.
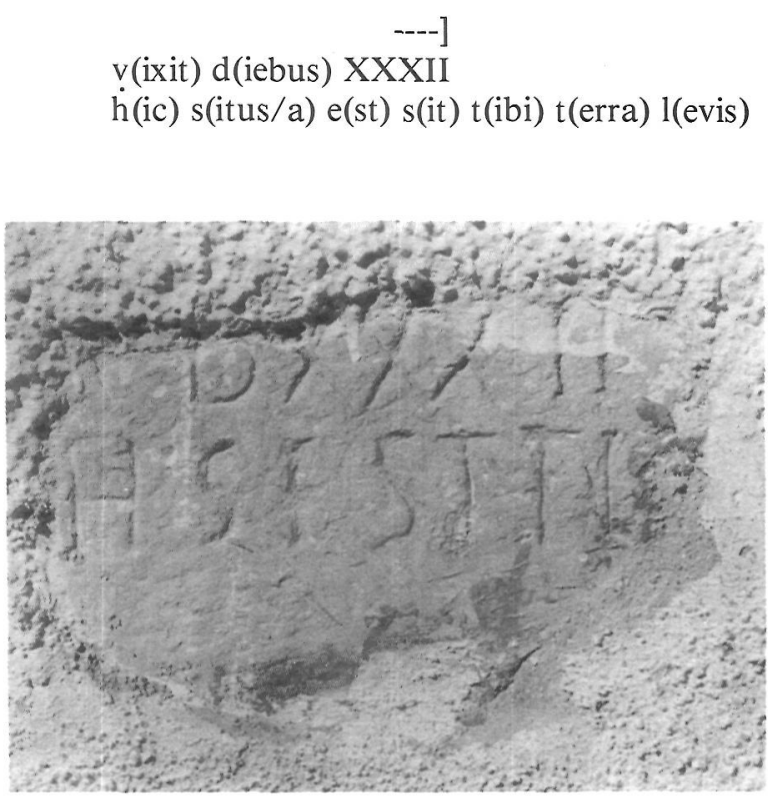

Fig. 36.-Inscripción n..$^{\circ} 60$.

\section{Traducción:}

.... vivió 32 días. Aquí yace; que la tierra te sea leve.

El supuesto desarrollo de la penúltima línea llevaría el texto a los primeros años del siglo III d. C.

61.-Villajoyosa. Inscripción sobre un soporte circular en mármol grisáceo con una orla lateral de ovas. Apareció durante unas obras en un edificio junto a la vía férrea Alicante-Denia, en su cruce con la carretera de La Ermita, dentro del casco urbano de Villajoyosa. Se conserva en el Museo Etnográfico de Villajoyosa. Diámetro de la pieza, 27 cms. Grosor parcial del soporte: $3 \mathrm{cms}$. Altura de las letras: $2 ; 3 ; 3,5 ; 2 ; 2 ; 1,5$ cms. Presenta interpunciones circulares. Inédita.

$\mathrm{D}$ (is) $\mathrm{M}$ (anibus) sacrum

Voconia

Macedonia

vix(it) ann(is) $\mathrm{XX}$

5 VI, m(ensibus) VII

h(ic) s(ita) e(st), s(it) t(ibi) t(erra) l(evis)

\section{Traducción:}

Consagrado a los Dioses Manes. Aquí yace Voconia Macedonia, que vivió 26 años y 7 meses. Que la tierra te sea leve.

El soporte circular del texto es idéntico a uno depositado en el Museo Monográfico de La Alcu-

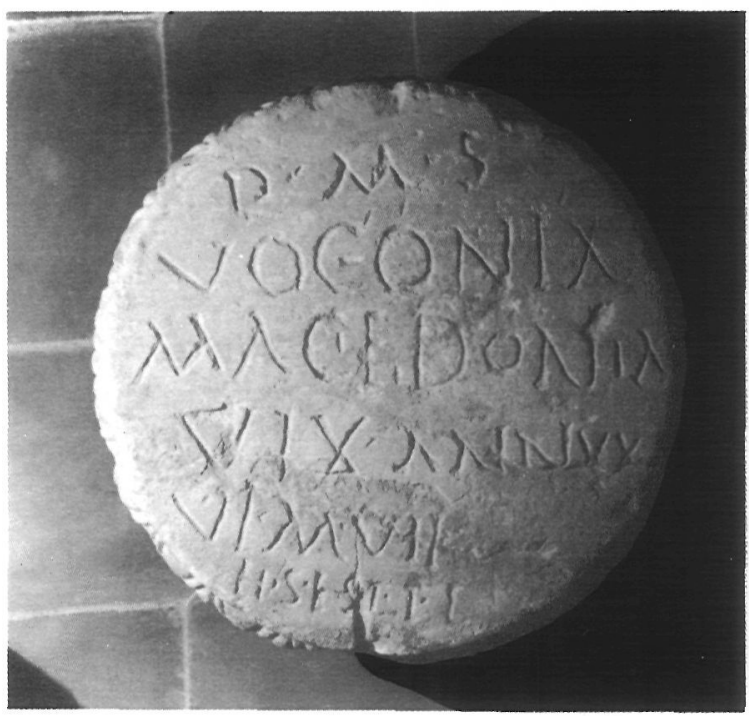

Fig. 37.-Inscripción n. ${ }^{\circ} 61$. 
dia de Elche, procedente de las excavaciones en los «pozos-manantiales» (RAMOS FOLQUES 1963, Fig. 37), con el que coincide incluso en la orla lateral, variando sólo levemente la coloración. Voconia se repite otras veces en la Península, si bien es más frecuente el masculino. Macedonia es inusual; más corriente es Macedonica. El formulario y la paleografía del texto permiten situarlo en la primera mitad del siglo III d. C., en lo que coincide con los hallazgos numismáticos que acompañan el hallazgo de la placa de Elche (RAMOS FOLQUES 1963, 249).

62.-La Alcudia de Elche. Dos fragmentos de una placa de bronce encontrados en la finca $\mathrm{El} \mathrm{Al-}$ caldet (Els Partiorets) en 1899 y 1949. Se encuentran depositados en el Museo Arqueológico Municipal de Elche y en el Monográfico de La Alcudia de Elche. Altura de las letras: $8 \mathrm{~mm}$. Medidas del fragmento mayor $18,5 \times 13 \times 0,5 \mathrm{cms}$.

\section{Bibliografia:}

EE IX, 1903, 10; IBARRA 1926, 40; D'ORS 1950, 280; GARCÍA Y BELLIDO 1950; GARCÍA Y BELLIDO 1951, 240; D’ORS 1953, 25ss. y 447ss. Vid. bibliografía citada en texto. RAMOS 1975, n. ${ }^{\circ} 23$.

[-- item]q(ue) [tabellas ceratas [--item t]abulas dealbatas in [quib(us)-------] [--perlegi p]ossint ponendas curet deinde[--] [--suffragi] um laturi erunt sede[ntium -----]

[--German]ici Caesaris suffrag[ium----------]

[--pila]s quam maxime a [equatas -----------]

[--iubeat] sortirique sen[atores --------------]

[--pri]mas qu[ae C(ai) et ---------------]

[--cuius s]ors [exierit

10

[--q]ui ex ea [tribu

[--f]erre iube[at

$[--t] r i b u$ vocet eq[uites

[--cum] alteram tri[bum

[--in c]istam in qu[am

El texto está reconstruido conforme a D'Ors 1953, 25 y 449, que utiliza como modelo el texto de la Tabula Hebana encontrada en Magliano y publicada por A. Minto y V. Coli (Roma 1948, 49ss.), con suplementos según la publicación colectiva que de la Tab.Hebana se hizo en La Parola del Passato XIV

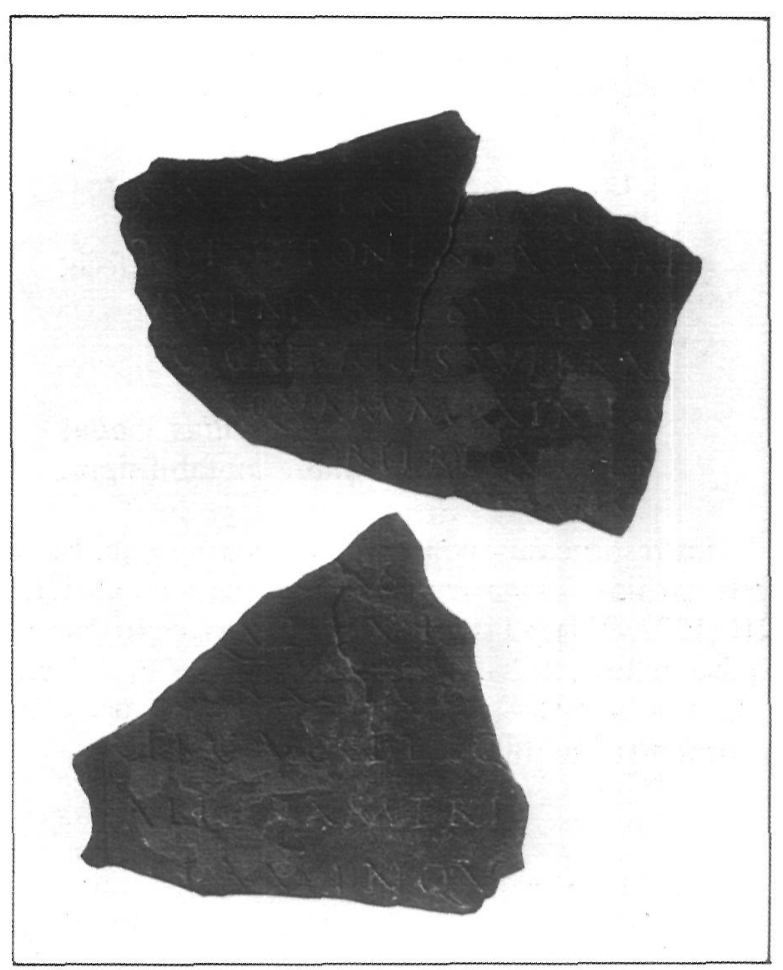

Fig. 38.-Inscripción n. ${ }^{\circ} 62$.

(1950) y las rectificaciones posteriores sobre el mismo documento. Bibliografía del documento hasta 1953 en D'Ors $(1953,29$ ss. y 447ss.). Bibliografía más reciente puede verse en Lomas, F. J. Tabula Hebana, en Habis 9, 1978, 323ss. Recientemente han sido dados a conocer los dos fragmentos de las Tablas de Siarium, el primero de los cuales contiene un texto ya conocido por CIL VI $911=31199$, y el segundo da luz a la lectura de las primeras líneas de la Tabula Hebana ( $\mathrm{Vid}$. GONZÁLEZ, J. Note e discussioni, en Iura 31, 1980, 1-3). Un nuevo comentario del hallazgo y algunas rectificaciones a la propuesta de González, así como toda la bibliografía que recientemente ha generado el hallazgo, en ARCE, J. Tabula Siarensis: primeros comentarios (I), en AEA 57, 1984, 149ss.

Los textos de las placas de Ilici fueron primeramente considerados como parte de la ley municipal de la colonia; hasta 1953 D’Ors los interpretó como parte de una copia de la Tabula Hebana, la conocida rogatio de Tiberio de finales del año 19 , referida a los honores fúnebres de Germánico; pero en esa fecha, el mismo D'Ors aceptó la tesis defendida por algunos autores italianos en el sentido de que estos fragmentos ilicitanos no corresponderían a la rogatio del año 
$19 \mathrm{~d}$. C., sino a una posterior, la del año $23 \mathrm{~d}$. C., sobre los funerales de Druso el menor (D'ORS 1953, 449).

63.-La Alcudia de Elche. Pedestal en mármol rosáceo muy deteriorado, empotrado actualmente en la fachada del Ayuntamiento de Elche. Dimensiones: $113 \times 68 \mathrm{cms}$. Campo inscrito: $48 \times 20 \mathrm{cms}$. Altura de las letras: $5 ; 4,5 ; 5 \mathrm{cms}$.

Bibliografia:

MAYANS 1771 (1982), 92-96; VALCÁRCEL 1852 (1979), n. ${ }^{\circ} 63$; CIL II 3555; OROZCO 1878, 155; IBARRA 1879 (1981), 151-154; ALFÖLDY 1969, 78; RAMOS FOLQUES 1970, 45; ILER 1025; RAMOS FERNÁNDEZ 1975, $\mathrm{n} .^{\circ}$ 9. Vid. ETIENNE 1958 (1974), 390.

[Au]gusto Divi f(ilio)

[C(aius) M]aecius C(ai) f(ilius) Celer dedit dedicavit

\section{Traducción:}

A Augustus, hijo del Divino (César). C.Maecius Celer, hijo de Caius, lo dio y dedicó.
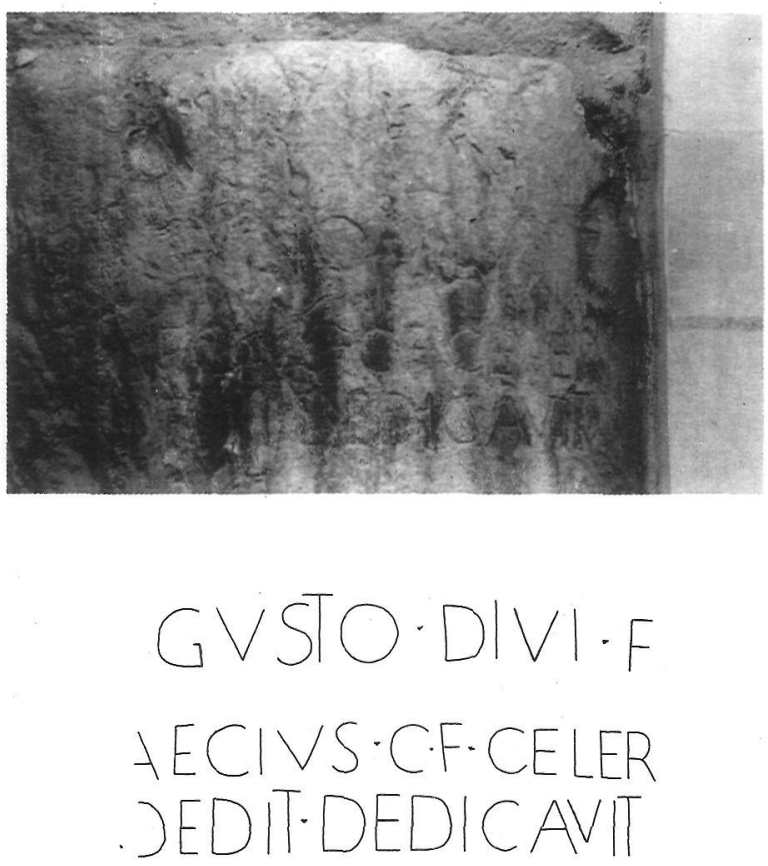

Fig. 39.-Inscripción n. ${ }^{\circ}$ 63. Calco sobre fotografía.
Alföldy $(1969,78$, nota 53) piensa que puede ser un ancestro de M.Maecius Celer, que fue jurídico de la citerior en algún momento entre los años 88-91, y que ocupó el consulado ordinario quizá en 101 (ALFÖLDY 1969, 76). El parecido onomástico le lleva a plantear la posibilidad de que M.Maecius Celer sea un hispano originario de Ilici (Ibid. 230), tal y como también sugiere Le Roux (1982b, 460).

64. - La Alcudia de Elche. Bloque en caliza muy deteriorado, encontrado en las excavaciones de La Alcudia el 4 de febrero de 1621 y empotrado actualmente en la fachada del Ayuntamiento de Elche. Dimensiones: $66 \times 90$ cms. Campo inscrito: $44 \times 29$ cms. Altura de las letras: $6,5 \mathrm{cms}$.

\section{Bibliografía:}

MAYANS 1771 (1982), 105; VALCÁRCEL 1852 (1979), n. ${ }^{\circ}$ 64; CIL II 3556; OROZCO 1878, 154; IBARRA 1879 (1981), 154-158; RAMOS FOLQUES 1970, 45; ILER 1292; RAMOS FERNÁNDEZ 1975, 275, n. ${ }^{\circ} 10$.
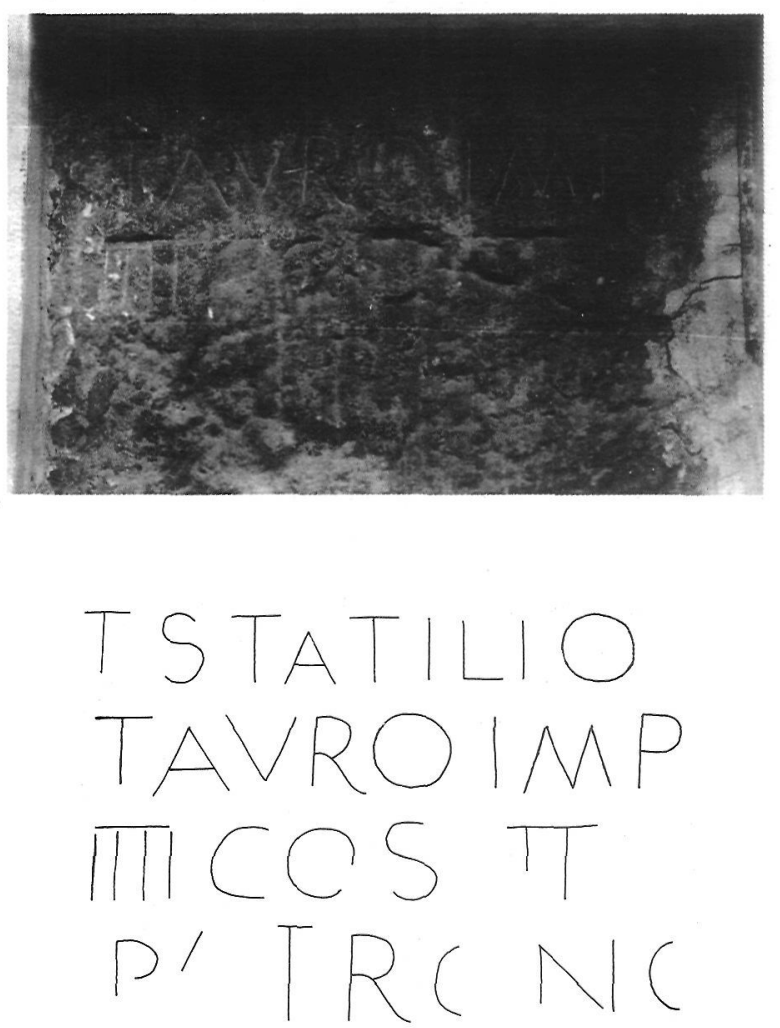

Fig. 40.-Inscripción n. ${ }^{\circ}$ 64. Calco sobre fotografía. 
T(ito) Statilio

Tauro, imp(eratore)

IIII, co(n)s(ulatu) II

$\mathrm{p}[\mathrm{a}] \operatorname{tr}[\mathrm{o}] \mathrm{n}[\mathrm{o}]$

\section{V2-3: IMP/III, Hübner.}

\section{Traducción:}

A Titus Statilius Taurus, patrono, aclamado Imperator por cuarta vez, en su segundo consulado.

Alföldy $(1969,4)$ sitúa su estancia como procónsul de la citerior entre 29/28, y su consulado el 37 a. C. Según Hübner (CIL II, p. 481) la inscripción debió redactarse entre los años 25 y 15 a. C., en que Statilius Taurus habría obtenido la praefectura urbis. Su patronazgo debió ejercerlo pues, sobre Ilici, la ciudad emplazada en La Alcudia. Sobre Statilius, vid. n. ${ }^{\circ} 47$ de Denia.

65.-La Alcudia de Elche. Placa de mármol blanco encontrada en el yacimiento y conservada en el Museo Arqueológico Municipal de Elche. Dimensiones: $14 \times 11 \times 2,5 \mathrm{cms}$. Altura de las letras: $3 \mathrm{cms}$.

\section{Bibliografía:}

RAMOS FERNÁNDEZ 1975, n. ${ }^{\circ} 2$.

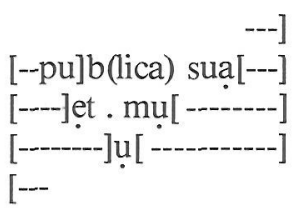

Presenta una hedera de separación en la primera línea conservada. Aunque de difícil desarrollo, cabe

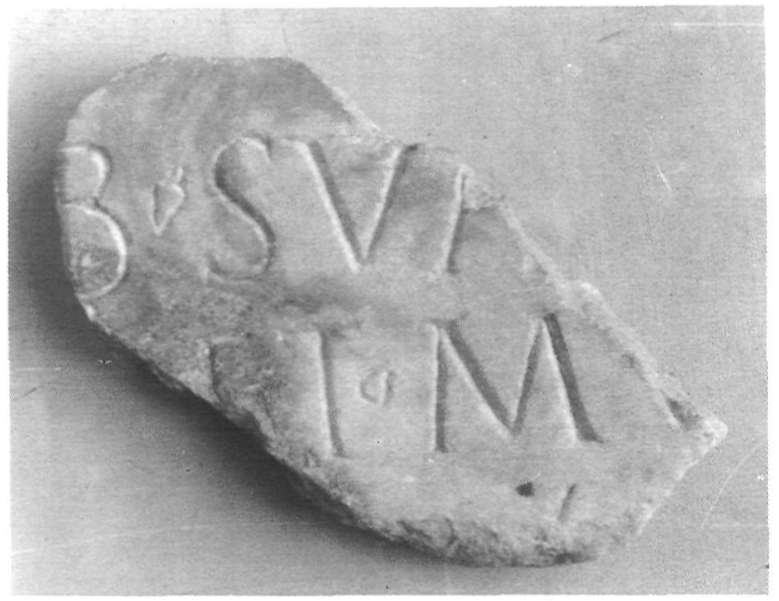

Fig. 41.-Inscripción n. ${ }^{\circ} 65$. suponer una carrera municipal en el resto de inscripción desaparecida.

66.-La Alcudia de Elche. Placa de mármol blanco fragmentada encontrada en las excavaciones del yacimiento y conservada en el Museo de las mismas. Dimensiones: $36,5 \times 16 \times 2$. Altura de las letras: 5 cms., excepto la E de ET, prolongada a 5,5 cms.

Bibliografía:

RAMOS FERNÁNDEZ 1975, n. ${ }^{\circ} 1$.

[-----]io Q(uinti) f(ilio) G (aleria tribu)

Aed(ili), IIvir(o) et Q[uaest(ori)---]

\section{Traducción:}

A......ius de la tribu Galeria, hijo de Quintus, edil, IIviro y quaestor...

La placa, aunque fracturada, parece contener sólo dos líneas, de las que desconoceríamos los extremos. El desarrollo Quaest(ori)-- precedido de et no es frecuente, siendo más usual la simple yuxtaposición, pero la placa parece contener el cursus de un solo individuo. Las letras proporcionan una cronología de fines del siglo I d. C.

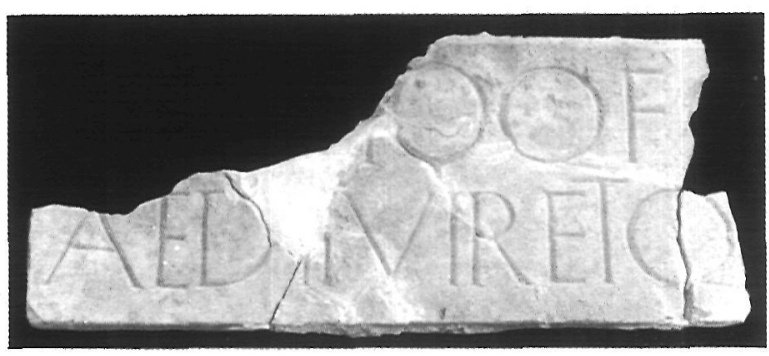

Fig. 42.-Inscripción n. ${ }^{\circ} 66$

67.-La Alcudia de Elche. Inscripción sobre mármol blanco encontrada en las excavaciones en el yacimiento en 1859, y actualmente perdida. Altura de las letras: $3 \mathrm{cms}$.

Bibliografía:

IBARRA 1879 (1981), 159-160, Lám. VIII, 6; CIL II Suppl. 5952; RAMOS FERNÁNDEZ 1975, n. ${ }^{\circ} 15$.

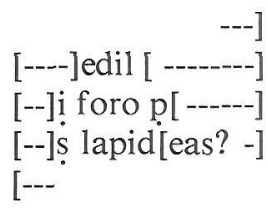


Sobre las letras dudosas difieren las versiones de Ibarra y Hübner. No es posible proporcionar una interpretación de la pieza.

68.-La Alcudia de Elche. Placa de mármol rojo perteneciente a la colección del Marqués de Lendínez y hoy desaparecida. Dimensiones: $7 \times 9$ cms.

\section{Bibliografía:}

PARÍS y HÜBNER 1896, 396; RAMOS FERNÁNDEZ 1975, n. ${ }^{\circ} 8$.

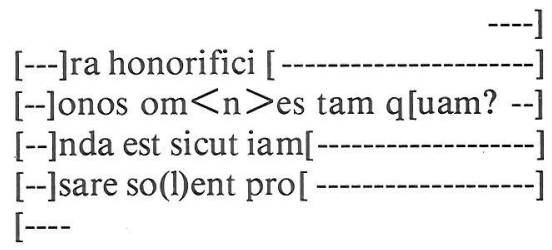

V2: OMSES.

Restitución según París y Hübner, quienes la suponen resto de una dedicación funeraria.

69.-La Alcudia de Elche. Inscripción hallada en el yacimiento y hoy desaparecida. Dimensiones: $17 \times 14,5 \mathrm{cms}$.
Bibliografia:

RAMOS FERNÁNDEZ 1975, n. ${ }^{\circ} 6$.

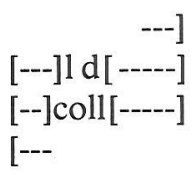

\section{V2: COLL(egio)?}

70.-La Alcudia de Elche. Inscripción sobre tres lados de un capitel hallada en el yacimiento. Conservado en el Museo Arqueológico Municipal de Elche. Dimensiones totales: $50 \times 52 \times 32 \mathrm{cms}$. Anchura de la banda inscrita: $10 \mathrm{cms}$. Altura de las letras: $6 \mathrm{cms}$.

\section{Bibliografía:}

MMAP IV, 1943, 189; RAMOS FERNÁNDEZ 1975, n. ${ }^{\circ}$ 16; SANTERO 1978,120, n. $^{\circ} 21$.

$$
\text { Colleg[------ / ------] Cen[- / --]recon! }[--]
$$

El texto puede, como supone Santero, hacer referencia a un Collegium de Centonarii (SANTERO 1978, 120), al igual que ocurre en Hispalis y Tarraco (Ibid. 119-120).
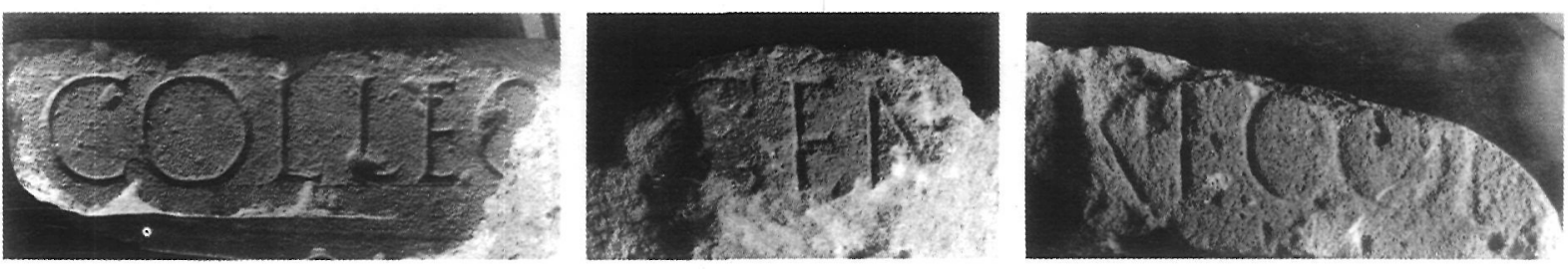

Fig. 43.-Inscripción n. ${ }^{\circ} 70$.

71.-Alcudia de Elche. Bloque de arenisca parcialmente fracturado, seguramente procedente de la Alcudia de Elche y encontrado en la obra de cimentación de una casa en la confluencia de las calles Corredera y del Conde, en Elche. Se conserva empotrada en la fachada del Ayuntamiento de esta ciudad. Dimensiones: $92 \times 42 \mathrm{cms}$. Altura de las letras: $8,5,5,5,5 \mathrm{cms}$.

\section{Bibliografía:}

CIL II Suppl. 5950; ILER 201.
Hercu[li]

Aug(usto) sac(rum)

L(ucius) Porciu[s]

[P]lutus, $\overline{\mathrm{III}}[\overline{\mathrm{III}}$ (vir)]?

5 Aug(ustalis) (de) s(ua) p(ecunia) d(edit)

\section{Traducción:}

Consagrado a Hércules Augusto. L.Porcius, Plutus, sevir Augustal, lo hizo a su costa. 


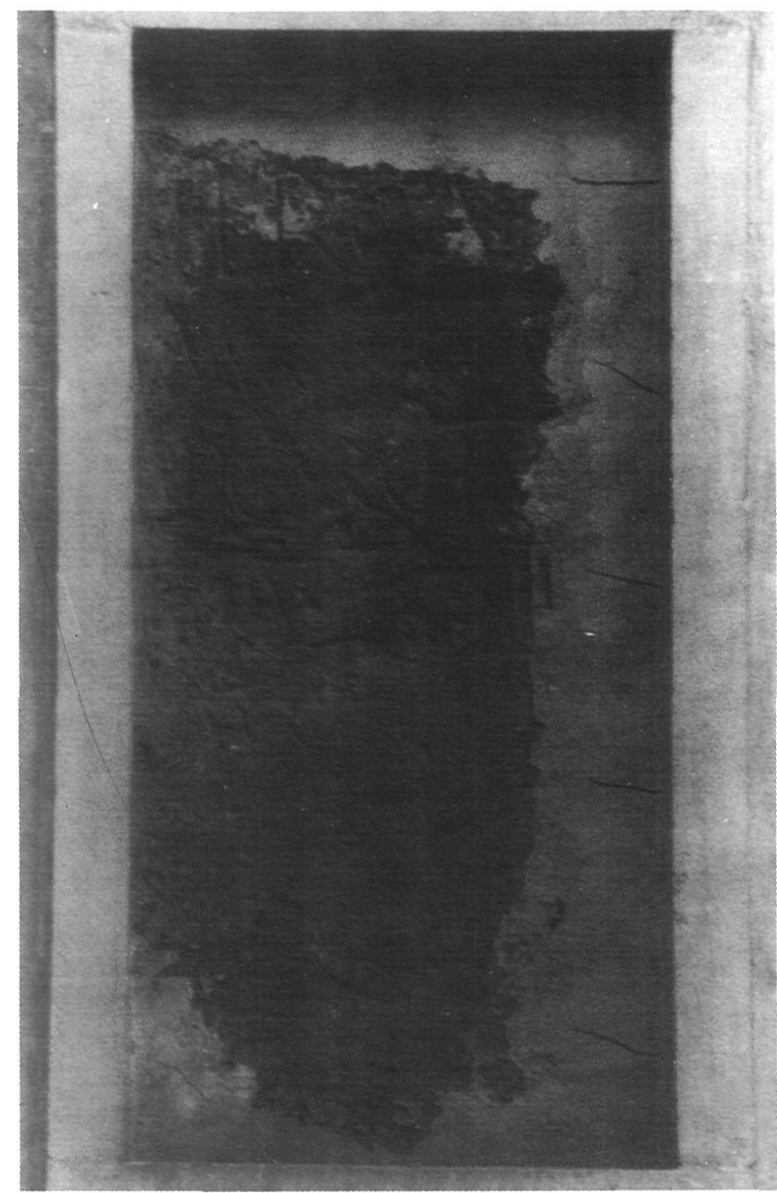

La dedicación a Hércules Augusto es testimonio del culto imperial de Ilici, avalado por la presencia del sevir mencionado en el texto. Sobre el personaje, vid. Porcius en n. ${ }^{\circ} 16$. Quizá podría relacionarse con el L.Porcius del n. ${ }^{\circ} 99$, aunque hay una clara diferencia temporal entre ambos epígrafes.

72. - La Alcudia de Elche. Pequeña ara en piedra caliza perteneciente a la colección del Marqués de Lendínez, procedente de este yacimiento y actualmente perdida. Según Fita, fue llevada a Madrid en 1913 desde Orihuela. Dimensiones: $10 \times 16 \times 8 \mathrm{cms}$.

\section{Bibliografía:}

PARÍS y HÜBNER 1896, 396; FITA 1913, 147-150, Foto; AE 1914, 20; RAMOS FERNÁNDEZ 1975, n. ${ }^{\circ}$ 7; MAULEON 1983, n. ${ }^{\circ} 1747$.

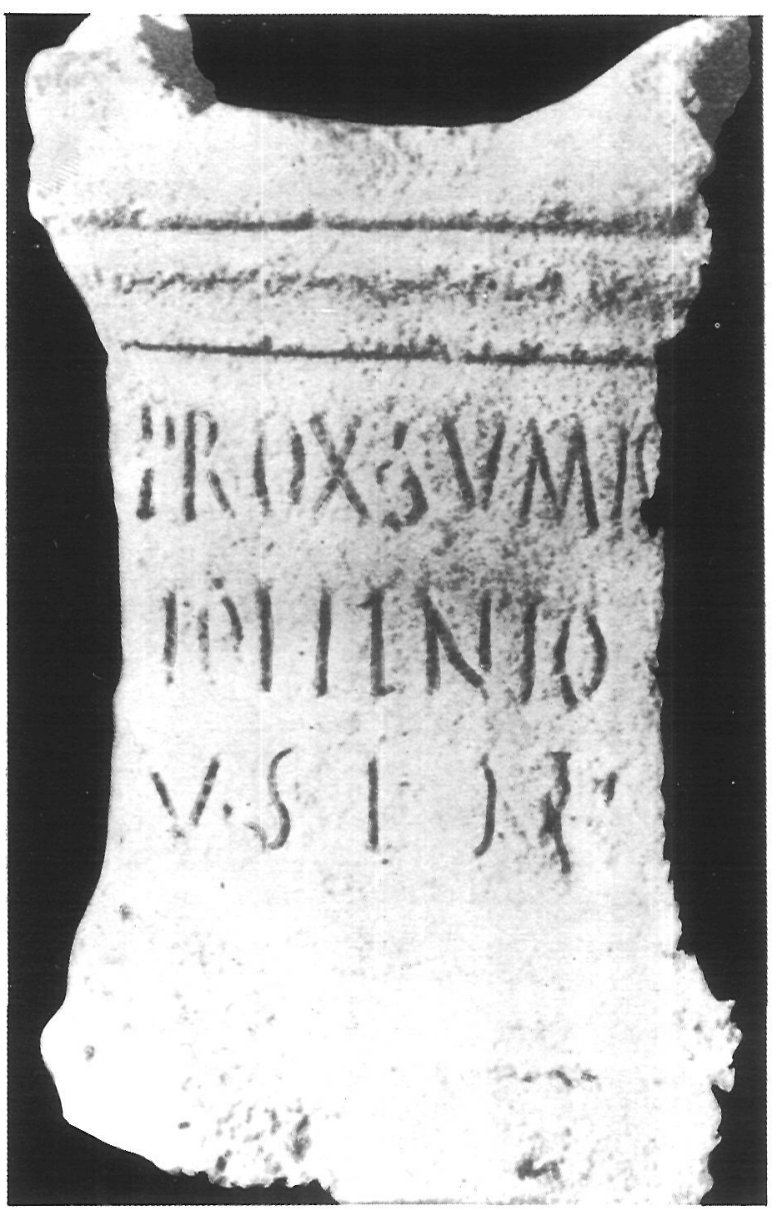

Fig. 44.-Inscripción n. ${ }^{\circ}$ 71. Calco sobre fotografía.

Fig. 45.-Inscripción n. ${ }^{\circ}$ 72. Según Fita. 
Prox $<\mathrm{i}>$ mis

Pollento

v(otum) s(olvit) l(ibens) m(erito)

\section{V1: PROXSUMIS en el texto.}

Traducción:

A los parientes. Pollento cumplió con gusto su promesa.

Esta pequeña pieza es, sin duda, un testimonio de los cultos domésticos de Ilici. La foto que presenta Fita muestra la pieza en excelente estado de conservación. Puede fecharse en el siglo II d. C. atendiendo al estilo de las letras.

73.-Elche. Tabula ansata sobre bloque rectangular con moldura lateral. Procede de Orán (Argelia), desde donde fue llevada a Santa Pola para trasladarse definitivamente a Elche, en donde permanece empotrada sobre la fachada de una casa en la calle Corredera. Está pintada toda la pieza en color oscuro en época reciente, por lo que el original está prácticamente arruinado. Dimensiones: $62 \times 33 \mathrm{cms}$. Campo inscrito: $42 \times 29 \mathrm{cms}$. Altura de las letras: $5 ; 4 ; 3,5 ; 3,5 ; 3,5 ; 3,5 \mathrm{cms}$.

Bibliografía:

MAYANS 1771 (1982), 105-106; VAL-

CÁRCEL 1852 (1979), 86-87, n. ${ }^{\circ} 299$;

CIL II Suppl. 5953; IBARRA 1879

(1981), 158; RAMOS FOLQUES 1970, 45; ILER 4516; RAMOS FERNÁNDEZ 1975, n. ${ }^{\circ} 11$.

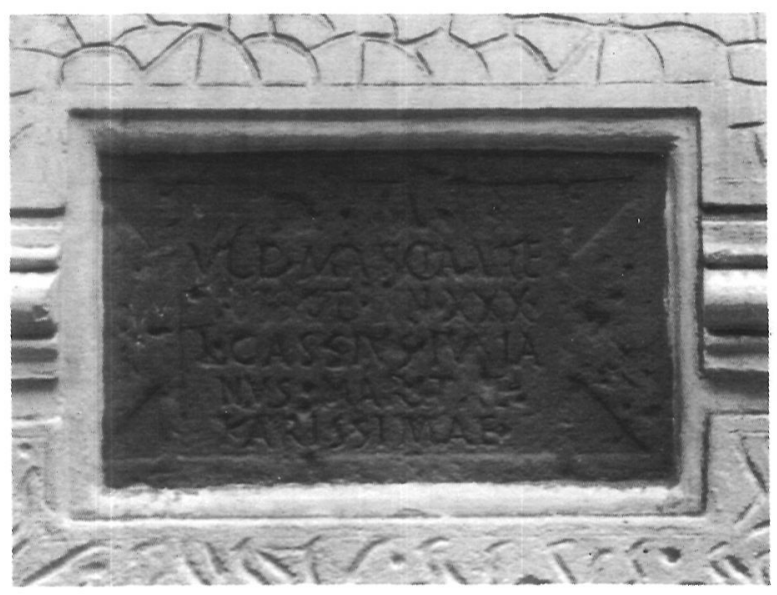

Fig. 46.-Inscripción n. ${ }^{\circ} 73$.
D(is) $\mathrm{M}$ (anibus)

Ulp(iae) Marcianae

vixit an(norum) $\mathrm{XXX}$

L(ucius) Cassius Iunia

5 nus, maritae

karissimae

\section{Traducción:}

A los Dioses Manes de Ulpia Marciana, que vivió 30 años. L. Cassius Iunianus (puso el monumento) para su queridísima esposa.

El texto puede situarse a fines del siglo II y principios del III.

74.-La Alcudia de Elche. Placa de mármol blanco fracturada, procedente de las excavaciones en este yacimiento y conservada en el Museo Monográfico de las mismas. Dimensiones: $15 \times 13 \times 2$ cms. Altura de las letras: 2,$8 ; 2,8 ; 2,8 ; 1,7 \mathrm{cms}$.

Bibliografía:

Emerita 28, 1960, 327; ILER 4347;

RAMOS FERNÁNDEZ 1975, n. ${ }^{\circ} 5$.

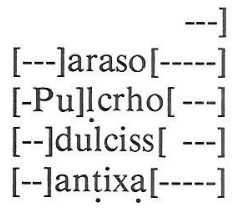

\section{Traducción:}

...antixa (puso este monumento) para ...arasus Pulcher, su (hijo?) queridísimo.

El formulario y el tipo de letras permiten fecharla a fines del siglo II y principios del III d. C.

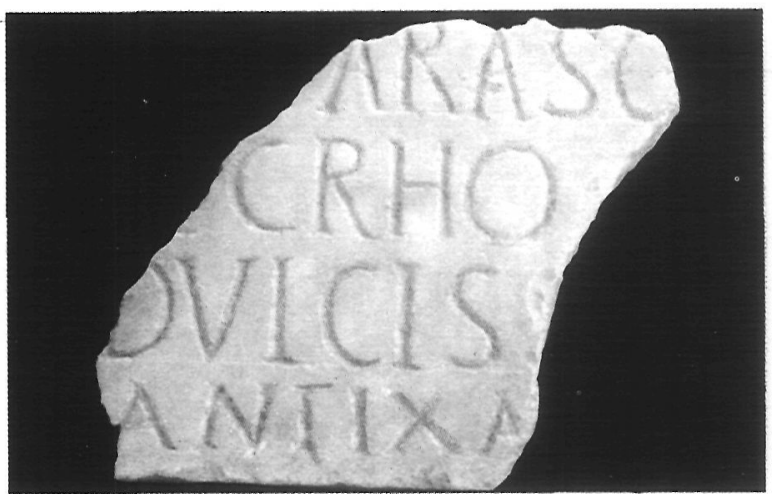

Fig. 47.-Inscripción n.$^{\circ} 74$. 
75.--La Alcudia de Elche. Placa de mármol rosado con una tabula ansata inscrita en la que figura el texto conservado. En el ansa aparece una flor. Presenta líneas de apoyo para el trazado. Procede de las excavaciones en el yacimiento y se conserva en el Museo Monográfico de las mismas. Dimensiones: $35 \times 18 \times 2 \mathrm{cms}$. Campo inscrito conservado: $17 \times 3,5 \mathrm{cms}$. Altura de las letras: $4 ; 4 ; 3 ; 2,5$ cms. Inédito.

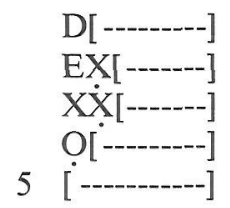

No es posible interpretar la pieza, que, sin duda alguna, es funeraria. El tipo de letra sugiere una cronología del siglo I d. C.

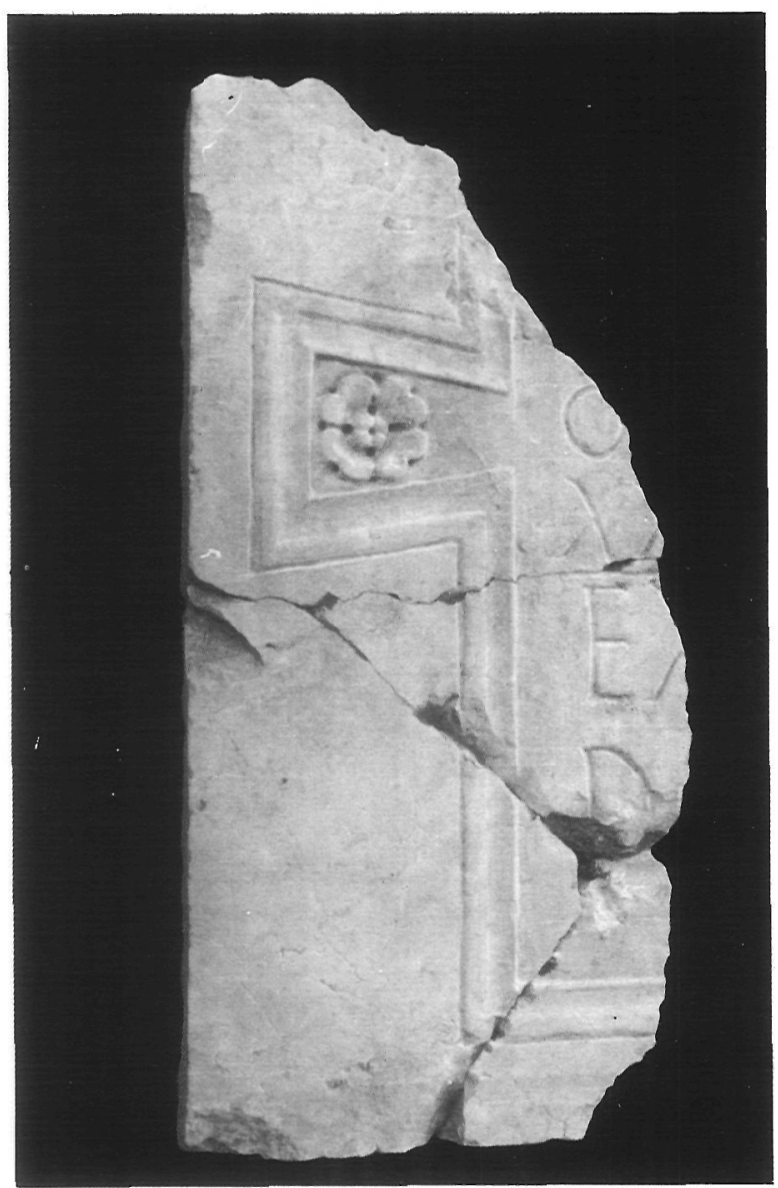

Fig. 48.-Inscripción n. ${ }^{\circ} 75$.
76. - La Alcudia de Elche. Placa de mármol blanco fragmentada, procedente de las excavaciones en el yacimiento y conservada en el Museo monográfico de las mismas. Dimensiones: $17 \times 14,5 \times 2 \mathrm{cms}$. Altura de las letras: $6 \mathrm{cms}$. Inédita.

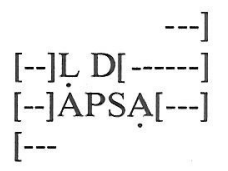

El tipo de letra es del siglo I d. C.

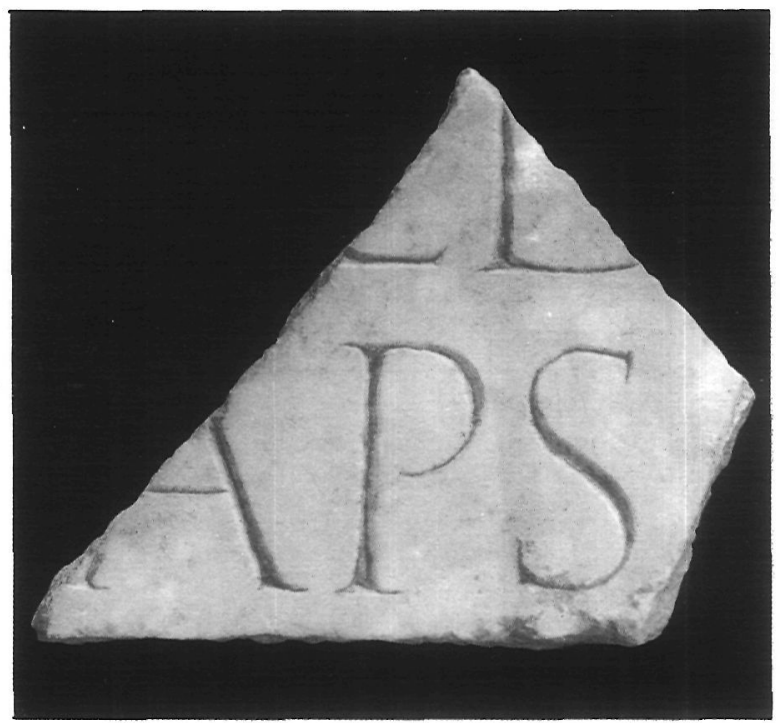

Fig. 49.-Inscripción n. ${ }^{\circ} 76$.

77. - La Alcudia de Elche. Fragmento de mármol amarillento encontrado en las excavaciones en el yacimiento y conservado en el Museo monográfico de las mismas. Dimensiones: $17 \times 14 \times 2,5$ cms. Altura de las letras: $3,5 \mathrm{cms}$.

Bibliografía:

RAMOS FERNÁNDEZ 1975, n.ํ 3.

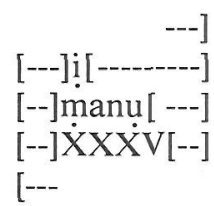

No es posible fijar el texto ni șu cronología. 


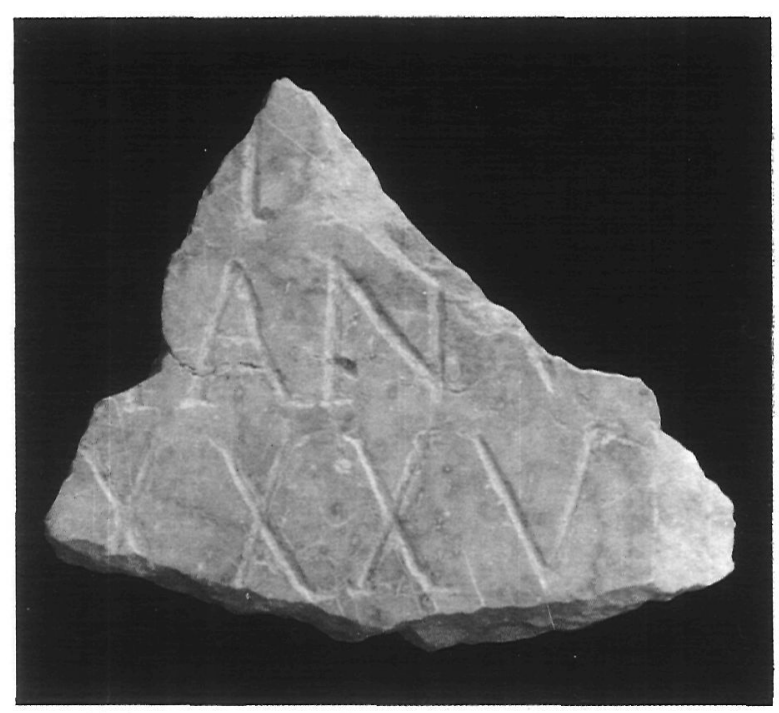

Fig. 50.-Inscripción n. ${ }^{\circ} 77$.

78. - La Alcudia de Elche. Columna de arenisca muy deteriorada, procedente de las excavaciones del yacimiento y conservada en el Museo monográfico de las mismas. Altura conservada: 66 cms. Diámetro: $34 \mathrm{cms}$. Altura de las letras: (-), 7 , $5 \mathrm{cms}$. Inédita.

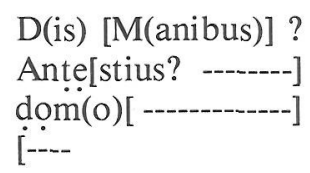

No es posible interpretar la pieza debido a su estado de deterioro.

79. - Elche. Bloque en piedra caliza encontrado en "La Moleta», en los alrededores de la ciudad, según Ibarra. Dimensiones: $128 \times 33 \times 50 \mathrm{cms}$. Campo inscrito: $108 \mathrm{cms}$. de longitud. Altura de las letras: $6 \mathrm{cms}$. Desaparecido.

Bibliografía:

IBARRA 1926, 25-26; RAMOS FERNÁNDEZ 1975, n. ${ }^{\circ} 22$.

Cn(eus) Aufidius, Cn(eus) Flacianus ?

No es posible interpretar el texto ni fijar su cronología.
80.-La Alcudia de Elche. Placa de mármol blanco veteado en verde, encontrada en la Hacienda de Porter, en La Alcudia, según Ramos Fernández. Desaparecida. Dimensiones: $20 \times 24,5 \mathrm{cms}$. Altura de las letras: $4,5 \mathrm{cms}$.

Bibliografía:

IBARRA 1889, I, n. ${ }^{\circ}$ 178; FITA 1907 , 323; RAMOS FERNÁNDEZ 1975, n. ${ }^{\circ}$ 19; MAULEON 1983, n. ${ }^{\circ} 1748$.

$$
\begin{aligned}
& \text { D(is) [M(anibus) -----] } \\
& \text { M(arco) Publ(icio)[---] } \\
& \text { et M(arco) Publ(icio)[--] } \\
& \text { [--- }
\end{aligned}
$$

\section{Traducción:}

A los Dioses Manes...; a Marcus Publicius y a Marcus Publicius...?

Según Ibarra, en carta dirigida a Fita, apareció cubriendo una sepultura con huesos y dos monedas, una de ellas un bronce de Filipo (FITA 1907, 323). El texto es, evidentemente, de tipo funerario, y por su estructura parece corresponder a fines del siglo II y principios del III, sin que el hallazgo numismático deba ir necesariamente asociado a la inscripción.

81.-Elche. Parte superior de una lápida encontrada en 1888 en Elche, en la «hacienda de D. Félix», según Hübner, quien recoge datos de Ibarra. Dimensiones: $28 \times 25 \mathrm{cms}$. Desaparecida.

Bibliografia:

CIL II Suppl. 5951; ILER 3291.

$\mathrm{D}$ (is) $\mathrm{M}$ (anibus)

Variae

Nigrinae

[---

\section{Traducción:}

A los Dioses Manes de Varia Nigrina...

No es posible fijar la cronología del texto, que no debe ser anterior a mediados del siglo II.

82.-Elche. Inscripción encontrada en «La Albufereta» de Elche, según Hübner. Desaparecida.

Bibliografía:

CIL II 3559; ILER 3450. 
Lucretia Maura

hic sepulta est

ann[-----------]

$[--$

\section{Traducción:}

Aquí yace Lucretia Maura, de .... años...

El texto parece corresponder al siglo III d. C.

83.- La Alcudia de Elche. Inscripción encontrada en la hacienda de «El Alcaldet» (Els Partiorets), en el mismo lugar que los dos fragmentos de la tabla de bronce (n. ${ }^{\circ} 62$ ). Desaparecida.

Bibliografía:

RAMOS FOLQUES 1970, 54-55; RA-

MOS FERNÁNDEZ 1975, n. ${ }^{\circ} 24$.

In his praedi

$s$ vivas cum

tuis omn(i)b(us)

multis an

$5 \mathrm{ni}(\mathrm{s})$

\section{Traducción:}

Reside en estas tierras con todos los tuyos por muchos años.

84.-La Alcudia de Elche. Inscripción sobre mármol blanco encontrada en las excavaciones en el yacimiento. Desaparecida. Dimensiones: $12 \times 10$ cms.

\section{Bibliografía:}

RAMOS FERNÁNDEZ 1975, n. ${ }^{\circ} 4$.

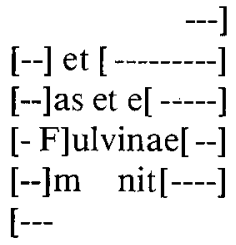

Se trata probablemente de una inscripción de tipo funerario para varios personajes, quizá esclavos o libertos, por el carácter acumulativo que tiene el texto.

85.-Elche. Inscripción encontrada en lugar y circunstancias no precisables. Desaparecida. Dice Hübner: «teníala $\mathrm{B}^{\mathrm{a}}$ Pagán».
Bibliografía:

CIL II 3560; ILER 6611.

Q(uintus) Voconi[us ----]

[---

86.-La Alcudia de Elche. Inscripción encontrada en el yacimiento y hoy perdida.

Bibliografía:

FITA 1907, 323.

vi[xit an]nis

TONNEI DEI GILINI

Según Fita, bajo la figura de un pastor y una oveja figuraba la indicación de edad, y alrededor de la escena las palabras escritas en letra mayúscula en la transcripción. No es posible interpretar este texto.

87.-La Alcudia de Elche. Inscripción encontrada en el yacimiento y hoy perdida. Dimensiones: 27 cms. (Ramos).

Bibliografía:

RAMOS FERNÁNDEZ 1975, n. ${ }^{\circ} 17$.

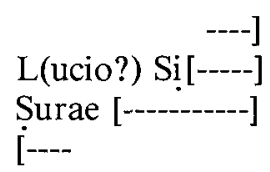

Parece tratarse de una inscripción funeraria.

88.-La Alcudia de Elche. Inscripción sobre mármol blanco, encontrada en el yacimiento y hoy perdida.

Bibliografía:

IBARRA 1879 (1981), 159; CIL II Suppl. 5956b; RAMOS FERNÁNDEZ $1975,{ }^{\circ}{ }^{\circ} 13$.

-- XBV --

89. - La Alcudia de Elche. Encontrada en el yacimiento y hoy perdida.

Bibliografía:

IBARRA 1879 (1981), 159; CIL II Suppl. 5956a; RAMOS FERNÁNDEZ 1975, n. ${ }^{\circ} 14$. 


\section{-- IXSX --}

90.-La Alcudia de Elche. Placa de mármol blanco fracturada encontrada en las excavaciones en el yacimiento y conservada en el Museo Arqueológico Municipal de Elche. Dimensiones: $11 \times 6 \times 1,5 \mathrm{cms}$. Altura de las letras: $2,5 \mathrm{cms}$. Presenta una interpunción triangular.

Bibliografía:

RAMOS FERNÁNDEZ 1975, n. ${ }^{\circ} 18$.

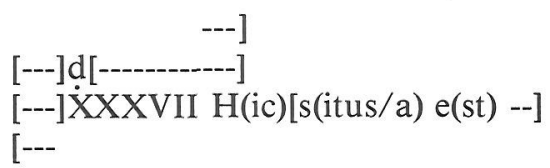

\section{Traducción:}

de 37 años de edad, aquí yace....

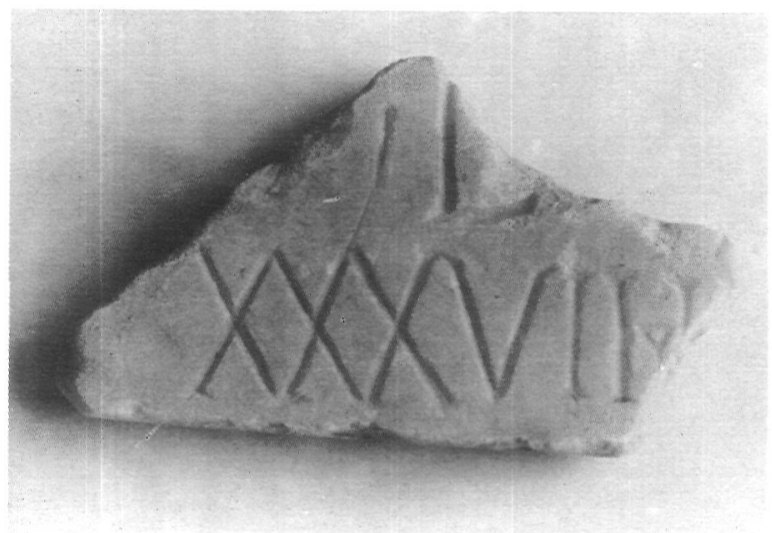

Fig. 51.-Inscripción n. ${ }^{\circ} 90$.

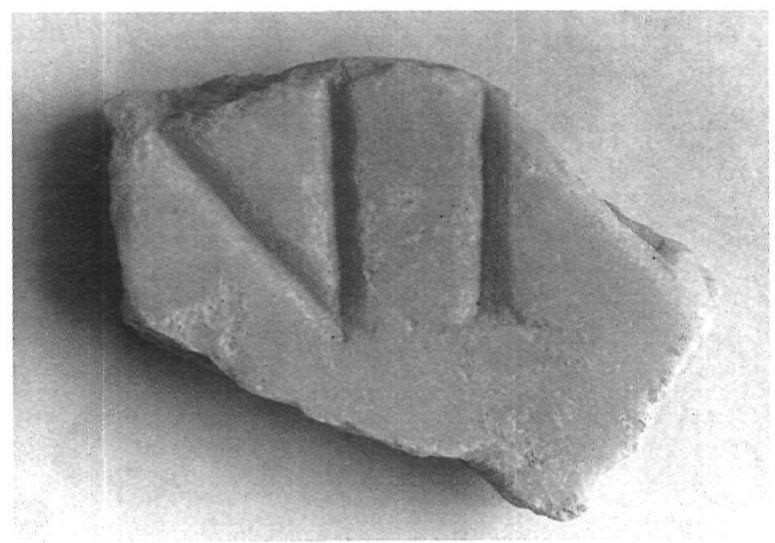

Fig. 52.--Inscripción n. ${ }^{\circ} 91$.
91.-La Alcudia de Elche. Inscripción encontrada en el yacimiento y conservada en el Museo Arqueológico Municipal de Elche (Ref. 263). Dimensiones: $6 \times 10 \times 1,5 \mathrm{cms}$. Fragmento en mármol blanco. Inédita.

$$
\text { -- N.I -- }
$$

92.-La Alcudia de Elche. Inscripción sobre fragmento de placa de mármol blanco procedente del yacimiento y conservada en el Museo Arqueológico Municipal de Elche. Dimensiones: $6 \times 8 \times 2,5 \mathrm{cms}$. Altura de las letras: $6 \mathrm{cms}$. Inédita.
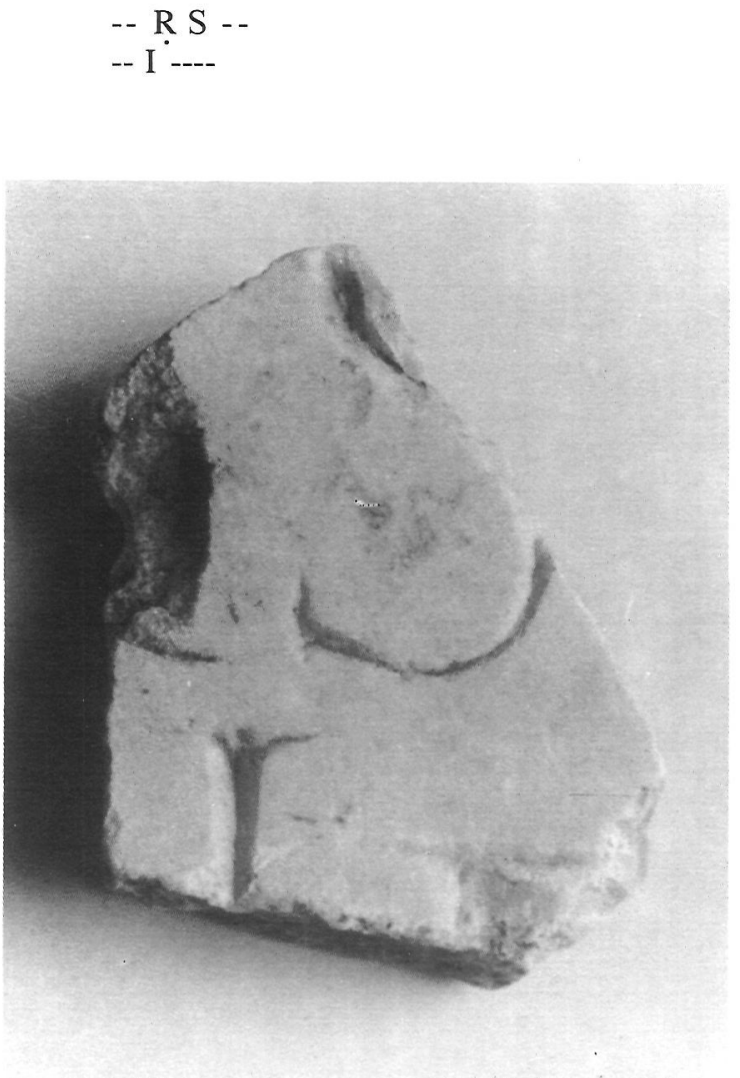

Fig. 53.-Inscripción n. ${ }^{\circ} 92$.

93.-La Alcudia de Elche. Inscripción sobre un fragmento de placa en mármol naranja, procedente de las excavaciones en el yacimiento y conservado en el Museo Arqueológico Municipal de Elche. Dimensiones: $7,5 \times 3,5 \times 1,5 \mathrm{cms}$. Altura aproximada de las letras: $6 \mathrm{cms}$. Se trata de la última línea de la placa. Inédita. 


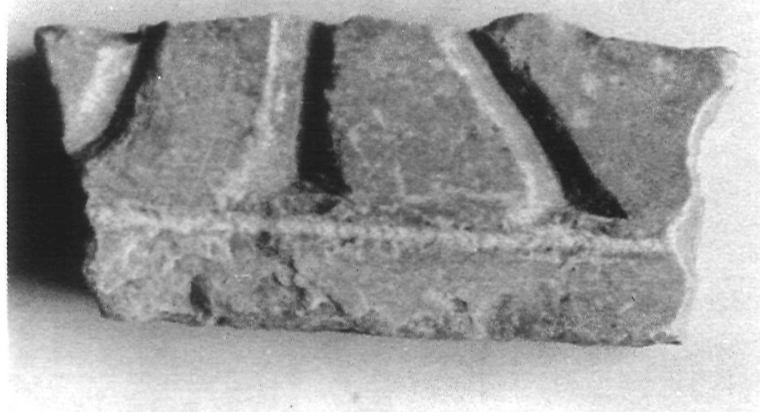

Fig. 54.-Inscripción n. ${ }^{\circ} 93$.

$$
\text { [--- ann]or[um ---] }
$$

Las letras parecen del siglo I d. C.

94.-La Alcudia de Elche. Inscripción sobre fragmento de una placa de mármol blanco procedente de las excavaciones en el yacimiento y conservada en el Museo Arqueológico Municipal de Elche. Dimensiones: $7 \times 5,5 \times 1,5 \mathrm{cms}$. Altura de las letras: $3 \mathrm{cms}$. Inédita.

$$
\text { --- N N --- }
$$

95.-La Alcudia de Elche. Inscripción, hoy desaparecida, supuestamente procedente de este yacimiento, y que Hübner remite a Alicante.

Bibliografía:

IBARRA 1879 (1981), 159; CIL II Suppl. 5954; ILER 2137.

\section{VENIL AVGVSTVS}

Hübner piensa, con mucha razón, que la inscripción no fue correctamente descrita por Ibarra, extremo que no pudo confirmar, pues el epígrafe había desaparecido.

96.-La Alcudia de Elche. Inscripción sobre mosaico encontrado en las excavaciones del yacimiento y conservado en el Museo monográfico de las mismas. A pesar de la aparente grafía latina, se trata de un texto ibérico cuyo significado se nos escapa.

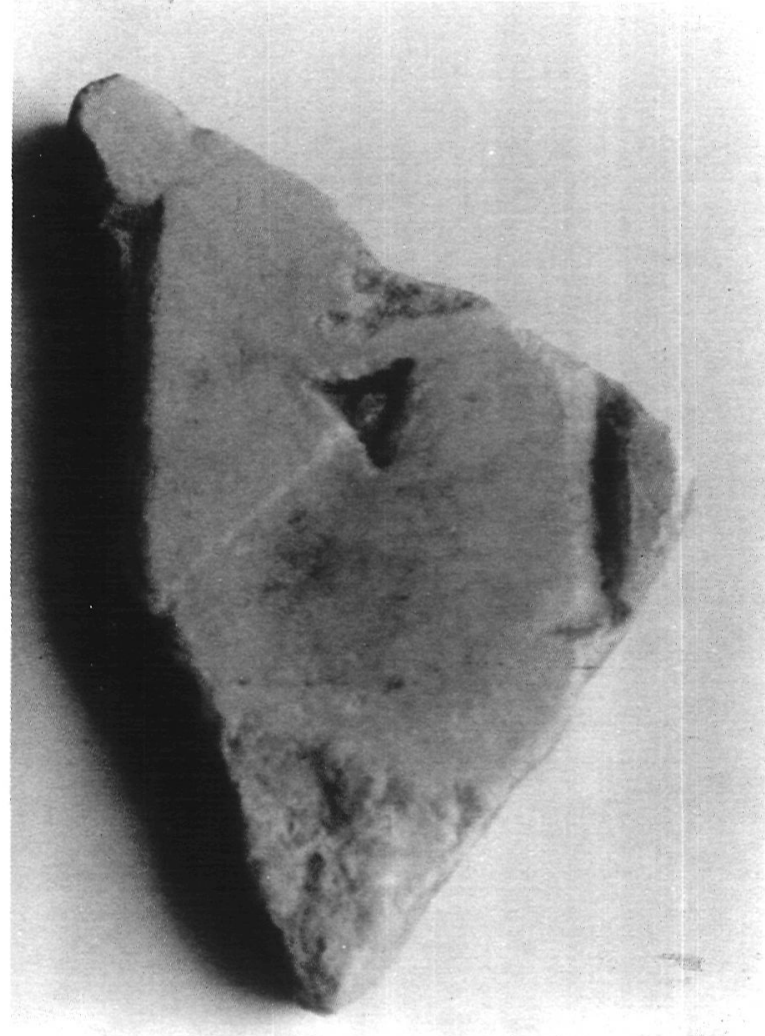

Fig. 55.-Inscripción n. ${ }^{\circ} 94$.

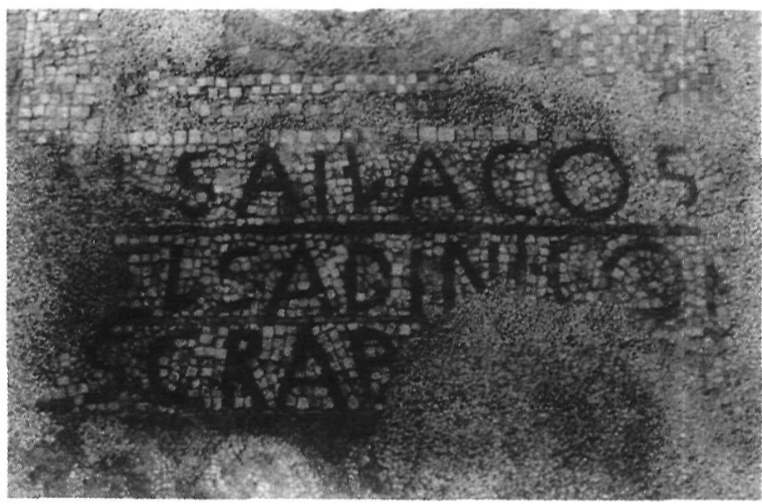

Fig. 56.-Inscripción n. ${ }^{\circ} 96$.

\section{Bibliografía:}

RAMOS FOLQUES 1975, 69-81; RA-

MOS FERNÁNDEZ 1975, n. ${ }^{\circ} 25$. 


A
C
O
S
$[---]$ L.SAILACOS [----]
$[---]$ ELSADINI.COR[--]
$[---]$ SCRAD[-------]

97.-La Alcudia de Elche. Inscripción sobre mosaico encontrado en agosto de 1861 en la partida de «Algorós», cerca de La Alcudia. Conservada en el Museo Arqueológico Municipal de Elche. Campo inscrito: $71 \times 25 \mathrm{cms}$.

Bibliografía:

CIL II 3554; IBARRA 1879 (1981), 179-184; RAMOS FOLQUES 1970, 55; ILER 2110.

\section{GALATEA}

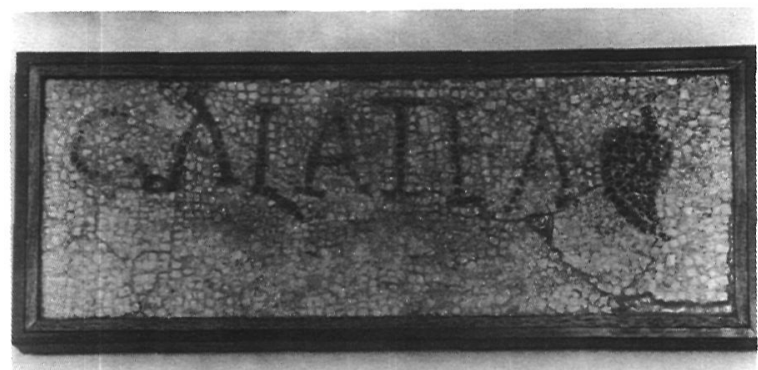

Fig. 57.-Inscripción n. ${ }^{\circ} 97$.

98. - Santa Pola. Inscripción sobre placa de mármol grisáceo encontrada en el paraje de «La Senia», en la finca de Antonio Múrtula, en el camino de Elche al castillo de Santa Pola (Fita). Conservada en el Museo Arqueológico Municipal de Elche. Dimensiones: $24 \times 30 \times 7 \mathrm{cms}$. Altura de las letras: 4,$5 ; 2,2 ; 2,6 ; 2,6 ; 1,6 ; 1,6 \mathrm{cms}$.

\section{Bibliografía:}

COGNAT, M. Bull. des Antiq. de France 5, 1892, 195, citado por Fita; EE VIII, $196 \mathrm{a}=\mathrm{EE}$ IX 354; FITA 1901，95-96; MANGAS 1971，391; RAMOS FERNÁNDEZ 1975, n. ${ }^{\circ} 20$; MAULEON 1983, n. ${ }^{\circ} 1750$.

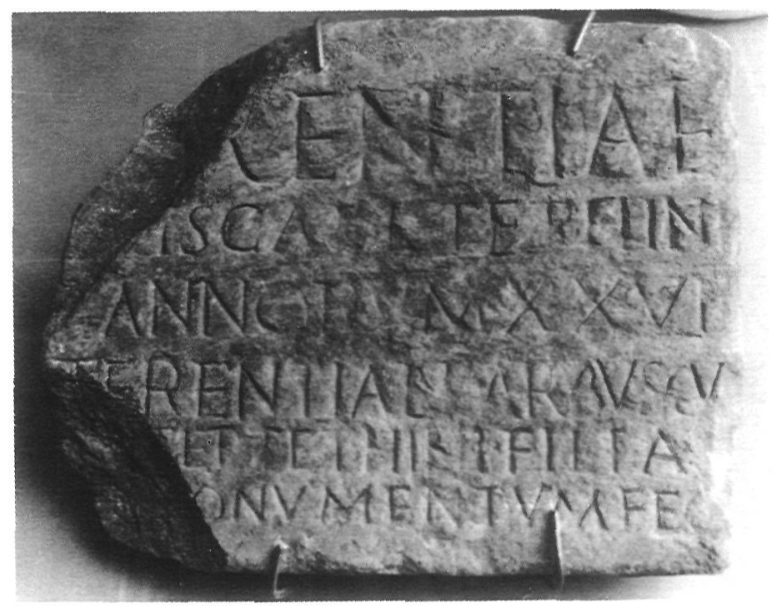

Fig. 58.-Inscripción n.$^{\circ} 98$.

[Te]rentiae

[--]iscae 1(ibertae) Tethini annorum XXVII

Terentia L(uci) l(iberta) Arbuscu(la)

5 [ma]ter Tethini filiae [m]onumentum fec(it)

\section{Traducción:}

A Terentia Tethine, liberta de ...isca, de 27 años de edad. Terentia Arbuscula, su madre, liberta de Lucius, hizo el monumento para su hija Tethine.

Sobre Terentius/a, vid. n. ${ }^{\circ} 31,32$ y 55. La inscripción se fecha en el siglo II.

99.- Santa Pola. Encontrada en el mismo lugar que la n. ${ }^{\circ} 98$. Sillar de piedra común, hoy perdido. Según Ibarra, sus dimensiones eran 3 palmos de longitud y $40 \mathrm{cms}$. de anchura.

\section{Bibliografía:}

IBARRA 1899, n. ${ }^{\circ}$ 178; RAMOS FERNÁNDEZ 1975, n. ${ }^{\circ} 21$.

$$
\begin{aligned}
& \mathrm{D}(\mathrm{is}) \mathrm{s} \text { (acrum) M(anibus) (sic) } \\
& \mathrm{L} \text { (ucio) Por[ci] } \\
& \text { o[--]icn[--------] } \\
& \text { ri[-------------] } \\
& \text { [--- }
\end{aligned}
$$

\section{Traducción:}

Consagrado a los Dioses Manes; a Lucius Porcius...

Sobre el personaje, vid. n. ${ }^{\circ} 71$. 
100. - Santa Pola. Encontrada en el mismo paraje que las n. ${ }^{\circ} 98$ y 99 . Desaparecida. Dimensiones: $32 \times 38 \mathrm{cms}$. Altura de las letras: $5 \mathrm{cms}$.

Bibliografía:

FITA 1901, 96-97; EE IX 352; MAU-

LEON 1983, n. ${ }^{\circ} 1749$.

Dis M(anibus) s(acrum) (sic)

L(ucio) Corneli

o, L(uci) f(ilio) Qui

rinali, ann[o]

5 ru $[\mathrm{m}$

$[--$

\section{Traducción:}

A los Dioses Manes. A Lucius Cornelius Quirinalis, hijo de Lucius, de ... años...

El texto presenta interpunciones en forma de hederae. Puede fecharse entre los siglos II y III.

101.- Santa Pola. Encontrada en el mismo paraje que los n. ${ }^{\circ} 98,99$ y 100 . Desaparecida.

Bibliografía:

IBARRA 1879 (1981), 270-271; CIL II

Suppl. 5957.

-- IVMINVS --

102.-Monforte del Cid. Estela en piedra caliza con cabecera semicircular y decorada con dos rosetas. Presenta incisiones horizontales de trazado. Encontrada en las cercanías de Monforte, posteriormente desaparecida, y conservada hoy en el Ayuntamiento de esta localidad. Dimensiones: $82 \times 49 \times 13 \mathrm{cms}$. Campo inscrito: $45 \times 28 \mathrm{cms}$. Altura de las letras: $5 \mathrm{cms}$.

Bibliografía:

CEAN BERMÚDEZ 1832, 92-93; VALCÁRCEL 1852 (1979), n. ${ }^{\circ} 101$; CIL II 3569 y Suppl. 6338; CHABÁS 1891, 88; ILER 2602; MAULEON $1983, \mathrm{n}^{\circ} 1752$.

Furia

Tyce

ann(orum) XXVIII

h(ic) s(ita) e(st)

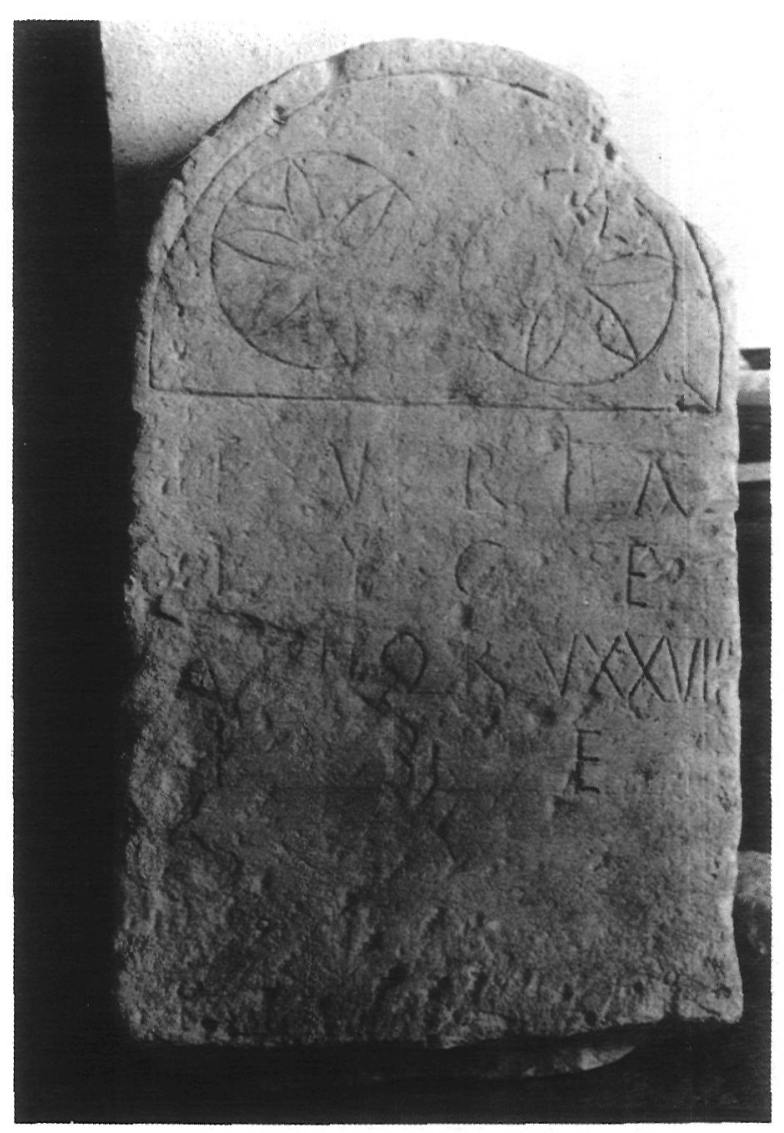

Fig. 59.-Inscripción n. ${ }^{\circ} 102$.

\section{Traducción:}

Aquí yace Furia Tyce, de 28 años de edad.

La estela presenta un carácter marcadamente distinto al del resto de los monumentos de la región por el tipo de cabecera y motivos decorativos. El nombre recuerda asociaciones onomásticas parecidas, construidas con este cognomen de origen griego cuya grafía es muy variable en las inscripciones. Vid. Turpa Thyce (CIL II 1740. Cádiz) y Fulvia Tyche (IRCádiz 449). La inscripción puede fecharse en el siglo I.

103.- Relleu. Bloque en piedra caliza que apareció empotrado en una de las casas de la localidad. Conserva una moldura en su parte superior y se encuentra fracturado por abajo y por la derecha. Dimensiones: $32 \times 32 \times 23 \mathrm{cms}$. Campo inscrito: $28 \times 22 \mathrm{cms}$. Altura de las letras: $5,5,5,4 \mathrm{cms}$. Conservado en casa de D. Hernán Cortés, en Relleu. 


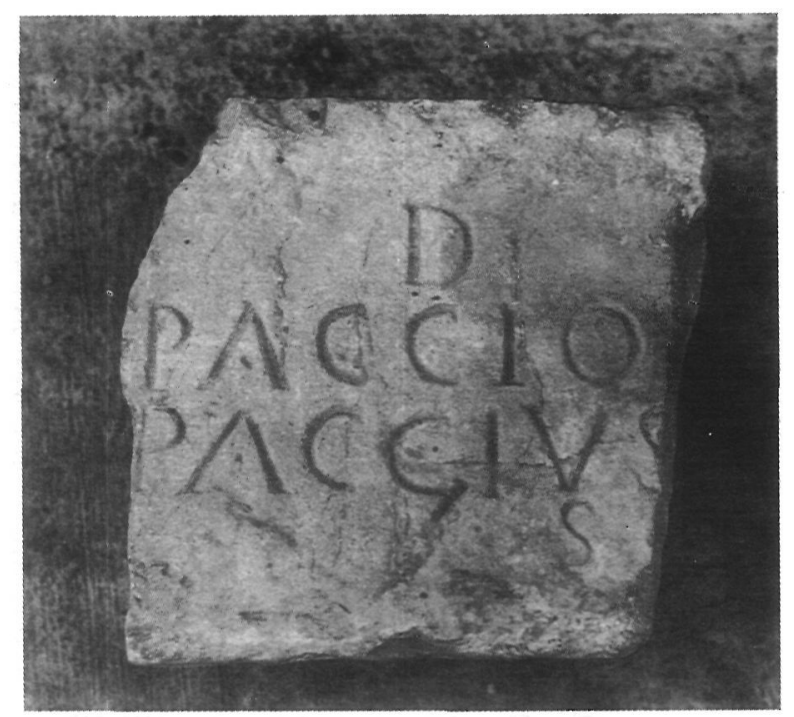

Fig. 60.-Inscripción n. 103.

\section{Bibliografía:}

SENDRA et alii 1980, 58.

$$
\begin{aligned}
& \mathrm{D} \text { (is) } \mathrm{M} \text { (anibus) } \\
& \text { Paccio[---------] } \\
& \text { Paccius[-------] } \\
& \text { s(it) [t(ibi) t(erra) l(evis)] }
\end{aligned}
$$

\section{Traducción:}

A los Dioses Manes, A Paccius.

Paccius.... (puso este monumento).

(Aquí yace), que la tierra te sea leve.

La $M$. de la primera línea se encuentra hoy perdida, pero en la publicación original se ve aún la parte izquierda de la misma. El tipo del monumento y la estructura del texto lo sitúan en el siglo II, a pesar del aspecto arcaizante de la grafía $A$ - Paccius no es frecuente en la región.

104.-Altea. Ara sepulcral de mármol azulado oscuro encontrado en las proximidades de la localidad. Desaparecida. Antigüamente estuvo en la Iglesia parroquial. Dimensiones: $71 \times 46 \times 33 \mathrm{cms}$. Bibliografía:

CEAN BERMÚDEZ 1832, n. ${ }^{\circ}$ 49; VALCÁRCEL 1852 (1979), n. ${ }^{\circ}$ 33; CIL II 3578; FITA 1908a, 375 = 1908b, 455 (Foto); LABORDE 1975, 122; MAULEON 1983, n. ${ }^{\circ} 1753$.

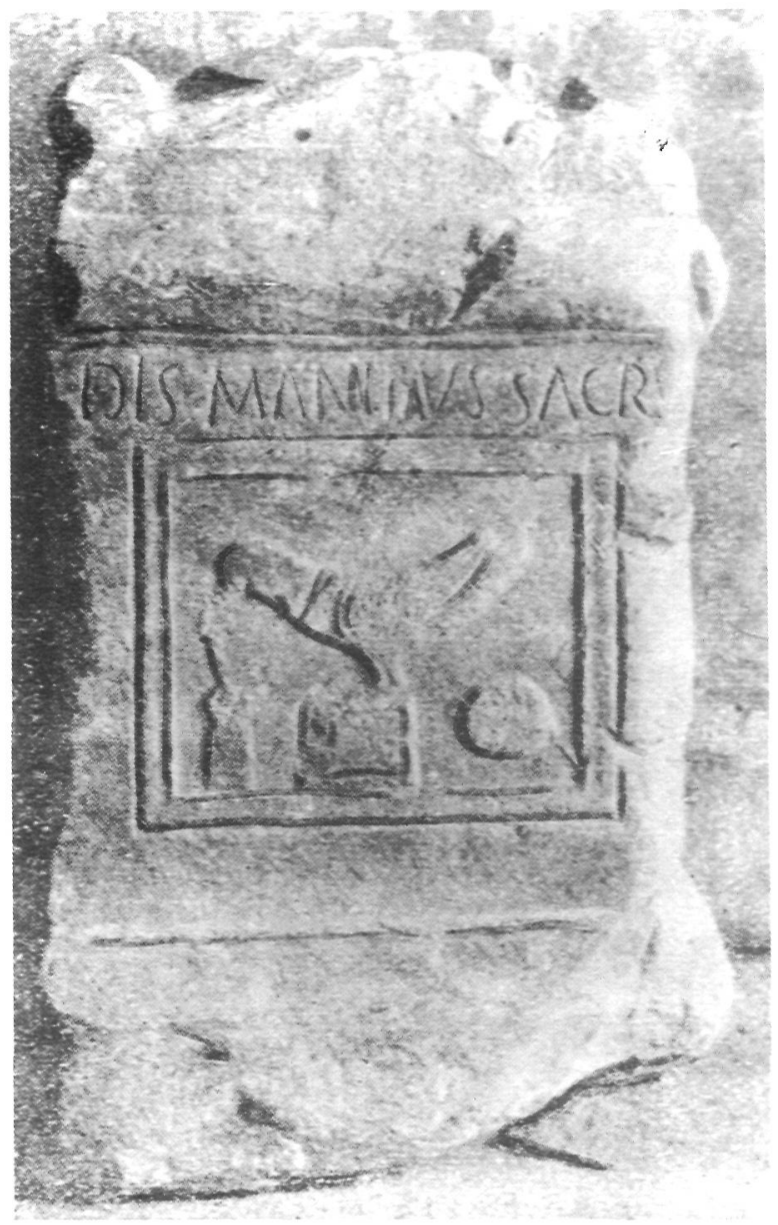

Fig. 61.-Inscripción n. ${ }^{\circ}$ 104. Según Fita.

Dis Manibus sacru[m] [---]nua [mate?]r p(osuit)

\section{Traducción:}

A los Dioses Manes. (Aquí yace) ...nua. Su madre? puso este monumento.

La fórmula sepulcral figura bajo el coronamiento del ara, y en la superficie frontal aparece una paloma mirando a izquierda apoyada sobre un pedestal en el que aparece la fórmula funeraria. A la derecha del texto aparece una flor de adormidera y a la izquierda un brocal de pozo del que surge una serpiente. El monumento fue publicado en detalle por Fita sobre fotos enviadas por D. Francisco Martínez Martínez el 30 de marzo de 1908, una 
de las cuales figura en un artículo posterior (FITA $1908 b, 455)$, por lo que no vemos razón para adscribirla a Villar del Arzobispo. El monumento debe fecharse a comienzos del siglo III d. C.

105.-Pego. Inscripción sobre soporte de mármol colorado rosáceo fracturado por su parte izquierda y por abajo; encontrada en la heredad de Sala, antes denominada de Camacho, en Pego, según Fita. Desaparecida. Dimensiones: $22 \times 50$ cms.

\section{Bibliografía:}

FITA 1908c, 508-509; MAULEON 1983, n. $^{\circ} 1775$.

C(aio) Licinio Mar[-------] an(norum) XXXVII, h(ic) [s(itus) e(st)] Licinius Maximu[s --------] [pa]tri piissimo[----------] $[-----$

\section{V3: Ligadura MA.}

\section{Traducción:}

Aquí yace C.Licinius Mar(...), de 37 años de edad. Licinius Maximus (dedicó este monumento) a su piadosísimo padre?

El texto presenta interpunciones puntuales. Fita (1908c, 509) piensa que el difunto es C.Licinius Marinus (CIL II 3866) de Sagunto y amigo de Plinio el Joven. Un P.Licinius Maximus aparece en Alhambra (Ciudad Real. CIL II 3230). El texto puede fecharse en la segunda mitad del siglo II. Sobre Marinus, vid. n. ${ }^{\circ} 49$.

106. -Elda. Fragmento de una placa de piedra caliza blanca procedente de las excavaciones en la villa romana de «Arco Sempere», en el casco urbano de esta localidad. Dimensiones: $8,5 \times 15 \times 2,5$. Altura de las letras: 4,6 cms.

Bibliografía:

POVEDA 1984, 47-49.

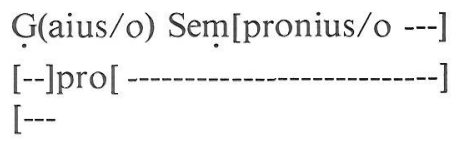

Se trata probablemente de una placa funeraria. El tipo de letra remite al siglo II d. C. Merece destacarse el desarrollo de la $G$ inicial.

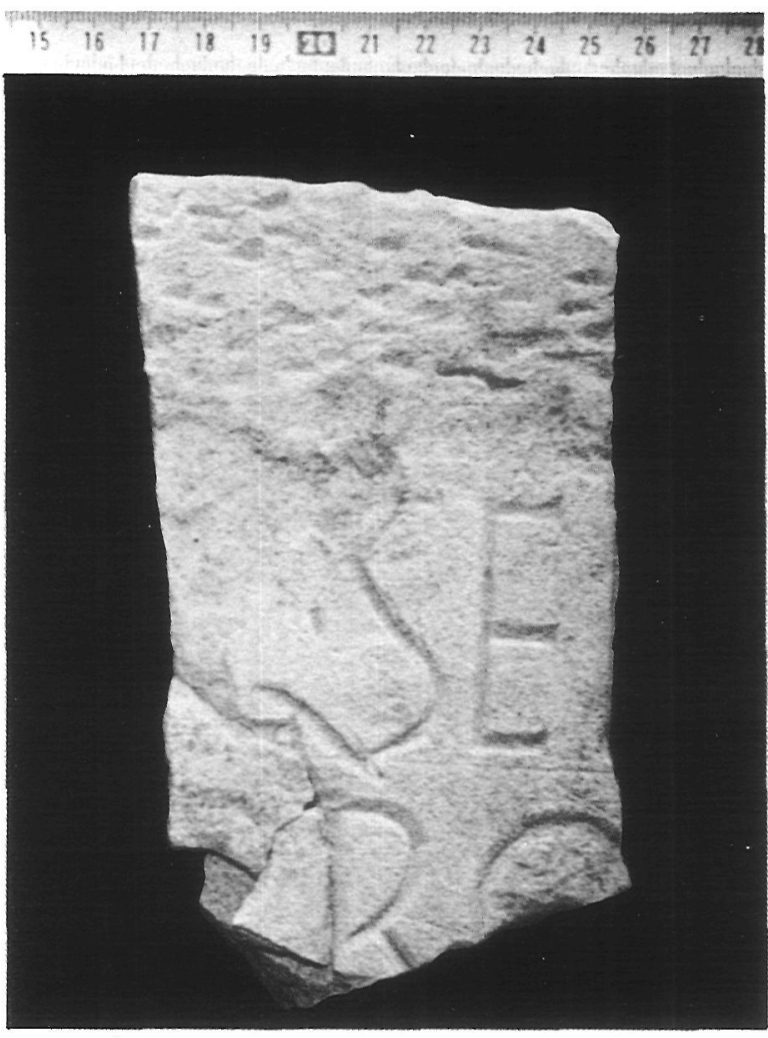

Fig. 62.-Inscripción n. ${ }^{\circ}$ 106. Foto A. Poveda.

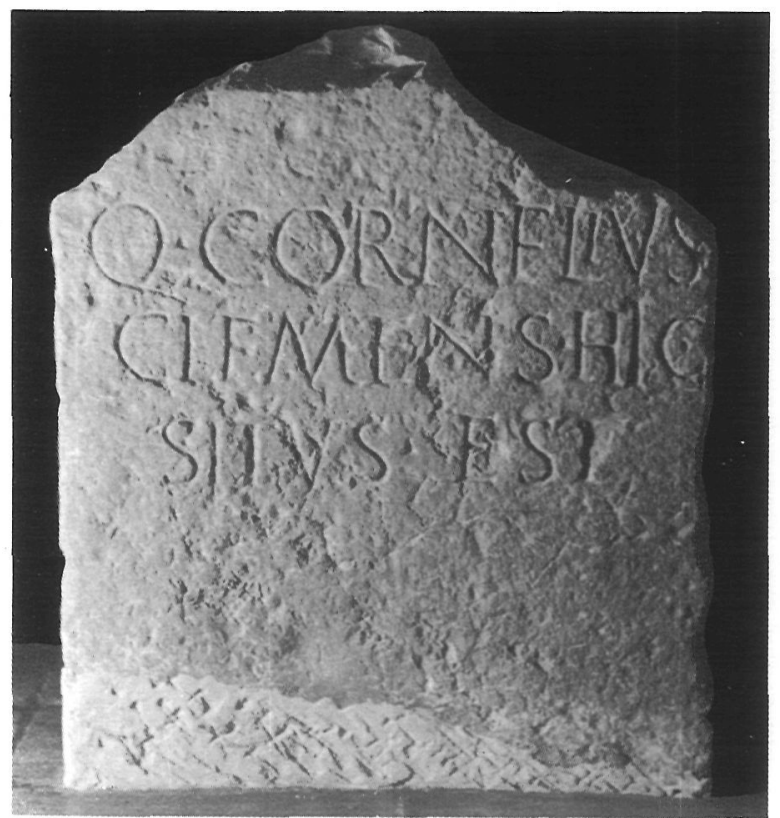

Fig. 63.-Inscripción n. ${ }^{\circ} 107$. 
107. - Jávea. Estela en piedra caliza procedente de la partida «La Riba», conservada en el Museo Municipal de Jávea. Dimensiones: $46 \times 57 \times 19$ cms. Altura de las letras: 5,$5 ; 5 ; 5$ cms., excepto la «I» de la primera línea que mide $3,5 \mathrm{cms}$. y la de la segunda, de $6 \mathrm{cms}$. La inscripción presenta interpunciones triangulares, y en la parte superior de la estela aparecen dos muescas.

Bibliografía:

ESPINOS QUERO, A. y POLO VILLASEÑOR, F. Xábia. Anotaciones históricas de una villa mediterránea, Jávea 1985, p. 17.

Q(uintus) Cornelius

Clemens, hic

situs est.

\section{Traducción:}

Aquí yace Q.Cornelius Clemens.

El tipo de monumento y la sencillez del formulario sugieren una cronología para la pieza de mediados del siglo I d. C.

\section{INSCRIPCIONES EQUIVOCADAMENTE ADSCRITAS A LA PROVINCIA DE ALICANTE Y POSIBLES FALSIFICACIONES}

I.-CIL II 3567. Se trata de una inscripción incluida en el manuscrito de Montesinos junto con otras seis, supuestamente procedentes todas del «Castillo de la Mola» de Novelda y que no son sino falsificaciones literarias sobre originales existentes en Elche y Alicante. Abad Navarro (1928/1984, 21 ss.) recoge todos estos testimonios del manuscrito original (MONTESINOS PÉREZ, J. Compendio histórico Oriolano, tomo 10, cap. 13) sin dudar de su autenticidad.

II.-CIL II 3574. Procede en realidad de Villar del Arzobispo (LLATAS BURGOS 1957, 175, n. ${ }^{\circ}$ 1, siguiendo a SANCHÍS $1920, n .^{\circ} 494$. Recientemente, WIEGELS 1985, 145, nota 1).

III.-CIL II 3575. Procede también del Villar del Arzobispo (LLATAS BURGOS 1957, n. ${ }^{\circ}$ 2; SANCHÍS 1920, n. $\left.{ }^{\circ} 495\right)$.

IV.-CIL II 3579. Pieza supuestamente procedente de La Nucía (Alicante). El fragmento, cuya noticia arranca en Cavanilles (1795, 237-238) es muy sospechoso desde el momento en que este autor pretende probar con él el origen romano de esta localidad alicantina, al tiempo que alude a otros epígrafes menores que no recoge, y que, de haber existido, habrían constituido pruebas adicionales nada desdeñables para un erudito del siglo XVIII. A ello se une la prodigiosa fractura del lateral izquierdo, que deja ver los datos básicos para que el epígrafe pueda ser leído e interpretado. En el dibujo publicado por Valcárcel $\left(1852 / 1979, n .^{\circ}\right.$ 72) los elementos están excesivamente colocados hacia la derecha, forzando la interpretación del lector, por lo que su situación parece arbitraria. Al mismo tiempo, presenta algunas disonancias en la estructura y desarrollo de formularios, que pueden obedecer a una falsificación erudita. Con las naturales reservas, incluimos el texto en este apartado de inscripciones de origen dudoso.

V.-SANCHÍS 1920, n. 50; MARTÍN 1970, n. ${ }^{\circ} 29$. Esta inscripción, tradicionalmente adscrita a Denia, procede del castillo de Fuentes de Encarroz (Valencia).

\section{ÍNDICES}

\section{NOMINA}

Aemilia Severina, 30

Aemil(ia) Scintilla, 31, 32

(A)em(ilius) Adrianus, 21

L.A[l]f[i]us Donatus, 22

Alfius Zosim[us], 57

Ante[stius?], 78

Antoni[--], 41

P.Astranius Venustus (sevir Aug.), 3

Aufudia [P.1.Hediste] (lib.), 38

Aufidia [P.lib. S]aturi[a], 38

Cn.Aufidius, 79

Aurelius ( $\dagger), 18$

Baebi(us) Iust[u]s, 26

Calpurnia Marcella, 33

Capraria, Valentis 〈uxor),

Sesquiplicani et Rogatae filia, 39

L.Cassius Iunianus, 73

Co[---] Sphr[---] (mulier), 37

L.Cornelius Carpus, 56 
Q.Cornelius Clemens, 107

[Q.Cor]nelius Q.f.Gal.Placidus, 30

L.Cornelius L.f.Quirinalis, 100

(Q.L.)DECIUS VALERIANUS, 22

L.Domitius Eques, 35

P.Fabricius Iustus, 4

P.Fabricius Resp[e]ct(us), 4

Cn.Flacianus?, 79

Furia Tyce, 102

Grani[us] [A]nicetu[s], 27

Q.Granius Q.f.Gal.Cilemens, 28

C.Iul(ius) H[----], 37

C.Iul(ius) Ürbanus, 22

T.Iunius Gal.Achilles, 50 Iuni(us) Festus, 28

T.Iunius T.f.Gal.Severus, 28, 29

C.Licinius Mar[---], 105

Licinius Maximu[s], 105

C.Lo(I)lius Rufus, 9

Lucretia Maura, 82

L.LVCRETIVS SERVILIVS

GALLVS SEMPRONIANVS, 59

[C.M] aecius C.f.Celer, 63

Manlia Chrysis, 54

Q.Manlius Q.f.Quir.Celsinus, 54

[M] unatia Restitut[a], (serva), 40

Cn.Octavius Florus (sevir Aug.), 20

Paccius [----], 103

Pacideia Hedone, 50

M.Popillius Onyxs (sevir Aug.), 1,2

L.Porciu[s] [P]lutus (sevir Aug.), 71

L.Por[ci]us [----], 99

Porcius Rufinus, 16

M.Publ(icius), 80

L.Saenius [----], 44

Sarra Ruireca(??), 18

Sempronia L.f.Campana, 35

L.Sempronius Enipeus, 29

(Sempronia) Marina, 49

M.Sempronius Hymnus, 53

M.Sempronius Reburrus, 53

Q.Semproni(us) Q.f.Gal.Taurus, 34

(Q.)Semproni(us) Valerianus, 49

Q.Sempronius Q.f.Gal.Valerianus (filius), 49

M.Semproniu[s] [----]dus, 33

L.Si[ ---] Sura, 87

Sicceia Donata (lib.), 11

P.Sicinius P.1.Eutychus (lib.), 36

P.Statilius African[us], 47

P.S[tatilius] Pammon, 47

T.STATILIVS TAVRVS, 64
Tadius Rufus, 8

Terentia L.1.Arbuscu(la), 98

Terent(ia) Doryphoride Sex.filia, 32

[Te]rentia [--]iscae 1. Tethine, 98

[Se]x.Terentius Lemnaeus, 31

Sex.Terentius Lemnaeus, filius, 31, 32

L.Tere[ntius] M.f.Mancin[us], 55

Ulp(ia) Diiofa[ne], 57

Ulp(ia) Marciana, 73

Valeria Diopane, 56

L.Valerius L.f.Gal.Propinquus, 25, 26, 27

L.V(alerius) Scrib(onianus), 21

M.Valerius Solanianus Severus Murenae f., 1

Varia Nigrina, 81

Voconia Macedonia, 61

Q.Voconi[us-----], 85

Volcinaea Calliste, 58

M. $\dot{V}$ ölcinae[us] Callistus, 58

[--]arasus [Pu]lcher, 74

[--]arinus [----]us, 7

(Q.)[--]ius Q.f. C.[---], 66

[--]mmius Gaetulicus, 43

\section{COGNOMINA}

Achilles, 50

Adrianus, 21

African[us], 47

[A]nicetu[s], 27

Arbuscu[la] (lib.), 98

Bassu[s] (scevus), 21

Beryl[la?] (serva), 51

C[---, 66

Calliste, 58

Callistus, 58

Calpurnianus, 26

Campana, 35

Carpus, 56

Celer, 63

Celsinus, 54

Chrysis, 54

Clemens, 28,107

Diiọfa[ne], 57

Diopane, 56

Donata (lib.), 11

Donatus, 22

Doryphoride, 32

Enipeus, 29

Eques, 35 
Eutychus (lib.), 36

$\mathrm{F}<\mathrm{e}>$ licio (servus), 59

Festus, 28; Festus, 42

Florus (sevir Aug.), 20

[F]ulvina, 84

Furonius, 5

Gaetulicus, 43

GALLVS, 59

Gamus (lib.), 25

$\mathrm{H}[-\cdots]$ (vir), 37

[Hediste] (lib.), 38

Hedone, 50

Hermeros (servus), 6

[Hono?]ratus ( ), 19

Hymnus, 53

Iunianus, 73

Iustus, 4; Iust[u]s, 26

Lemnaeus, 31,32

Lucanus, 13

Macedonia, 61

Mancin[us], 55

Mar[----] (vir), 105

Marcella, 33

Marciana, 73

Marina, 49

Maura, 82

Maximu[s], 105

Murena, 1

Nigrina, 81

Onesimus, 44

Pammon, 47

Pausilipus (servus), 51

Pierus, 11

Placidus, 30

Pollento, 72

[P]lutus (sevir Aug.), 71

Praeno[---] (mulier), 7

Primigenia Sinponiaca?, 10

Propinquus, 25, 26, 27

[Pu]lcher, 74

Pyraltide (servus), 6

Quirinalis, 100

Reburrus, 53

Resp[e]ct(us), 4

Restitut[a] (serva), 40

Rogata, 39

Rufinus, 16

Rufus, 8, 9

Ruireca (??), 18

[S]aturi[a] (lib.), 38

S[at]urninus (servus), 5
[Sat]urn[inus], 14

Scintilla, 31, 32

Scribonianus, 21

SEMPRONIANVS, 59

SERVILIVS, 59

Sesquiplicanus, 39

Severina, 30

Severina $(\dagger), 48$

Severus, 28, 29

Severus, 1

Sinponiaca, 10

Solanianus, 1

Sphr[----] (mulier), 37

Sura, 87

TAVRVS, 64

Taurus, 34

Tethine (lib.), 98

Trophime (lib.), 25

Tyce, 102

Urbanus, 22

Valens, 39

VALERIANVS, 22

Valerianus, 49

Venustus (sevir Aug.), 3

Zosim[us], 57

[--]antixa, 74

[--]dus, 33

[--]nua, 104

[--]us, 7

[--]isca, 98

\section{EMPERADORES Y FAMILIA IMPERIAL}

Augustus

Augustus Divi filius, 63

Germanicus

Germanicus Caesar, 62

Traianus

Imp.Caesar Nerva Traianus Augustus

Germanicus Dacicus, 23

Marcus Aurelius

[M(arcus) Aur(elius) Ant]oninus, Aug.Ger.Sar., 15

Lucius Verus

L(ucius) [Aelius imp.Antonini filius Aurelius Commodu]s, Aug.Ger.Sar., 15 Referencias imprecisas

Augustus, 20, 95

Germanicus, 23 


\section{ACLAMACIONES}

T.Statilius Taurus, Imp. IIII, cos. II

\section{ADMINISTRACIÓN}

adlectus in $\mathrm{V}$ decurias, 25

co(n)s(ularis), 22

quaestor trium decuriarum, 50

scriba, 50

vir clarissimus, 59

\section{EJÉRCITO}

\section{Unidades}

cohors IIII Dalmatarum, 29

legio VII Gemina p.f. [[M[a]xim[i]n(iana)]], 22

legio XX Valeria victrix, 29

vexil(latio), 22

Mando militar. Rango.

optio, 22

praef. cohortis IIII Dalmatarum, 29

princ(eps) vexillationis leg.VII gem.p.f.., 22

tribunus leg. XX Valeriae vict., 29

vet(eranus), 22

\section{GEOGRÁFICO}

Dianensis, 29

Dianensium (res publica), 23

Dianensium (dec.Decurionum), 24

[m] unicipii Lucen[tis?], 15

\section{VIDA MUNICIPAL}

Aedilis (Alcudia de Elche), 66

[A]edil[--?] (Alcudia de Elche), 67

d(ecreto) D(ecurionum)(Denia), 20

[decr] to Decurionum Dianensium, 24

decreto ordin(is) (Tossal de Manises, Alicante), 4

decreto ordinis (Denia), 49

D(ecurio) M(unicipii) (en Denia), 34

IIvir (en Villajoyosa), 54

IIvir (en Alcudia de Elche), 66

IIviri (en Tossal de Manises, Alicante), 4

municipes (en Denia), 24

omnibus honoribus in r.p. sua functo, 25

omnibus honorib(us) in re publica

$<$ sua $>$ functo, 28

omnibus honoribus in re p(ublica)

sua functo, 29

omnibus honoribus in rep(ublica)

sua functo, 30 [omnibus honoribus in re

pu]b(lica) sua, 65

Patronus, 64

Praef(ectus) (en Tossal de Manises), 8

Q[uaest(or?)] (en Alcudia de Elche), 66

\section{TRIBUS}

Galeria, 26, 27, 28, 29, 30, 34, 49, 50,66

Quirina, 54

\section{RELIGIÓN}

\section{Divinidades}

Hercules Aug. 71

Silvanus, 21

Venus, 20

Culto imperial

flamen (en Villajoyosa), 54

flamen p.H.c. 25,26

honore functo seviratus, 31

magister, 1

IIIIIIvir Aug., 1

IIIIIIvir Aug. Lucentis, 3

IIIIIIvir Aug. municipio D(ianensis), 20

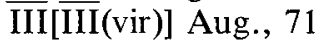

\section{COLEGIOS Y PROFESIONES}

coll[----], 69

colleg[---]Cen[tonarii ?], 70

medicus, 36

\section{OBRAS PÚBLICAS}

arcum, 16

forum, 67

macellum, 53

mensae lapidae, 53

statuam, 49

templum, 1

templ(um) Iunonis, 4

tur(rim/res), 8

CORRESPONDENCIA DE LAS

INSCRIPCIONES CON CIL II y Supplementum

$\begin{array}{lll}\frac{C I L ~ I I}{} & & n_{\sigma^{\circ}} \\ 3554 & & 97 \\ 3555 & & 63 \\ 3556 & & 64\end{array}$




\begin{tabular}{|c|c|}
\hline 3557 & 4 \\
\hline 3558 & 16 \\
\hline 3559 & 82 \\
\hline 3560 & 85 \\
\hline 3561 & 8 \\
\hline 3562 & 12 \\
\hline 3563 & 1 \\
\hline 3564 & 9 \\
\hline 3565 & 10 \\
\hline 3566 & 11 \\
\hline 3567 & I \\
\hline 3568 & 17 \\
\hline 3569 & 102 \\
\hline 3570 & 53 \\
\hline 3571 & 54 \\
\hline 3572 & 57 \\
\hline 3573 & 56 \\
\hline 3574 & II \\
\hline 3575 & III \\
\hline 3576 & 55 \\
\hline 3577 & 58 \\
\hline 3578 & 104 \\
\hline 3579 & IV \\
\hline 3580 & 20 \\
\hline 3581 & 23 \\
\hline 3582 & 30 \\
\hline 3583 & 29 \\
\hline 3584 & 25 \\
\hline 3585 & 26 \\
\hline 3586 & 24 \\
\hline 3588 & 22 \\
\hline 3589 & 38 \\
\hline 3590 & 33 \\
\hline 3591 & 42 \\
\hline 3592 & 34 \\
\hline 3593 & 36 \\
\hline 3595 & 23 \\
\hline 3596 & 50 \\
\hline 3597 & 31 \\
\hline 3598 & 49 \\
\hline 3599 & 51 \\
\hline 3600 & 52 \\
\hline 5950 & 71 \\
\hline 5951 & 81 \\
\hline 5952 & 67 \\
\hline 5953 & 73 \\
\hline 5954 & 95 \\
\hline $5956 a$ & 89 \\
\hline $5956 \mathrm{~b}$ & 88 \\
\hline 5957 & 101 \\
\hline 5958 & 15 \\
\hline
\end{tabular}

$\begin{array}{lr}5959 & 23 \\ 5960 & 22 \\ 5961 & 24 \\ 5962 & 28 \\ 5963 & 39 \\ 5964 & 35 \\ 5965 & 37 \\ 5966 & 43 \\ 5967 & 44 \\ 5968 & 40 \\ 5969 & 47 \\ 5970 & 32 \\ 5971 \mathrm{a} & 46 \\ 5971 \mathrm{~b} & 45 \\ 633800 & 102\end{array}$

PROCEDENCIA DE LAS INSCRIPCIONES

Alicante: $15-18$

Altea: 104

Denia: $20-48$

Elche y La Alcudia de Elche: 62-97

Elda: 106

Jávea: 107

Monforte del Cid: 102

Ondara: 49-52

Pego: 105

Relleu: 103

Santa Pola: 98-101

Sierra de Foncalent: 19

Tossal de Manises: 1-14

Villajoyosa: $53-61$

\section{BIBLIOGRAFÍA}

ABAD CASAL, L.

1984a Los orígenes de la ciudad de Alicante. Alicante.

1984b Arcos romanos en el País Valenciano: los testimonios epigráficos, en Lucentum III, 193ss.

ABAD NAVARRO, $\mathbf{J}$.

1928 El castillo de La Mola de la ciudad de Novelda. Murcia. (reimpresión 1984, Alicante).

ALFÖLDY, G.

1969 Fasti Hispanienses. Wiesbaden.

1973 Flamines provinciae Hispaniae cilerioris. Madrid.

1975 Die römischen Inschriften von Tarraco. Berlín.

1977 Ein Ziegelstempel mit dem Namen eines Senators aus Villajoyosa in der Hispania citerior, en ZPE 27, 217 ss.

1978 Eine Inschrift auf dem Montgó bei Dianium an der spanischer Ostküste, en Epigraphica XL, 59-90. 
BELTRÁN LLORIS, F.

1980 Epigrafía latina de Saguntum y su territorium. Trabajos Varios del SIP 67 . Valencia.

BENDICHO, $\mathrm{V}$.

1960 Crónica de la muy ilustre, noble y leal ciudad de Alicante (resumida y anotada por D. Francisco Figueras Pacheco). Alicante.

BLÁZQUEZ, J. M. ${ }^{a}$.

1962 Religiones primitivas de Hispania I. Fuentes literarias y epigráficas. Madrid.

BUCHNER, E.

1971 Neue christliche Inschrift aus Alicante, en MDAI(M) 12, 195-201.

CAVANILLES, $\mathbf{J}$.

1795 Observaciones sobre la historia natural, geografia, agricultura, población y frutos del reyno de Valencia. Madrid.

CEAN BERMÚDEZ, F.

1832 Sumario de las antigüedades romanas que hay en España. Madrid.

CHABÁS, R.

1874 Historia de la ciudad de Denia. Alicante (reedición Alicante, 1972).

1886 El sepulcro de Severina, en El Archivo I, 2-4, 9-11 y 17-18.

CRESPO, S. y SAGREDO, L.

1976 Las profesiones en la sociedad de Hispania romana, en HA VI, 53-78.

CORTÉS, S. et alii,

1984 Nuevas inscripciones romanas del Museo de Santa Cruz de Toledo, en Museos 3, 73ss.

D'ORS, A.

1950 Tabula Ilicitana, en Iura I, 280ss.

1953 Epigrafia jurídica de la España romana. Madrid.

DUTHOY, R.

1976 Recherches sur la repartition gèographique et chronologique des termes «sevir Augustalis», «Augustalis» et «sevir» dans l'Empire romain, en Epigraphischen Studien 11, Köln, 143ss.

ELSag. = BELTRÁN LLORIS, F. 1980

ETIENNE, R.

1958 Le culte impérial dans la Péninsule Ibérique d'Auguste à Dioclètien. París (Reed. de 1974).

FIGUERAS PACHECO, F.

1959 Dos mil años atrás. Las ciudades, el puerto y la necrópolis de La Albufereta. Alicante.

1971 Relación de hallazgos arqueológicos en el Tossal de Manises (Alicante), 1933-35. Alicante.

FITA, F.

1884 Lápidas romanas del valle de San Millán, Vallada, Ternils y Denia, en BRAH IV, 10 ss.

1887 Lápidas romanas de Denia, en El Archivo I, 331333, 337-339 y 347-348 (Reedición, Alicante 1985).

1901 Apuntes epigráficos, en BRAH XXXVIII, 84-99.

1907 Nuevas inscripciones de Elche, en BRAH L, 323.

1908a Noticias, en BRAH LII, 375.

1908b Las puertas del sueño: nueva ara votiva de Córdoba, en BRAH LII, 453ss.

$1908 \mathrm{c}$ Inscripciones romanas y griegas de Cartagena, Almazarrón, Pego, Valera, Herramelluri, Córdoba, Vélez Rubio y Vera, en BRAH LII, 505ss.

1913 Ara votiva ilicitana, en BRAH LXIII, 147-150.
FLÓREZ, E.

1900 España Sagrada, Vol. VII. Madrid.

GARCİA Y BELLIDO, A.

1950 Sobre la supuesta lex municipalis ilicitana, en AEA XXIII.

1951 De nuevo sobre la Tabula ilicitana, en AEA XXIV, 240ss.

GONZÁLEZ, J.

1982 Inscripciones romanas de la provincia de Cádiz. Cádiz.

HÜBNER, E.

1871 Inscriptiones Hispaniae Christianae. Berlín.

1901 Supplementum a IHC. Berlín.

IBARRA MANZONI, A.

1879 Ilici; situación y antigüedades. Alicante. (Reedición Alicante 1981).

1889 Efemérides Ilicitanas (manuscrito inédito).

IBARRA, P.

1926 Elche. Materiales para su historia. Cuenca.

ILER = VIVES, J. 1971

IRCádiz = GONZÁLEZ 1982

LABORDE, A

1975 Viatge pintoresc i històric. El País Valencià i les Illes Balears. Barcelona.

LAFUENTE VIDAL, $\mathbf{J}$.

1948 Alicante en la Edad Antigua. Alicante.

1959 Museo Arqueológico Provincial de Alicante. Catálogo Guía. Alicante.

LE ROUX, P.

1972 Recherches sur les centurions de la legio VII Gemina, en MCV VIII.

$1982 a$ L'armèe romaine et l'organisation des provinces ibériques d'Auguste à l'invasion de 409. París.

$1982 b$ Les senateurs originaires de la province d'Hispania citerior au Haut Empire romain, en Epigrafia e ordine senatorio, Tituli 5, 439-464.

LLATAS BURGOS, V.

1957 Carta arqueológica de Villar del Arzobispo y su comarca, en APL VI, 153ss.

LLOBREGAT, E. A.

1970 Materiales hispano-visigodos del Museo Arqueológico Provincial de Alicante, en PLAV 10, 189-204.

1977 La primitiva cristiandad valenciana. Valencia.

1981 Una nueva inscripción romana del Tossal de Manises y la localización del topónimo Lucentum, en Boletín del Instituto de Estudios Alicantinos 33, 23-38.

LLORENTE, T.

1886 Pérez Bayer y las lápidas romanas de Denia, en El Archivo I, 260-262 y 268-270 (Reedición Alicante 1985).

MANGAS, J

1971 Esclavos y libertos en la España romana. Salamanca.

MARTÍN, G.

1970 Dianium. Valencia.

MAULEON, M. ${ }^{\text {a }}$ D.

1983 Índice de las inscripciones latinas publicadas en el Boletín de la Real Academia de la Historia (18771950). Pamplona.

MAYANS y SISCAR, $\mathfrak{J}$. A.

1771 Ilici, hoi la villa de Elche. Valencia (reimpresión de 1982). 
MORA, G.

1981 Las termas romanas en Hispania, en AEA 54, 37-86.

MUÑIZ COELLO, J.

1980 El sistema fiscal en la España romana: República y Alto Imperio. Huelva.

NOTICIAS

1887 Noticias, en BRAH X, 241ss.

1887 Noticias, en BRAH XI, 286ss.

1888 Noticias, en BRAH XII, 360.

1888 Noticias, en BRAH XII, 89ss.

OROZCO SÁNCHEZ, P.

1878 Manual geográfico-estadístico de la provincia de Alicante. Alicante.

PALÁU, M. A.

1643 Diana desenterrada. Alicante (reedición de 1975).

PALOL, P. de

1967 Arqueología cristiana de la España romana. Madrid.

PAPI, F.

1889 La inscripción de Lucentum, en El Archivo III, 18 ss.

PARIS, P. y HÜBNER, E.

1896 Inscriptions latines d'Espagne, en Revue des Universités du Midi IV, 396ss.

PASTOR MUÑOZ, M.

1981 El culto del dios Silvano en Hispania, innovación o sincretismo?, en MHA V, 108ss.

PUIG i CADAFALCH, J.

1934 L'arquitectura romana a Catalunya. Barcelona.

RABANAL ALONSO, M. A.

1985a El Alto Imperio, en Historia de la provincia de Alicante, vol. II, Murcia, 9ss.

1985b La ciudad de Alicante en las fuentes literarias y epigráficas antiguas. Studia Historica; in honorem Vicente MARTINEZ MORELLA. Alicante, 375-384.

RAMOS FERNÁNDEZ, R.

1975 La ciudad romana de Ilici. Alicante.

RAMOS FOLQUES, A.

1963 Unos pozos manantiales de época romana en la provincia de Alicante, en AEA XXXVI, 234-249.

1970 Historia de Elche. Elche.

RIT $=$ ALFÖLDY 1975

RODRÍGUEZ NEILA, J. F.

1978 Los jueces de las cinco decurias oriundos de la España romana. Una contribución prosopográfica, en HA VIII, 17ss.
ROLDÁN, J. M.

1974 Hispania y el ejército romano. Salamanca.

RUBIO, J.

1959 Españoles por los caminos del Imperio romano. Estudios en torno a Reburrus y Reburrinus, en CHE XXIX-XXX

RUYT, C. de

1983 Macellum, marché alimentaire des romains. Lovaina.

SANCHIS SIVERA, $\mathbf{J}$.

1920 Epigrafía romano-valenciana. Valencia.

SANTERO, J. M.

1978 Asociaciones populares en Hispania romana. Sevilla.

SAXER, R.

1967 Untersuchungen zu den Vexillationen der römischen Kaiserheeres von Augustus bis Diokletian, en Epigraphischen Studien I. Köln.

SENDRA, A. et alii

1980 Relleu: conocer un pueblo. Alicante.

TAFALLA, D.

1972 El Lucentum hispano-romano de Benalúa-Antigons; siglo II d. C., en Historia de Alicante y castillo. Alicante.

TARRADELL, M. y MARTÍN, G.

1970 Els Antigons-Lucentum; una ciudad romana en el casco urbano de Alicante. Valencia.

VALCÁRCEL Y PIO DE SABOYA, A.

1780 Lucentum oy la ciudad de Alicante en el reyno de Valencia. Valencia (reed. de 1979).

1852 Inscripciones y antigüedades del reyno de Valencia. Memorias de la Real Academia de la Historia. (Reed. de 1979).

VIVES, J.

1969 Inscripciones cristianas de la España romana y visigoda. Barcelona.

1971 Inscripciones latinas de la España romana. Barcelona.

WIEGELS, R.

1985 Die tribusinschriften des römischen Hispanien. Ein Katalog. Madrider Forschungen 13. Berlín. 